Estudios sobre armas antiguas, arte militar $\mathrm{y}$ vida cultural en oriente y occidente XXVIII (2008), pp. 5-85 ISSN: 0436-029X

\title{
EL PUÑAL BIDISCOIDAL PENINSULAR: TIPOLOGÍA Y RELACIÓN CON EL PUÑAL MILITAR ROMANO (PUGIO)
}

\author{
THE PENINSULAR «BIDISCOIDAL» DAGGER: TYPOLOGY AND RELATION WITH \\ THE ROMAN MILITARY DAGGER (PUGIO)
}

POR

\author{
Eduardo Kavanagh de Prado*
}

\section{RESUMEN - ABSTRACT}

La historiografía de principios del s. XX recogía ya la teoría que relacionaba el puñal «bidiscoidal» (tradicionalmente denominado «dobleglobular» o «biglobular») característico de la cultura celtibérica del Hierro II, con el pugio, puñal usado por los legionarios romanos al menos desde el fin de la República. La razón estriba en la evidente similitud tipológica, en concepción general y detalles, entre ambos tipos. El objetivo principal de este trabajo es presentar un análisis del puñal bidiscoidal y su evolución a caballo entre ambos universos, celtibérico y romano. Secundariamente, demostrar la filiación entre ambas armas: el origen celtibérico del puñal romano legionario (pugio).

The hypothesis that considered the Celtiberian Iron Age «bidiscoidal» type dagger (also traditionally known as «doubleglobular» or «biglobular») as the prototype of the pugio, or dagger used by the Roman legionaires since the Late Republic, was put forward by specialists as early as the begining of the $20^{\text {th }}$ century. The main purpose of this paper is to provide an analysis of the «bidiscoidal» dagger and of its evolution. Our second objective, derived from the first, is to prove the filiation of the Roman legionary dagger (pugio) as an evolution of the Celtiberian prototype.

\section{Palabras Clave - Keywords}

Puñal bidiscoidal; puñal dobleglobular; armas prerromanas; Hierro II; Pugio; vaina; Celtiberia; ejército romano. Bidiscoidal dagger; Iron Age weapons; Second Iron Age; Pugio; Sheath; Celtiberia; Roman Army.

\section{PARTE I: INTRODUCCIÓN, OBJETIVOS Y METODOLOGÍA}

\section{INTRODUCCIÓN}

\section{Cuestiones de TerminOlogía}

Las primeras publicaciones que recogían este género de puñal ${ }^{1}$ acordaron bautizarlo como «dobleglobular» ${ }^{2}$, en atención a las dos formas proto-esféricas o globulares que presenta la

* Universidad Autónoma de Madrid. C/ Velázquez, 73 (28006, Madrid). E-mail: ekavanagh66@hotmail.com

1 Aguilera y Gamboa, 1911; Cabré Aguiló, 1932; Cabré Aguiló y Cabré Herreros, 1933; y en general todas las obras de la primera mitad del s. XX.

2 Artiñano y Galdácano, 1919; suponemos que inspirado por las directrices del marqués de Cerralbo (E. de Aguilera y Gamboa). 
empuñadura, una en el pomo, la segunda a media distancia entre éste y la guarda o arriaz. Más tarde apareció el término «biglobular» que nunca alcanzó la popularidad de su predecesor. A finales de los sesenta, el investigador alemán $\mathrm{W}$. Schüle ${ }^{3}$ bautizó a este género de puñales como Zweischeibendolche (dolche: puñal; zwei: dos; scheiben: discos) ${ }^{4}$.

Por último, nosotros proponemos un último vocablo que, aunque no logre sustituir los términos tradicionales, sirva por lo menos para llamar la atención sobre las verdaderas características formales del arma. Nosotros proponemos el término «bidiscoidal» que consideramos más correcto ya que las características definitorias del modelo no son glóbulos, como aludía el término original, sino discos. El glóbulo define a una forma esférica correspondiente sólo con una, y muy minoritaria, de las muchas variantes o subgrupos del arma que tratamos. El grueso de los subtipos de esta arma, sin embargo, muestra dos formas discoides, y no globulares, en la empuñadura. Es por ello por lo que consideramos más correcto denominar a esta arma como bidiscoidal, en lugar de dobleglobular o biglobular.

\section{EsTADO DE LA CUESTIÓN}

Las primeras obras que abordan el tema del puñal bidiscoidal, en las décadas de los años 10-20 del s. XX, entonces llamado dobleglobular, tratan el tema de forma tangencial, dentro de análisis generales sobre la cultura material celtibérica o en memorias de excavación, generalmente de poblados celtibéricos sorianos. Ya en época tan temprana como 1919, Artiñano ${ }^{5}$ utiliza el término «dobleglobular» para referirse a nuestro bidiscoidal. Blas Taracena poco después refiere un gran número de ellos al abordar los yacimientos de Soria ${ }^{6}$, y este último junto con Mélida hacen lo mismo en la memoria de excavación de Numancia ${ }^{7}$. Les seguirán publicaciones como las de Cabré Aguiló ${ }^{8}$ (1931) y Cabré Aguiló y Cabré Herreros ${ }^{9}$ en el célebre «Datos para la cronología del puñal en la cultura de Las Cogotas» de 1933. De hecho, en un primer momento muchos autores incluían al bidiscoidal dentro del grupo de los puñales de frontón exento ${ }^{10}$. Hoy en día reconocemos una diferencia no sólo física sino temporal que nos impide seguir manteniendo esta relación.

Desde que Cabré ${ }^{11}$ estableciera la secuencia tipológica de los puñales meseteños de la II Edad del Hierro, se vienen aceptando para el tipo dobleglobular fechas genéricamente tardías, aunque con límites algo difusos, que actualmente, según algunos autores, sitúan su aparición a fines del siglo III o principios del II a.C. ${ }^{12}$ Según Martín Valls y Esparza ${ }^{13}$ la dispersión de hallazgos de bidiscoidal insinúa dos focos de producción, uno oriental y otro abulense. La asociación de estos puñales con espadas La Tène y de antenas, así como la mayor concentración en estas latitudes, avalarían el origen celtibérico del arma. Estos mismos autores destacan el insólito hecho de la asociación de algunos bidiscoidales a broches de cinturón de tres garfios,

\footnotetext{
3 Schüle, 1969: karte 50.

4 Esta terminología sería posteriormente adoptada por el resto de autores germanos, por ejemplo Ulbert, 1984: 108-109.

5 Artiñano, 1919, n. $^{\circ} 24$ y 25.

6 Taracena, 1927: 18.

7 Mélida y Taracena, 1921.

\& Cabré Aguiló, 1931: 222-223.

9 Cabré Aguiló y Cabré Herreros, 1933: 37-47.

10 Ver apartado «Origen del bidiscoidal».

11 Cabré Aguiló, 1932: 37-45.

12 Campano Lorenzo y Sanz Mínguez, 1990.

13 Martín Valls y Esparza, 1992: 262-263.
} 
piezas que han sido fechadas entre los ss. VI y mediados del IV a. $\mathrm{C}^{14}$, fechas por tanto muy anteriores a las que venimos considerando para este género de puñales. Estos mismos autores señalan la perduración de los mismos hasta finales del I a.C., como lo demuestran los hallazgos de Herrera de los Navarros o El Raso ${ }^{15}$ (Ávila).

Según A. Lorrio ${ }^{16}$ el bidiscoidal hace su aparición en la cuenca alta del Duero en lo que él denominará Subfase II B de la evolución del armamento celtibérico, un periodo que arranca a fines del siglo IV a.C. y se desarrolla fundamentalmente a lo largo del siglo III. Este mismo autor señala que los yacimientos más significativos en cuanto a volumen e importancia de hallazgos de armas en este periodo y lugar son los de Quintanas de Gormaz y Osma. Hacia el salto entre el siglo III y II a.C., con el primer contacto entre Roma y Celtiberia ${ }^{17}$ pasamos a la denominada por Lorrio Fase III, en la que asistimos a una ampliación y difusión del bidiscoidal a lo largo de tierras del Alto Tajo y Alto Jalón, aunque también encontramos algunos bidiscoidales aislados en Cataluña, Andalucía, Valencia, y territorios muy distantes de la zona focal.

Será Cabré de Morán ${ }^{18}$ quien recientemente aborde el estudio de los puñales meseteños en análisis monográfico, con su «Espadas y puñales de las necrópolis celtibéricas». Por su parte Encarnación Cabré Herreros y Juan Antonio Morán Cabré ${ }^{19}$ defienden una relación entre los cultos astrales de la Hispania prerromana y las formas esféricas y crecientes lunares que algunos puñales presentan en los pomos, que creen trasunto o alusión al culto lunar, tan popular del septentrión peninsular. Estos mismos autores defienden una cronología para el puñal bidiscoidal entre el segundo cuarto del s. III a.C. y el c/era, siendo su florecimiento entre la segunda mitad del III y primera del II a.C. En cuanto a la adopción del bidiscoidal por los ejércitos romanos, se decantan por fecharla en el s. I d.C.

Ya en 1997 Quesada Sanz publica su voluminoso corpus sobre el armamento prerromano peninsular, en el que clasifica al puñal bidiscoidal bajo el referente de puñal «Tipo VI ${ }^{20}$. Señala que se trata del modelo de puñal más popular del mundo prerromano, extremo avalado por la superioridad cuantitativa de los ejemplares hallados. Tras analizar toda una serie de ejemplares relativamente bien datados, Quesada concluye en cuanto a su cronología, sugiriendo un periodo entre mediados del III a.C., hasta el I a.C. También señala que el origen del puñal parece iniciarse en el Alto Duero, zona celtibérica plena, desde donde se difunden hacia la Meseta Occidental, cuenca del Ebro y otros puntos. Por último, señala la posible relación de este tipo de armas con las esculturas de bronce y las denominadas «lusitanas» o «Guerreros Galaicos», del norte de Portugal y Galicia, así como su probable representación en las monedas de P. Carisio.

Según opinión de Idoia Filloy Nieva y Eliseo Gil Zubillaga ${ }^{21}$ sería el grupo de los puñales peninsulares que usan vainas de cañas los que evolucionarán hasta dar lugar al pugio romano. Sería por tanto fundamentalmente la vaina de cañas, y no tanto una particular morfología de la empuñadura lo que definirá el grupo de puñales en los que se inspirará Roma para crear su modelo. Dentro del grupo de los puñales con vaina de cañas se incluyen fundamentalmente los bidiscoidales y los algo anteriores, aunque también en parte coetáneos, puñales de frontón. En menor medida, los híbridos bidiscoidal-frontón y en algún caso muy aislado el híbrido

14 Cerdeño Serrano, 1978: 279-306.

15 Con algún ejemplar fechado en fecha tan tardía como el 62 a.C., fecha concretada merced a su asociación a un denario romano.

16 Con las campañas de Catón el Viejo por tierras numantinas (195 a.C.). Véase Lorrio Alvarado, 1994b: 212-257.

7 197-195 a.C.

8 Cabré de Morán, 1990: 205-224.

19 Cabré Herreros y Morán Cabré, 1991.

20 Quesada, 1997a: 292-295, fig. 164, VI y fig. 173.

21 Filloy Nieva y Gil Zubillaga, 1997: 137-150. 
bidiscoidal-antenas. Este último modelo aparecerá recurrentemente representado en las estelas funerarias de soldados limetanos, si bien aún no goza de respaldo arqueológico ${ }^{22}$.

Muy recientemente se ha señalado también ${ }^{23}$ que la presencia del bidiscoidal podría ser un indicativo de estatus social para su posesor. En este sentido algunas tumbas de Carratiermes ${ }^{24}$ donde se asocian gran dispendio y derroche con la presencia de armas, prueban el carácter militar de las elites celtibéricas. No obstante sus propios excavadores señalan que la presencia de armas en tumbas posteriores a los siglos V y IV a.C. no supone necesariamente un elevado estatus social para su portador, al contrario de lo que sucedería en los siglos anteriores. En cuanto al puñal bidiscoidal insisten, dichos autores, en el valor funcional del arma en contraste con el simbólico, lo que nos permite cuestionar la tendencia a identificar la tenencia de armas con un elevado estatus social.

Por último, presentamos con este trabajo el primer monográfico sobre el bidiscoidal, para el que hemos sido capaces de recabar la cifra de ciento treinta y cinco ejemplares sólo en territorio peninsular ${ }^{25}$.

\section{ORIGEN Y PROBLEMÁTICA DEL PUÑAL}

\section{ORIGEN}

Todos los indicios apuntan a identificar el puñal «de frontón», o frontón exento, tipo $\mathrm{I}^{26} \mathrm{de}$ la clasificación de Quesada (1997), como el antecedente inmediato en la línea evolutiva del puñal bidiscoidal. La semejanza morfológica entre ambos modelos, así como la cronología más temprana -y brevemente coetánea- del primero (frontón), así lo sugieren. Este modelo parece tener un origen meridional, andaluz. Además contamos con un modelo transicional, híbrido entre ambos modelos, que sirve como sanción última de la relación evolutiva entre ambos. Se trata del denominado «híbrido dobleglobular-frontón»» ${ }^{27}$ o tipo IV ${ }^{28}$ según la clasificación de Quesada (1997). En este caso la dispersión geográfica es coherente con aquella del modelo bidiscoidal, pues ambos modelos se distribuyen a lo largo de la cuenca alta del Duero, zona nuclear celtibérica. Todo apunta a que el híbrido bidiscoidal-frontón sea una variante celtibérica del puñal de frontón, meridional.

El modelo de frontón y sus híbridos se definen por una estructura de doble chapa metálica, alma o espiga de hierro extensión de la hoja, y dos piezas orgánicas embutidas en el espacio intermedio entre las cachas y la espiga. Es decir, sistema idéntico al del bidiscoidal. La empuñadura se define por un ensanchamiento central y por la característica que la da nombre: un pomo semicircular formado por una pieza independiente del resto, exenta. La cronología del modelo de frontón pertenece a los ss. V-IV a.C. ${ }^{29}$, luego anterior al conjunto de los bidiscoidales. Por su parte, el híbrido bidiscoidal-frontón se fecha entre fines del IV a.C. (momento

22 A excepción tal vez del ejemplar de Doroño (Álava) que podría seguir estas características. Filloy Nieva y Gil Zubillaga, 1997: fig.5, 2.

23 Argente Oliver; Díaz Díaz y Bescós Corral, 2001: 63.

24 N. ${ }^{\circ} 131,223,407$ y 411.

25 Estudios precedentes sólo alcanzaron a clasificar cifras más reducidas. Tal es el caso del trabajo de Quesada (1997a), en el que se recogen 86 ejemplares de este tipo.

26 Quesada, 1997a: 278 y ss.

27 Que, según nuestra moderna terminología, deberíamos llamar «híbrido bidiscoidal-frontón».

28 Quesada, 1997a: 290 y ss.

29 Quesada, 1997a: 279. 
en que desaparece el frontón) y mediados del II a.C. ${ }^{30}$, ya en coexistencia plena con el modelo bidiscoidal. Por último, contamos con un modelo «híbrido dobleglobular-antenas» ${ }^{31}$, del que encontramos probable representación en la iconografía romana imperial, pero que aún no ha sido verificado arqueológicamente ${ }^{32}$.

Tanto el híbrido frontón-bidiscoidal, como el híbrido bidiscoidal-antenas y el puñal de frontón son considerados por Idoia Filloy ${ }^{33}$ como pertenecientes a un mismo subtipo, el de los puñales de lengüeta tripartita, en virtud de la factura de su empuñadura ${ }^{34}$.

El puñal bidiscoidal aparece, según nuestro análisis, en torno a finales del s. IV-principios del III a.C. en la Meseta Oriental, lo que significa que en un primer momento es coetáneo al híbrido frontón-bidiscoidal. Es por tanto muy probable que, a tenor de las coincidencias morfológicas, cronológicas y geográficas, el bidiscoidal sea evolución del híbrido bidiscoidalde frontón, conviviendo con su predecesor durante un tiempo, para finalmente reemplazarle completamente.

\section{PROBLEMÁTICA: LA ADOPCIÓN POR ROMA}

Tradicionalmente se ha considerado al puñal bidiscoidal como un posible antecesor del puñal romano militar (pugio), un modelo de inspiración cuyas características más importantes serían reproducidas por los artesanos romanos. No obstante la comunidad científica aún no guarda acuerdo al respecto, dado que no se ha podido probar este extremo ni, en caso de verificarse, su datación.

El problema más grave al que nos enfrentamos es que no conocemos la morfología exacta de las armas romanas de época republicana. Gracias a las décadas de investigaciones llevadas a cabo en la frontera septentrional del Imperio Romano (Francia, Alemania, Inglaterra...), así como a representaciones iconográficas puntuales ${ }^{35}$, conocemos bastante bien todos los detalles del ejército romano imperial, pero no así con su homólogo republicano, sobre el que aún se proyectan grandes sombras de duda. Este extremo es hasta cierto punto razonable, habida cuenta del carácter no profesional que presenta el ejército anterior a las reformas de Cayo Mario (circa 100 a.C.). Antes de esa fecha el soldado romano se armaba de su propio peculio, lo que inevitablemente redundaría en una fuerte heterogeneidad de la panoplia militar, incluso dentro de una misma legión.

Este hecho no deja de plantear problemas pero, siendo grave, no es el único al que se enfrentan los estudiosos del armamento romano republicano. Más problemática resulta la práctica de asimilar cuerpos de infantería y caballería auxiliar dentro de las legiones, hasta el punto de asentarlas dentro de los mismos campamentos junto a las tropas romanas. Este hecho provoca que los hallazgos efectuados sobre un yacimiento de carácter militar romano, castramental normalmente, sean de factura imposible de precisar. Sobre cada hallazgo de un arma se suscita una fuerte duda acerca de su origen y usuario. Puede ser acaso arma romana, indígena o incluso llegado el extremo, númida, en atención a los mercenarios del príncipe Yu-

\footnotetext{
30 Quesada, 1997a: 291.

31 O «híbrido bidiscoidal-antenas».

2 Ver apartado «Iconografía».

3 Filloy Nieva, 2002: 57-72 (especialmente p. 70).

34 Formada por tres elementos: espiga central metálica prolongación de la hoja del arma, y dos cachas, bien orgánicas o metálicas, a cada lado de la misma.

35 Notablemente la Columna Trajana, en Roma, donde se representan las campañas dácicas emprendidas por dicho emperador.
} 
gurta traídos a Celtiberia por Escipión Emiliano. Valga esto último como exageración, pues la huella arqueológica de ese minúsculo contingente de caballería probablemente jamás se llegue a documentar; pero sirva de ejemplo para ilustrar la especial problemática que el estudio del armamento romano presenta.

Este extremo resulta además especialmente grave en el caso peninsular, donde la adopción de contingentes auxiliares indígenas fue especialmente masiva, como informan las fuentes clásicas. Este punto llega a su paroxismo en el contexto de las Guerras Sertorianas, donde un mínimo de tropas romanas encabezaba grandes contingentes de tropas de adscripción cultural mixta (celtíberos, íberos, lusitanos...); una realidad que se manifiesta fundamentalmente - pero no en exclusiva - entre las filas de la facción sertoriana. A su vez, debemos deducir que, si las armas cartaginesas en un primer momento, — celtibéricas, íberas, lusitanas y romanas después - se enfrentan en el teatro peninsular y durante dos centurias, el resultado no puede ser otro que la hibridación del conjunto de sus panoplias ${ }^{36}$.

En cualquier caso nos encontramos ante el problema de identificar la autoría y propiedad de cada arma, especialmente de aquellas halladas en contexto castramental. En última instancia esta ambición es baladí, habida cuenta el grado de hibridación entre unas panoplias y otras, posiblemente desde un principio, un extremo no sólo documentado arqueológicamente sino constatado por las fuentes literarias en construcciones como el gladius hispaniensis ${ }^{37}$.

Quiero decir con esto que tal vez ni siquiera podamos hablar de armamento romano republicano, habiendo mayores semejanzas entre la panoplia de una legión y las tropas indígenas de su entorno - entre las que convive, recluta mercenarios y lucha - que con la panoplia de otra legión romana ubicada en el otro extremo del Mediterráneo. Valga esta hipótesis como exageración, puesto que efectivamente se han reconocido patrones armamentísticos homogéneos en distintos puntos del Mediterráneo romano republicano, pero ¿hasta qué punto puede ser válida esta afirmación en el contexto de una administración romana que no se preocupa por la distribución de armas entre sus soldados sino que, al menos hasta la profesionalización del ejército, les permite armarse por sus propios medios? O, lo que es simple extensión de lo anterior, ¿sigue cumpliéndose esa homogeneidad armamentística en contextos como el aislamiento completo durante lustros de los ejércitos sertorianos en territorio peninsular?

Es evidente que necesariamente nos encontramos ante una realidad muy heterogénea, de hecho nos sorprendería documentar lo contrario. La presencia de fuertes contingentes auxiliares indígenas, el aislamiento durante largas campañas en territorio peninsular pudiendo recurrir sólo a armeros indígenas o a material de botín, todo ello unido a la libertad del legionario romano de hacerse con su propio equipo, provocaría en suma una situación muy confusa en la que es posible que fuera incluso difícil reconocer romanos de indígenas. Por tanto, el responder a la pregunta ¿cual es el armamento romano?, exige responder antes ¿y a qué consideramos ejército romano?

\section{DOCUMENTACIÓN DISPONIBLE}

\section{DOCUMENTACIÓN ARQUEOLÓGICA}

Gran parte del material arqueológico peninsular referente a nuestro tema de estudio procede de las necrópolis celtibéricas de la II Edad del Hierro, en menor medida de los poblados celtibéricos, y un tercer, ya minoritario conjunto procedente de los campamentos militares

\footnotetext{
36 Ver apartado «Momento de adopción».

37 Sobre este punto ver Quesada, 1997b y 1997 c.
} 
romanos en territorio peninsular ${ }^{38} \mathrm{y}$ algún caso procedente de un depósito o tesorillo ${ }^{39}$. Hemos podido reconocer hasta un total de cuarenta y cuatro yacimientos peninsulares con presencia de puñales bidiscoidales ${ }^{40}$, en algunos casos con una concentración de ellos verdaderamente alta $^{41}$, sugiriendo una zona nuclear o de origen del modelo. Entre este grupo de yacimientos se distribuye el número de ciento treinta y cinco ejemplares de bidiscoidal peninsular, cifra máxima que hemos podido recabar para este trabajo. Como decimos, la presencia de bidiscoidales no es homogénea por todo el territorio peninsular, sino que se concentra en la cordillera central, mayoritariamente en el área celtibérica, y secundariamente en el área vettona (fig. 20).

Un fenómeno interesante, pero que suma dificultad a nuestra empresa, es el hecho de que un importante número de las armas halladas en las necrópolis celtibéricas parecen hacer sufrido algún género de ritual de inutilización intencionada, por lo que aparecen doblados y mellados en extrañas posturas ${ }^{42}$. Desconocemos qué proporción de imperfecciones son producto de la prolongada deposición, pero la coincidencia de estas piezas en contexto de necrópolis nos inclina a pensar que en su mayoría son inutilizaciones voluntarias ${ }^{43}$.

Lamentablemente observamos cómo las piezas mejor conservadas, así como las más ricamente decoradas, proceden, no de excavaciones científicas, sino de colecciones privadas, y en consecuencia están completamente descontextualizadas ${ }^{44}$. A esto podemos añadir el problema de las restauraciones bien antiguas, bien ejecutadas por particulares, en ambos casos con poco o nulo respeto por los más básicos criterios de restauración ${ }^{45}$, lacras que dificultan

38 Caso de los campamentos numantinos (fundamentalmente Castillejo y Renieblas, Soria), Cáceres el Viejo (Cáceres), Herrera de Pisuerga (Palencia), el posible campamento de ala de caballería de Monte Cildá (Aguilar de Campoo, Palencia), y el también dudoso campamento de Aguilar de Anguita (Soria).

39 Caso del puñal de La Azucarera (Alfaro, La Rioja).

40 1. Julióbriga (Retortillo, Cantabria); 2. Herrera de Pisuerga (Palencia); 3. Palencia ciudad (Palencia); 4. Sta. Cruz de Camazos (Cabezón de Pisuerga, Valladolid); 5. Pinilla de Toro (Zamora); 6. Sotopalacios (Burgos); 7. Las Ruedas (Padilla de Duero, Valladolid); 8. Cuesta del Burro (Castrillo de la Reina, Burgos); 9. Langa de Duero (Soria); 10. Uxama (Osma, Soria); 11. Carratiermes (Montejo de Tiermes, Soria); 12. Ucero (Soria); 13. Quintanas de Gormaz (Soria); 14. Izana (Soria); 15. Numancia (Soria); 16. Renieblas (Soria); 17. La Azucarera (Alfaro, La Rioja); 18. Espinal (Navarra) 19. Arcóbriga (Monreal de Ariza, Zaragoza); 20. Aguilar de Anguita (Guadalajara); 21. Ciruelos (Guadalajara); 22. Castellares de Herrera de los Navarros (Zaragoza); 23. La Caridad (Caminreal, Teruel); 24. Mas de Barberán (Nogueruelas, Teruel); 25. El Molón (Camporrobles, Valencia); 26. Punto de Agua (Benageber, Valencia); 27. Elche (Alicante); 28. Cogotas (Cardeñosa, Ávila); 29. La Osera (Chamartín de la Sierra, Ávila); 30. Ulaca (Solosancho, Ávila); 31. El Raso (Candeleda, Ávila); 32. Manzanas (Las Herencias, Toledo); 33. Cáceres el Viejo (Cáceres); 34. Romazal (Plasenzuela, Cáceres); 35. Torre de Palma (Monforte, Portalegre); 36. Castrejón de Capote (Higuera la Real, Badajoz); 37. Aroche (Huelva); 38. Cerro de las Balas (Écija, Sevilla); 39. Azaila (Teruel); 40. Calatañazor (Soria); 41. Turó del Vent (Llinars del Vallès, Barcelona); 42. Dehesa del Rosarito (Cáceres); 43. Monte Cildá (Aguilar de Campoo, Palencia); 44. La Bienvenida (Ciudad Real).

${ }^{41}$ Caso de la ciudad de Uxama (Osma, Soria) donde, aunando sus dos necrópolis (Portuguí y la algo más moderna Fuentelaraña), hemos encontrado una concentración no menor a dieciocho ejemplares de bidiscoidal. También son numerosos los ejemplares de Numancia (17), El Raso (8), Arcóbriga (8) y Carratiermes (8) entre otros.

42 Caso de los puñales hallados en Ucero (Soria), Numancia (Soria), Punto de Agua (Valencia), La Osera (Ávila), Mas de Barberán (Teruel), Cerro de las Balas (Sevilla).

43 En uno de los casos, procedente del yacimiento de Turó del Vent, Barcelona. Rovira Hortalá, 1999: 20-22 y lám. 4; López Mullor; Rovira Port y Sanmartí Greco, 1983: 615; Quesada, 1997a: 294 (n. ${ }^{\circ}$ cat. 6177), la inutilización ha llegado al extremo de atravesar vaina y hoja con un mismo clavo, posiblemente con la finalidad de suspender y así exponer el conjunto a modo de trofeo, interpretación que podría ser refrendada por el exotismo de la pieza en la latitud en que fue hallada.

44 Esta paradoja se explica por dos razones: en primer lugar la cuantitativamente muy superior remoción del terreno llevada a cabo por los campesinos, en contraste con las — proporcionalmente modestas - excavaciones científicas, y en segundo lugar por la exigencia de un lego en arqueología de que una pieza se encuentre en perfecto estado de conservación para ser merecedora de su atención. Por esta razón los descubrimientos casuales, probablemente mucho más numerosos, sufren una criba muy severa que desecha las piezas de modesto estado de conservación, siendo así que llegan sólo hasta nosotros poco ejemplares descontextualizados, pero de un valor inmenso.

45 En algunos casos la pieza arqueológica ha llegado a sufrir intervenciones de una severidad tal como la soldadura metálica, caso de algún ejemplar procedente de Uxama depositado en el MAN. o a la práctica totalidad de los puñales de la colección Axel Guttmann, también depositada en el MAN. 
la correcta interpretación de las piezas. En cuanto a los hallazgos de armas romanas, éstos se distribuyen fundamentalmente a lo largo de las fronteras del Imperio, con una concentración especial en las fronteras septentrionales del mismo, i.e., fronteras renana, danubiana y britana. La concentración de ejemplares en la zona fronteriza se explica por la presencia en ella de grandes contingentes de tropas destinadas a la defensa del Imperio, ausentes en otras latitudes ${ }^{46}$.

\section{DOCUMENTACIÓN LITERARIA}

Aunque escasas y breves, contamos con algunas menciones literarias, todas ellas latinas, tanto al puñal celtibérico como al romano. Lamentablemente no contamos con ninguna referencia clara que sancione nuestra teoría acerca de la estrecha relación entre una y otra arma. No referiremos las citas relativas al puñal celtibérico por considerarlas poco determinantes en nuestro estudio. Nos limitaremos a recordar que Estrabón ${ }^{47}$ menciona que se trata de un arma muy común entre los íberos ${ }^{48}$ y que Diodoro Sículo ${ }^{49}$ describe un modelo concreto de un palmo de longitud, en cuyo caso no parece que se haga referencia al puñal bidiscoidal ${ }^{50}$ ya que las dimensiones no coinciden ${ }^{51}$.

El puñal romano recibe tres nombres: sica, pugio y parazonium. La primera de ellas (sica) carece de toda connotación militar, y podría traducirse como daga de uso civil o navaja ${ }^{52}$. El segundo término, pugio, está cargado de fuertes connotaciones castrenses. Podemos traducirlo como «puñal»o «puñal militar». Etimológicamente la palabra hace alusión a la mano en posición cerrada o prensil $\left(\right.$ pugnus $\left.^{53}\right)$, del mismo modo que la palabra pugilatus ${ }^{54}$, pues ambos términos pertenecen a la misma familia. El tercer término, parazonium, parece referirse a algún puñal de representación y prestigio más que a un arma práctica. Se relaciona con el Tribuno militar a tenor de una cita de Marcial que abordaremos más adelante. Por tanto parece que la palabra que nos interesa el pugio, se refiere al puñal militar, sin mayores acepciones. Del mismo contamos con un interesantísimo epigrama de Marciall $^{55}$ :

\section{Pugio, quem curva signat brevis orbita vena.} Stridentem gelidis hunc Salo tinxit aquis.

46 Es posible, no obstante, que se deba también al mucho más avanzado estadio de las investigaciones arqueológicas en los países que las ocupan y por tanto no obedezca a una diferencia histórica real.

47 Str, Geografia III, 4, 15.

48 Entre los que incluye a los celtíberos.

49 Diodoro Sículo o de Sicilia: Biblioteca Histórica (V, 33, 3), publicada en torno al 30 a.C. La cita exacta es «[...],

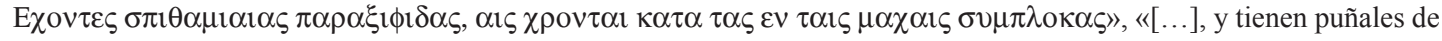
un palmo de longitud, de los que se sirven en los combates cuerpo a cuerpo» (Traducción de Juan José Torres Esbarranch, 2004).

50 En su lugar puede que se trate de una referencia a otra pieza documentada arqueológicamente, el breve cuchillo afalcatado que a menudo aparece acompañando a la espada compartiendo y vaina con ésta. Pero en estos casos el puñal es de tipo curvo, afalcatado, bastante pequeño, y sin relación con el modelo bidiscoidal.

51 No coincide la dimensión citada (un palmo) con los $18 \mathrm{~cm}$ de media del bidiscoidal peninsular, habida cuenta que el palmo griego ( $\delta \varpi \rho \circ v / \pi \alpha \lambda \alpha \iota \tau \eta)$ mide aproximadamente $7,75 \mathrm{~cm}, \mathrm{o}_{1}^{1 / 4}$ de pie griego ( $\pi \mathrm{ous}$ ), cuya medida, dependiendo de la ciudad, varía entre los 30 y $33 \mathrm{~cm}$ de longitud.

52 El hecho de que eventualmente esta palabra termine dando lugar al término sicario (sicarius) nos indica el carácter despectivo de la palabra.

53 Pugnus: puño.

54 Pugilatus: pugilato, boxeo.

55 Marcial, Apophoreta, Libro XIV, Epigrama XXXIII. 
Este puñal cuya hoja está limitada por el filo curvo ${ }^{56}$, lo recibieron rusiente ${ }^{57}$ las aguas heladas del Jalón.

En el epigrama, Marcial nos ofrece, aunque de forma algo críptica, importante información. La referencia al río Jalón (afluente del Ebro) ubica este puñal en Hispania, concretamente en Celtiberia ${ }^{58}$, donde creemos tiene su origen. ¿Se trata acaso de una sanción de Marcial a la teoría del origen celtibérico del pugio romano? No nos podemos pronunciar con seguridad, pero la alusión conjunta al arma y a un río peninsular que cruza el área celtibérica no deja de ser sospechosa.

Contamos, también, con la mención del arma en un discurso de Cicerón ${ }^{59}$ :

Qui postea quam illo quo conati erant Hispaniensi pugiunculo nervos incidere civium Romanorum non potuerunt, duas uno tempore conantur in rem publicam sicas destringere.

El texto, de fuerte carácter metafórico, alude a determinados políticos y a sus acciones refiriéndose a ellos con distintos nombres alusivos al puñal, concretamente sica y pugio. Según A. C. Clark (1907) el «puñalito hispano» (hispaniensis pugiunculus) referido en el texto alude al político romano Cneo Pisón, mientras que las dos «dagas» (sicas) aluden a Catilina y M. Antonio. Aunque no ofrece demasiada información acerca del puñal en sí, al menos nos indica la posibilidad de relacionar ambos conceptos, «puñal» e «hispano», con coherencia. Asimismo, existe la posibilidad de que la asociación de ambas palabras no sea acuñación original de Cicerón, sino que perteneciera ya al acerbo latino y éste se aprovechara de ella, añadiéndole un contenido metafórico. De ser así se trataría de la prueba que buscamos de que el puñal militar (pugio) conservaba en el lenguaje latino una referencia a su probable origen hispano, una referencia fosilizada en la unión de las palabras «puñal» e «hispano» en una misma expresión.

En cuanto al Parazonio (parazonium) contamos con otra referencia de Marcial ${ }^{60}$ :

\section{XXXII: Parazonium \\ Militiae decus hoc gratique erit omen honoris \\ Arma tribunicium cingere digna latus ${ }^{61}$.}

Se trata por tanto de una pieza más de representación que práctica. La historiografía numismática ha hecho de este término el genérico para referirse a toda arma blanca corta representada en moneda, lo que juzgamos altamente erróneo, a tenor del carácter minoritario y excepcional que el concepto «parazonio» sugiere.

Contamos, por último, con un documento procedente de Egipto escrito sobre papiro ${ }^{62}$. $\mathrm{Su}$ cronología se conoce gracias a que el propio texto la indica de forma indirecta: 27 a.C. El

56 No ha de entenderse como alusión a una hoja curva. El filo por fuerza ha de ser en todo caso curvo, sea la hoja curva o recta.

57 Rusiente: que se pone rojo o candente con el fuego.

58 El río Jalón cruza el área celtibérica y a su margen se ubican algunas de las ciudades celtibéricas más importantes, caso destacado de Occilis (Medinaceli, Soria), Arcóbriga (Monreal de Ariza, Zaragoza), Nertóbriga (Almunia de Doña Godina, Zaragoza) o Bílbilis (bien en Huérmeda, Zaragoza, bien en Valdeherrera, Zaragoza, según teorías divergentes defendidas por M. Martín Bueno y F. Burillo respectivamente).

59 Cicerón Oratio in Senatu in Toga Candida, texto contra la conjura de Catilina y Antonio. Texto referido por Quinto Asconio Pediano (9 a.C. - 76 d.C.).

${ }_{60}$ Marcial, Apophoreta Libro XIV epigrama XXXII.

${ }_{61}$ Parazonio: «este ornato de la milicia y prenda del suspirado honor, es un arma digna de ceñir al costado de un tribuno».

62 P. Vindob. L 135. Gilliam, 1981: 277-280. 
texto recoge a modo notarial el préstamo de una cantidad de dinero a un soldado romano ${ }^{63}$. En él, el deudor ofrece como garantía del préstamo - entre otros objetos - una vaina de puñal (vagina pugionis). En el texto se especifica que la vaina estaba adornada con plata y marfil. El texto es interesante porque, independientemente de su valor como refrendo de la existencia de vainas de puñal así decoradas en tal fecha, permite demostrar que el pugio era también usado por contingentes de caballería ${ }^{64}$. Pero sobre todo nos indica el relativamente alto valor que una simple vaina de puñal podía alcanzar, lo suficiente como para servir de garantía de un préstamo. Asimismo nos informa acerca del grado de posesión de un militar romano en los albores del Principado sobre su propio equipo. El poder ofrecerlo como garantía no puede sino traducirse como propiedad plena ${ }^{65}$.

\section{DOCUMENTACIÓN ICONOGRÁFICA}

Subdividimos las representaciones plásticas en virtud de su lugar de hallazgo, un hecho que, salvo excepciones, determina la adscripción cultural del objeto representado.

\section{Iconografia peninsular}

En el ámbito peninsular contamos con muy pocos posibles ejemplos de representación iconográfica de puñal bidiscoidal. Uno de los casos más interesantes lo conforma determinada estela funeraria de Beleño ${ }^{66}$ (Ponga, Asturias). En ella encontramos una interesante representación de lo que sin duda es un arma blanca con una hoja fuertemente pistiliforme, nervio central y dos acanaladuras. La empuñadura presenta un nudo central aparentemente romboidal, aunque puede también ser discoidal, y un pomo cuya lectura puede ser, o bien de antenas sin cabeza, o bien de creciente lunar o pezuña muy simplificado. Según Fernández Ibáñez ${ }^{67}$ se trata de una representación de un puñal del grupo de los representados por el ejemplar de Julióbriga $^{68}$ (Cantabria), clasificado por nosotros como «de creciente lunar» ${ }^{69}$, y los ejemplares de Sotopalacios ${ }^{70}$ (Burgos) o Pinilla de Toro ${ }^{71}$ (Palencia), estos dos últimos clasificados como «de pezuña». La cronología de todos estos ejemplares se extiende, con toda probabilidad, entre los ss. II-III d.C., fecha coherente con aquella de la estela de Beleño ${ }^{72}$. Podría por tanto tratarse de una representación de un puñal perteneciente al género de los de pezuña o creciente lunar, y el

63 Jinete L. Caecilius Secundus del cuerpo de caballería Ala Paullini.

64 Este extremo no se puede verificar iconográficamente ya que la costumbre epigráfica romana es representar al jinete cabalgando hacia la derecha, de modo que un hipotético puñal que pende de su costado izquierdo no podría ser visto. En los casos, minoritarios, en que se representa al jinete cabalgando hacia la izquierda nos encontramos con un problema similar, ya que el escudo portado por el mismo tiene el efecto de esconder cualquier arma que cuelgue de su cintura.

65 No es el lugar para debatir la cuestión de la propiedad de la panoplia militar, para más información sobre este punto ver Breeze, 1976: 93-95.

66 Correspondiente con la estela funeraria de un personaje de nombre romano: Septimio Silo, muerto a los 35 años de edad. CIL II 5735 ; Epigrafía romana de Asturias n. ${ }^{\circ}$ 40; Fernández Ibáñez, 2005a: 211 y fig. 13, B y C.

67 Fernández Ibáñez, 2005a: 211.

68 García Bellido, 1963: 200-201; Fernández Ibáñez, 2005a: 210 y fig. 13, A.

69 Ver apartado «Empuñadura de creciente lunar».

70 Monteverde, 1957: 792-795; Cabré Herreros y Morán Cabré, 1991: 341-346; Fernández Ibáñez, 2005a: 211 y fig. 1.11.

71 Varia, 1975: 461-463.

72 A través del análisis de las peculiaridades epigráficas del texto y los nombres propios de los mentados, la Dra. Alicia Canto de Gregorio sugiere una cronología no anterior al siglo II d.C. (información publicada en www.celtiberia.net el 28-03-06). 
figurante en la lápida podría ser un legionario romano. Los 35 años de edad que llegó a cumplir podrían haber comprendido perfectamente un periodo de instrucción militar, y la presencia del puñal podría pretender referir la actividad castrense del aludido ${ }^{73}$.

La cercanía formal de esta representación con el puñal de Julióbriga cobra especial importancia si lo relacionamos con la particular cercanía física de ambos hallazgos, pertenecientes ambos al territorio de los astures. Este dato enlaza con la teoría defendida por Encarnación Cabré y Juan Antonio Morán ${ }^{74}$ según la cual los puñales con empuñadura de creciente lunar - y sus morfológicamente similares de pezuña - obedecen a una particular simbología astral (concretamente lunar), consecuencia del culto que los pueblos septentrionales peninsulares rendían al astro $^{75}$.

Además de este ejemplo puntual contamos con representaciones de un posible puñal bidiscoidal en algunas de las célebres esculturas de los denominados «Guerreros Galaicos», propios del norte de Portugal y sur de Galicia. Muchos de los ejemplos conocidos presentan algún género de puñal suspendido de la cintura, y algunos de éstos presentan un pomo esferoidal ${ }^{76}$. Tal es el caso de las estatuas de Lezenho ${ }^{77}$, con puñal de pomo esferoidal suspendido del costado derecho; Lezenho/Campos ${ }^{78}$, con vaina de armazón; S. Juliao ${ }^{79}$, con suspensión por dos correas y anillas; Meixedo ${ }^{80}$; Sta. Comba de Basto ${ }^{81}$ posiblemente bidiscoidal, y con idéntico sistema de correaje que en el caso anterior; y por último Sto. Ovídio de Fafe ${ }^{82}$, con la vaina inclinada por el peso de la mano que la ase.

Lo sorprendente de este conjunto es que representan un género de puñal que arqueológicamente sólo se documenta en áreas celtibéricas, vettonas (Soria, Ávila...) o puntualmente en otras regiones de la península, pero nunca hasta ahora en Galicia. Por tanto resulta sorprendente la representación en estas latitudes de un tipo de arma que no es propia de los galaicos.

De este conjunto de esculturas se deduce un dato de vital importancia, hasta cierto punto ya insinuado por el registro arqueológico. Nos referimos a la suspensión del puñal — prácticamente sin excepción- del costado (o cadera) derecha ${ }^{83}$.

\section{Iconografia extrapeninsular}

Documentamos gran número de representaciones iconográficas de adscripción puramente romana, correspondientes a las lápidas sepulcrales de militares romanos de distinto rango. En ellas aparece recurrentemente la figura del difunto, vestido con las prendas castrenses y acom-

73 Dado que en Roma el puñal tenía la cualidad de referir simbólicamente al mundo militar.

74 Cabré Herreros y Morán Cabré, 1991: 341-346.

75 Debatiremos este punto en extenso en el apartado acerca de la «empuñadura de creciente lunar».

6 Quesada, 2003: 87-112, tablas 1 y 2.

77 Dos ejemplares, numerados por Quesada, 2003: n. ${ }^{\circ} 11$ y 12.

78 Quesada, 2003: n. ${ }^{\circ} 14$

79 Quesada, 2003: n. ${ }^{\circ} 24$.

80 Quesada, 2003: n. ${ }^{\circ} 25$.

81 Quesada, 2003: n. ${ }^{\text {o } 28 .}$

82 Quesada, 2003: n. ${ }^{\circ} 30$.

83 El modelo de suspensión de dos anillas diagonales es la mejor prueba arqueológica que corrobore este extremo, puesto que en la gran mayoría de las ocasiones la suspensión se dispone desde las anillas superior derecha e inferior izquierda. Sabemos que es así y no a la inversa pues muchas vainas presentan una única cara decorada, indicándonos el correcto sentido de suspensión. (Ver apartado «Vaina de dos anillas diagonales»). Esto supone que, para conseguir que el puñal se incline hacia el frente del soldado, como sería deseable, y no a hacia su espalda, este tipo de vainas exigirían ser suspendidas del costado derecho. Como decimos, de otro modo la empuñadura se inclinaría hacia la espalda del portador, dificultando enormemente la extracción del puñal de la vaina. Este sistema se invertirá en época romana, con el traslado del puñal del costado derecho al izquierdo, como debatiremos a continuación. 
pañado de toda su panoplia guerrera. Halladas en su mayoría en la frontera renana, el grueso de las representaciones pertenecen a época imperial, concretamente a los ss. I-III d.C.

Como se deduce de la iconografía, el lado de la cadera del que se suspende el puñal depende de la función del soldado. Los legionarios rasos (milites), así como los oficiales inmediatamente superiores (optiones) penden su puñal de la cadera izquierda, mientras que los centuriones y portaestandartes (aquiliferes, signiferes e imaginiferes) lo hacen de la derecha, y en algún caso excepcional, en posición horizontal sobre el vientre. La situación es exactamente la inversa en cuanto a la suspensión del arma principal, la espada ${ }^{84}$.

Sorprende también la presencia de los ejemplos de suspensión horizontal del puñal ${ }^{85}$, sistema que nos remite tal vez a las vainas de dos anillas isolaterales ${ }^{86}$ cuyas anillas de suspensión, ambas en el mismo costado de la vaina, sugieren una suspensión horizontal del conjunto.

También observamos que la suspensión de la espada (gladius) se soluciona bien mediante una bandolera (balteus), bien del cinturón (cingulum), mientras que en el caso del puñal éste aparece sin excepción suspendido del cingulum. En los casos en que la espada se suspende del cinturón a menudo se recurre a un segundo cingulum, independiente de aquél y destinado a la suspensión del puñal, si bien en otros casos ambas armas comparten un mismo cinturón para su suspensión. De cualquier modo, se observa la práctica universal de repartir las armas a ambos lados de la cadera, suponemos que con el fin de equilibrar pesos y volúmenes. Por tanto nunca encontraremos dos armas en un mismo costado.

Son quizá las estelas funerarias de los legionarios Pintaius ${ }^{87}$ y Petilius Secundus ${ }^{88}$ las que nos muestran los ejemplares más cercanos al modelo celtibérico de puñal. Las características de pomo discoide o semidiscoide y nudo central son comunes a ambos y típicos del mundo celtibérico. El caso de Pintaius, signifer de origen astur que sirvió a lo largo del s. I d.C. en Germania Inferior, puede ser la prueba de una cierta continuidad de elementos materiales peninsulares a pesar de la uniformidad exigida por el régimen castrense. Es evidente, por tanto, que esa uniformidad era sólo relativa y no absoluta, permitiéndose el uso de objetos individualizados, siempre que cumplieran con su función militar. Dicho de otro modo, se exigía que un legionario contara con una serie de elementos propios de la «panoplia legionaria», pero la morfología exacta de cada uno de ellos no era precisada ${ }^{89}$.

84 Dado que lo que verdaderamente diferenciaba al primer grupo (legionarios) del resto era el uso de escudo, podemos pensar que la causa de llevar el arma principal en la cadera derecha obedece a la necesidad de extraerlo de la vaina sin ser estorbado por el escudo propio. En su lugar, ni centuriones ni portaestandartes de ningún tipo hacían uso de escudo alguno, por lo que podían suspender su espada del, posiblemente más cómodo en cuanto a la extracción, costado izquierdo, y relegar el derecho al puñal. Lo que nunca se observa es la suspensión de ambas armas (principal y secundaria, o espada y puñal) del mismo costado, posiblemente por evitar el desequilibrio de peso a lo largo de la cintura.

85 Caso de las estelas funerarias de Minucius Lorarius y Gnaeus Musius.

86 Ver apartado «Vaina de dos anillas isolaterales».

87 CIL XIII 8098.

88 CIL XIII 8079

89 Resulta evidente que el tipo de industria romana, eminentemente artesanal, determinó la heterogeneidad de las armas legionarias. No será hasta el Bajo Imperio cuando aparezcan las grandes fábricas de armas controladas por el Estado, permitiendo una producción mucho más homogénea. En el Alto Imperio la producción se repartía entre un gran número de pequeños talleres artesanales, lo que inevitablemente imprimaría individualidad formal a las piezas. En el caso previo a las reformas de C. Mario (circa 107 a.C.) este extremo se veía agravado por la circunstancia de que cada soldado había de proveerse de armas de su propio peculio, lo que inevitablemente habría de redundar en una heterogeneidad armamentística aún más acusada. 


\section{PARTE II. TIPOLOGÍA DEL PUÑAL BIDISCOIDAL}

\section{INTRODUCCIÓN: FORMA Y FACTURA (figs. 1, 4-7)}

El bidiscoidal se define por una estructura relativamente compleja, formada genéricamente por un mínimo de seis piezas principales, unidas entre sí por un número variable de remaches. Éstas son:

A. Hoja de hierro con espiga solidaria.

B. 2 cachas orgánicas (madera o hueso).

C. 2 cachas metálicas (generalmente bronce, en los modelos tardíos hierro).

D. Interior del pomo (madera o hierro).

E. X remaches.

\section{Hoja y espiga}

La hoja del arma presenta una extensa variabilidad en proporciones y morfologías ${ }^{90}$. Destaca la «espiga» ${ }^{91}$ o prolongación de la hoja en su extremo proximal ${ }^{92}$, prolongación que tiene la función de integrar el alma de la empuñadura al ser abrazada por las cachas de ésta. Al pertenecer espiga y hoja a una misma pieza, la unión entre la empuñadura y la hoja es muy sólida. En el caso celtibérico la espiga será invariablemente plana, en el mismo sentido que la hoja ${ }^{93}$. Esto le distinguirá de los ejemplos limetanos ${ }^{94}$, muchos de los cuales presentan una espiga cilíndrica ${ }^{95}$.

Esta única pieza formada por la hoja y la espiga forjadas solidariamente presentará, según el caso, variable número de orificios a través de los cuales se fijarán los remaches que unirán esta pieza a las cachas de la empuñadura. Estos agujeros se distribuyen a lo largo de la espiga y en algunas ocasiones también en los «hombros» ${ }^{96}$ de la hoja.

\section{Empuñadura}

La empuñadura se forma a base de capas superpuestas de distintos materiales. El centro de la misma la forma la espiga de hierro, solidaria con la hoja del arma. Sobre ella se aplican dos cachas ${ }^{97}$ orgánicas, o «piezas orgánicas embutidas», una por cada cara. A su vez, sobre

90 Véase el apartado «Tipología de hojas».

91 Tang en terminología anglosajona. Véase Scott, 1985.

92 Extremo proximal: parte del arma próxima a la mano asidera. Se opone al extremo distal.

93 De lo que deducimos que el arma se fabricaba a partir de una chapa de metal con la silueta del arma recortada y posteriormente batida, motivo por el cual la espiga-como parte no batida de la pieza metálica-conserva la forma plana de la chapa original.

94 V.g. hallados en el Limes o frontera septentrional del Imperio romano.

95 Rod Tang en terminología sajona. Su presencia es un indicio de que el arma pertenece a mediados del s. I d.C. en adelante.

96 Aquí seguimos terminología anglosajona y referimos la expresión blade shoulders (hombros de la hoja). La expresión hace referencia a los laterales del extremo proximal de la hoja (o base de la hoja) anterior al arranque de la espiga.

97 Cachas (de un arma): laterales de una empuñadura y por extensión, las piezas que lo componen, que son generalmente dos, una por cada lado. 


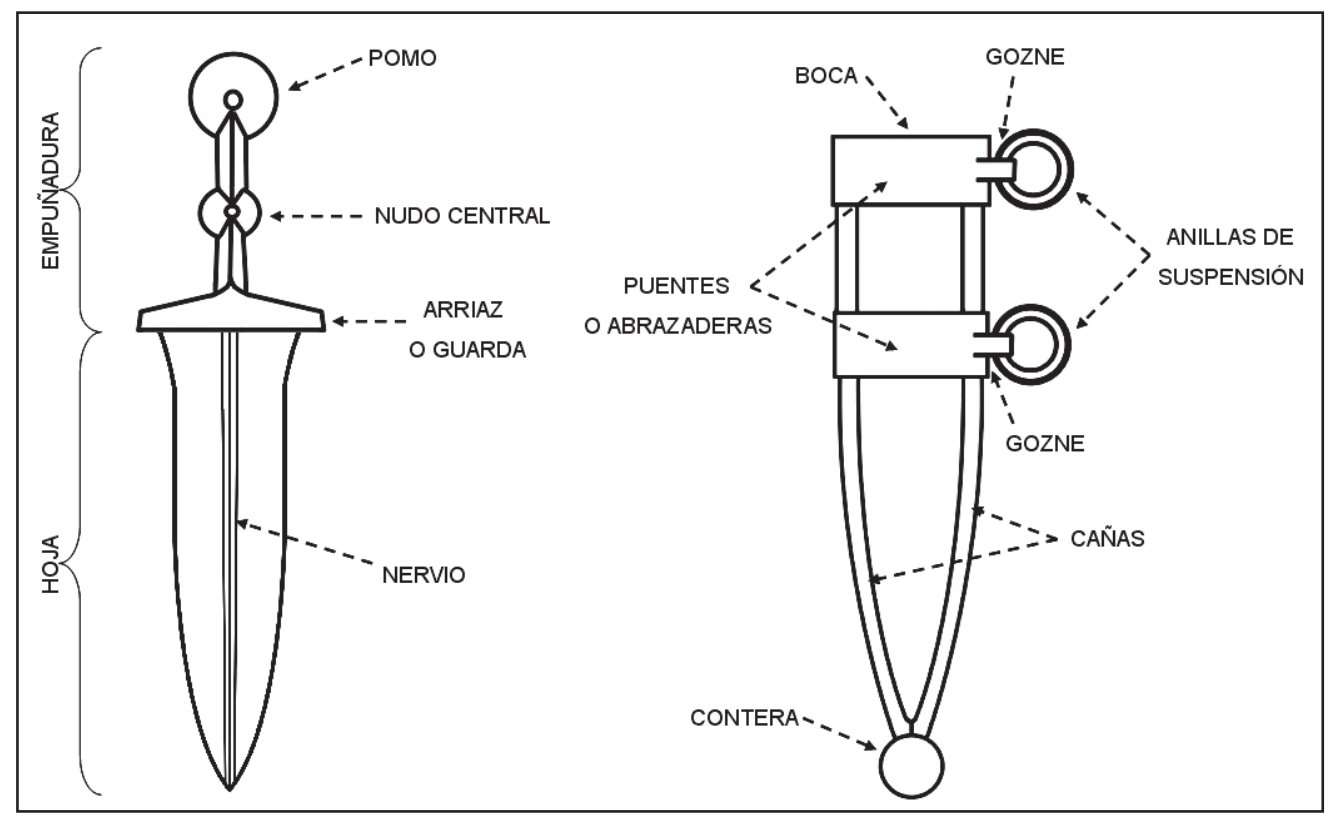

Figura 1. Nomenclatura de las piezas que componen el puñal bidiscoidal y su vaina.

estas últimas se aplican dos pletinas metálicas ${ }^{98}$, de nuevo una por cada cara. Estas últimas sobresalen más allá del límite de la espiga formando las cubiertas del pomo ${ }^{99}$. Por último, se rellena el especio interior del pomo con una pieza maciza de madera o hierro ${ }^{100}$. Todo ello queda afianzado por medio de un número variable de remaches cuya punta es remachada - 0 aplanada — ${ }^{101}$. Esta construcción «por capas» no es original del bidiscoidal, sino heredada de la tradición armera celtibérica, como lo demuestran los modelos de puñal meseteño IV y $\mathrm{V}^{102}$, anteriores a aquél en el tiempo.

Según Vanden Berghe ${ }^{103}$ ambas cachas del puñal de Titelberg ${ }^{104}$, perteneciente al grupo de los bidiscoidales, se fabricaron de una sola pieza, una única pletina metálica cortada, doblada sobre sí misma y alrededor de la espiga de la hoja, formando así las dos cachas metálicas que

98 Podemos de hecho afirmar una relación entre el material de las cachas, la cronología y tipología de puñal. De este modo las cachas de bronce se corresponden con los modelos de puñal de pletina plana y discos concéntricos propios de fines del III-fines del II a.C. mientras que por el contrario las cachas de hierro se corresponden con el puñal de aristas propio de fines del II-principios del I a.C.

99 Por tanto la espiga de la hoja no cruza el interior del pomo, sino que se desarrolla longitudinalmente justo hasta alcanzar el perímetro del pomo, donde termina.

100 De madera formando el interior del pomo contamos con el caso de Capote, Badajoz. Berrocal Rangel, 1993: 366; y de hierro el ejemplar de La Bienvenida, C. Real (en prensa).

101 Según creemos, el clavo utilizado contaba con cabeza redondeada en un extremo y punta en la otra, de modo que - una vez usado el clavo y atravesadas las cachas con él_ parte de su punta sería seccionada y el remanente remachado con algún género de martillo. El resultado de este remachado sería que el clavo quedara afianzado a las cachas y con él, el conjunto de piezas de que éstas se componen.

102 Siguiendo la clasificación de Quesada, 1997a. La analogía entre los tres modelos de arma en p. 292.

103 Vanden Berghe y Simkins, 2001/2: 77: As we keep speaking of two separate pieces of skinning, they (daggerhandles) are not separate. At the handguard one can see that the skinning is made out of one piece of iron. It has been bent around the blade, tang and organic filling until both sides meet. This part has been carefully worked away in order to show the junction by hammering the ends down.

104 Titelberg: oppidum galo sito en Luxemburgo. 


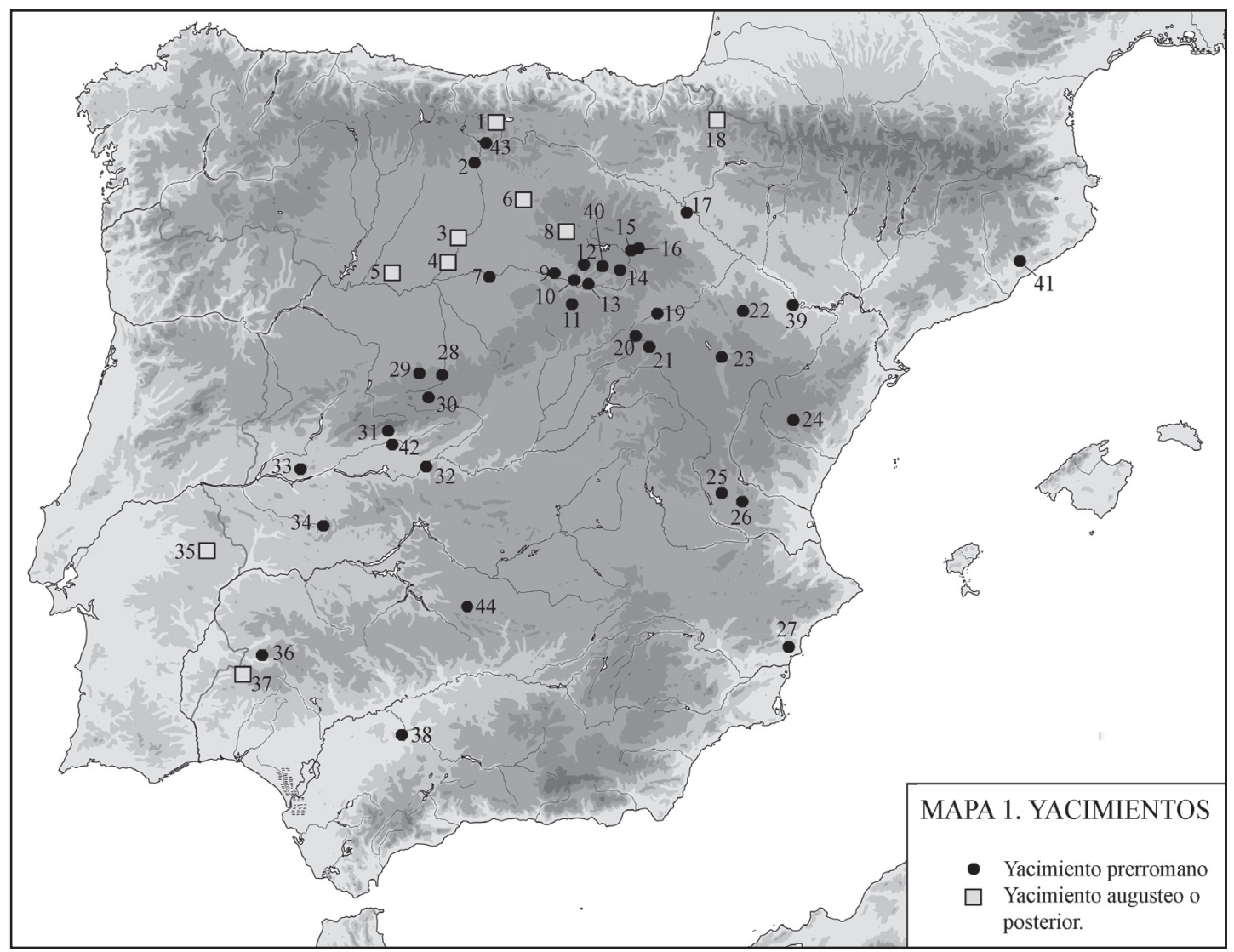

Figura 2. Mapa de dispersión de hallazgos de puñales bidiscoidales. Los círculos representan ejemplares hallados en contexto prerromano; los cuadrados, augusteos o posteriores: 1. Julióbriga (Retortillo, Cantabria); 2. Herrera de Pisuerga (Palencia); 3. Palencia ciudad (Palencia); 4. Sta. Cruz de Camazos (Cabezón de Pisuerga, Valladolid); 5. Pinilla de Toro (Zamora); 6. Sotopalacios (Burgos); 7. Las Ruedas (Padilla de Duero, Valladolid); 8. Cuesta del Burro (Castrillo de la Reina, Burgos); 9. Langa de Duero (Soria); 10. Uxama (Osma, Soria); 11. Carratiermes (Montejo de Tiermes, Soria); 12. Ucero (Soria); 13. Quintanas de Gormaz (Soria); 14. Izana (Soria); 15. Numancia (Soria); 16. Renieblas (Soria); 17. La Azucarera (Alfaro, La Rioja); 18. Espinal (Navarra); 19. Arcobriga (Monreal de Ariza, Zaragoza); 20. Aguilar de Anguita (Guadalajara); 21. Ciruelos (Guadalajara); 22. Castellares de Herrera de los Navarros (Zaragoza); 23. La Caridad (Caminreal, Teruel); 24. Mas de Barberán (Nogueruelas, Teruel); 25. El Molón (Camporrobles, Valencia); 26. Punto de Agua (Benageber, Valencia); 27. Elche (Alicante); 28. Cogotas (Cardeñosa, Ávila); 29. La Osera (Chamartín de la Sierra, Ávila); 30. Ulaca (Solosancho, Ávila); 31. El Raso (Candeleda, Ávila); 32. Manzanas (Las Herencias, Toledo); 33. Cáceres el viejo (Cáceres); 34. Romazal (Plasenzuela, Cáceres); 35. Torre de Palma (Monforte, Portalegre); 36. Castrejón de Capote (Higuera la Real, Badajoz); 37. Aroche (Huelva); 38. Cerro de las Balas (Écija, Sevilla); 39. Azaila (Teruel); 40. Calatañazor (Soria); 41. Turó del Vent (Llinars del Vallès, Barcelona); 42. Dehesa del Rosarito (Cáceres); 43. Monte Cildá (Aguilar de Campoo, Palencia). 44. La Bienvenida (Ciudad Real).

abrazan la empuñadura. Según este método, ambas cachas pertenecen a una misma pieza metálica, y uno de los dos extremos del arriaz mostraría la continuidad de la pletina que forma ambas empuñaduras. Ninguno de los ejemplares que hemos podido analizar para este trabajo ofrecían un estado de conservación lo suficientemente bueno como para comprobar la teoría 
de Vanden Berghe. No obstante, creemos que el conjunto de bidiscoidales es tan heterogéneo que es posible, o incluso probable, que se dieran ambas técnicas de factura, incluso de forma simultánea ${ }^{105}$.

De forma excepcional una lámina metálica, generalmente fina, abraza el pomo por todo su perímetro exterior, cubriendo a las piezas orgánicas del interior de la empuñadura. Esta chapa exenta parece tener como única función el servir de superficie donde aplicar motivos decorativos, por tanto meramente estética.

\section{TIPOLOGÍA DE EMPUÑADURAS}

\section{GeNeralidAdes DE LA EMPUÑaduRA}

\section{Función anatómica}

La especial morfología del enmangue bidiscoidal suscita la pregunta acerca de su elección, y sugerimos que ésta puede tener una doble explicación práctica y ornamental. La presencia del ensanche en forma de nudo distal en el pomo del arma tiene la función obvia de evitar que el arma se deslice a lo largo de la mano del usuario, eventualmente soltándose de la misma. En cuanto al disco o nudo central del arma, y detalle que da nombre al arma, puede tener el mismo objeto, v. g., permitir un asimiento más perfecto del arma. Si analizamos la anatomía de la mano humana, observaremos cómo, en el acto prensil, actúan preferentemente determinados músculos ${ }^{106}$. La consecuencia de esto es que en el centro de la palma o parte interna de la mano, carente de músculos de importancia, se crea una leve cavidad al acontecer el acto prensil y la tensión muscular. Precisamente el nudo central que presentan los bidiscoidales en el centro de la empuñadura ocupa la posición de la leve cavidad que acabamos de referir. Defendemos, por tanto, que la presencia de este nudo central no es baladí sino que atiende a necesidades anatómicas, y tiene por objeto el permitir una aprehensión más firme y homogénea de la empuñadura en su conjunto.

\section{Importancia de la empuñadura}

Elegimos la empuñadura como principal elemento de diferenciación tipológica por ser la parte del arma que más variaciones experimenta a lo largo del tiempo. Va a ser ésta, por tanto, la que nos permita establecer una secuencia evolutiva formal.

Partimos de la premisa de que la industria armamentística del periodo que nos ocupa se encontraba en un nivel puramente artesanal, lo que sin duda tendrá como consecuencia una fuerte heterogeneidad de los productos y una tendencia a que las diferencias locales superen a las cronológicas ${ }^{107}$. Si a este hecho le sumamos la circunstancia de que la empuñadura es la parte del puñal más sujeta a diferencias producto de la moda o el gusto del cliente, entendere-

\footnotetext{
${ }_{105}$ Al menos contamos con un ejemplar procedente de la necrópolis, no ciudad, de Numancia, cuya publicación sugiere que la factura de las pletinas de las cachas se formaron de una única chapa metálica. Se trata del puñal hallado en la tumba n. ${ }^{\circ}$ 60. Jimeno; De la Torre; Berzosa y Martínez, 2005: 106 y fig. 64, 5. En cualquier caso el resultado final es prácticamente idéntico.

${ }^{106}$ Los músculos que efectivamente actúan en dicho movimiento son los denominados «lumbrical de la mano», «aductor del pulgar» (entre el pulgar e índice), y músculos «oponente del meñique» y «aductor del meñique».

107 Dicho de otro modo, la descentralización de la producción — a consecuencia de su carácter artesanal- redundaría en diferencias locales muy acusadas. Al mismo tiempo, dicha descentralización haría difícil una linealidad evolutiva global.
} 
mos que sea ésta la que presente el mayor grado de heterogeneidad. Será igualmente la zona del arma que más decoración comprenda.

No obstante, sí hemos sido capaces de identificar una serie de evoluciones tipológicas que, con mayor o menor éxito, hemos procurado datar. Aunando los ejemplos conocidos, tanto de bidiscoidal celtibérico como de puñal romano, establecemos una lista limitada de variantes, que a continuación detallamos.

\section{BIDISCOIDALES CON EMPUÑADURA DE DOBLE CHAPA METÁLICA}

\section{Empuñadura de pletina plana (figs. 3 y 4)}

Se trata del modelo cuantitativamente superior en territorio peninsular con una perduración notablemente amplia, al menos desde principios del III a.C. hasta el c/era. Aunque nos es difícil precisarlo, podría tratarse del modelo que comience la línea de bidiscoidales ${ }^{108}$. Se define por presentar cachas llanas, sin decoración alguna ${ }^{109}$, producto de aplicar sendas láminas o pletinas metálicas planas, generalmente broncíneas, una por cada lado. Lo hallamos a lo largo del territorio peninsular, aunque con una mayor concentración en la zona celtibérica. Los ejemplares más antiguos documentados podrían corresponderse con aquellos hallados en la necrópolis de Portuguí (Osma, ant. Uxama), concretamente en las tumbas 9 y 11, que podrían datar - con reservas - del segundo y tercer cuarto del s. III a.C. respectivamente ${ }^{110}$. Algo más recientes son los ejemplares de Quintanas de Gormaz ${ }^{111}$ y Ucero ${ }^{112}$, el primero de los cuales podría datarse en torno al ecuador del s. III a.C., mientras que en el caso de Ucero la cronología puede corresponder tanto al s. IV como al III a.C. Igualmente elevada es la cronología de los once ejemplares procedentes de la necrópolis de Portuguí ${ }^{113}$ (Uxama), en torno al siglo III a.C. Por último contamos con un ejemplar procedente de Arcóbriga ${ }^{114}$ cuya asociación a una vaina de espada laténica ${ }^{115}$ sugiere una cronología anterior al 280 a.C.

${ }^{108}$ En antigüedad sólo compite con el modelo de círculos concéntricos, del que no sabemos si es variante o modelo. Probablemente ambos modelos compartan un origen común y coetáneo, tratándose en ambos casos de evoluciones — simultáneas o prácticamente simultáneas- del puñal de frontón exento.

109 A excepción de los casos en los que la decoración sea no geométrica, que también se incluyen en el grupo.

110 A) Tumba 9 de Portuguí (Quesada, 1997a: n. ${ }^{\circ}$ 4317): aparece en asociación con un broche de cinturón de tres garfios, lo que en principio - si seguimos las cronologías de Cerdeño, 1978 - sugiere una cronología en ningún caso posterior al 350 a.C. que se nos antoja temprana. Según Jimeno, De la Torre, Berzosa y Martínez, 2005: 251, el broche de cinturón de tres garfios en asociación al cual fue hallado el puñal que aquí tratamos arrastra la cronología de la tumba hasta un periodo comprendido entre finales del s. VI a.C. y finales s. IV a.C. Según García Merino, 2005: 177, la necrópolis arranca a fines del IV a.C. y continúa hasta el I a.C. Según Lorrio Alvarado (1994b: tabla 2), esta sepultura concreta (n. ${ }^{\circ}$ 9) pertenece al segundo cuarto del siglo III a.C. B) Tumba 11 de Portuguí (Quesada, 1997a: n. ${ }^{\circ}$ 4325): aparece en asociación con una fíbula anular hispánica de tipo «broche anular» (6A de Argente Oliver) cuya cronología (según Argente Oliver, 1994) arranca en el siglo VII y finaliza a fines del IV a.C. Dado lo exageradamente temprano de estas fechas, podemos pensar en una ¿amortización muy prolongada? Posiblemente sí ya que en la misma tumba hallamos una fíbula de «torre libre cónica» (González Zamora 1999: 166) cuya cronología según este mismo autor se correspondería con un periodo de entre mediados s. III al 180 a.C. Según Lorrio Alvarado (1994b: tabla 2) esta sepultura concreta (n. $\left.{ }^{\circ} 11\right)$ pertenece al tercer cuarto del siglo III a.C.

${ }^{111}$ Museo Celtibérico de Soria 1412; Quesada 1997a: n. ${ }^{\circ}$ cat. 4407; Schüle, 1969: taf. 38.2; Lorrio Alvarado, 1994b: 212-257 y fig. 2.

112 Inv. de excavación: NUT 19; Quesada 1997a: n. ${ }^{\circ}$ cat. 4277.

113 Antigua Uxama, Burgo de Osma (Soria).

114 Arcóbriga, «sepultura i». Lenerz de Wilde, 1991: taf. 219, 842.

115 Vaina de espada laténica metálica enteriza con contera circular horadada (tipo «Hatvan-Boldog»), muy típica del IV a.C., y nunca posterior a inicios del III a.C. Agradecemos esta información a Gustavo García Jiménez. 
El modelo experimenta su gran momento de expansión en el s. II a.C., a tenor del número de hallazgos. Entre ellos podemos citar el Cerro de las Balas ${ }^{116}$ (Sevilla), Renieblas ${ }^{117}$ (Soria) y Numancia ${ }^{118}$. En el caso de los procedentes de la ciudad, es difícil precisar su datación, siempre posterior a fines del III, pero en el caso de la necrópolis han de ser anteriores al 133 a.C. ${ }^{119}$. Con un lapso más amplio de error en la datación contamos con los dos ejemplares de Izana ${ }^{120}$ (ss. II-I a.C.), Arcóbriga $^{121}$ (ss. III-I a.C.) y Capote $^{122}$ (probablemente entre el s. III y principios del I a.C. ${ }^{123}$ ). Más problemática es la situación que presentan los ejemplares de Aguilar de Anguita $^{124}$ (Guadalajara), siendo el caso que el yacimiento aún no goza de una interpretación cronológica ni cultural satisfactoria ${ }^{125}$. Por último, los ejemplares más tardíos se corresponden posiblemente con los dos casos de Fuentelaraña ${ }^{126}$ — Uxama, Soria — (fines II a.C.-fines I a.C.), uno de Cáceres el Viejo ${ }^{127}$ - Cáceres-(circa 80 a.C.), y los muy avanzados casos de Ilici ${ }^{128}$ - Alicante- (42 a.C.-50 d.C.) y Herrera de Pisuerga ${ }^{129}$-Palencia- (15-20 a.C. al 100 d.C. ${ }^{130}$ ).

Por tanto, la aparición del modelo de pletina plana se constata al menos desde el segundo cuarto del s. III a.C. pudiendo ser algo anterior, y su perduración hasta finales del I a.C.- principios del I d.C., alcanzando su momento de máxima popularidad en los siglos III y II a.C. No hay ejemplares que sigan este modelo en el mundo limetano, extrapeninsular ${ }^{131}$, no será por tanto el modelo que inspire a sus homólogos romanos ${ }^{132}$. No obstante, el modelo de pletina plana resulta de gran importancia porque constituye el modelo más popular en Celtiberia du-

116 Propio de la primera mitad del siglo II a.C. Tumba 13; Quesada 1997a: n. ${ }^{\circ}$ cat. 5367; Núñez Pariente de León y Muñoz Tinoco, 1988: 429-433; Núñez Pariente de León y Quesada, 2000: 191-220 y figs. 6 y 7.

${ }_{117}$ Römisch - Germanischen Zentralmuseum, Mainz, n. ${ }^{\circ}$ inv. R-69; Luik, 2002: Abb. 171, 69.

118 Tres de la ciudad y cuatro de la necrópolis.

119 Al perder la ciudad su adscripción cultural arévaca en beneficio de la pelendona como consecuencia de su derrota ante Escipión, la necrópolis arévaca es abandonada.

${ }^{120}$ Quesada 1997a: n. ${ }^{\circ}$ cat. 3990 y 3991; Taracena, 1927: 18 y láms. XII y XI respectivamente.

121 En número de dos puñales. MAN 1949/27/ARC-2462 y MAN 1940/27/ARC-2278 respectivamente.

122 CAP91 / LO-1 / Calle Occtal; Quesada 1997a: n. ${ }^{\circ}$ cat. 5327; Berrocal Rangel, 1993: 366, lám. 17.

${ }^{123}$ En ningún caso posterior al conflicto sertoriano. Berrocal Rangel, 2003: 185-217.

124 MAN 1940/27/AA/1248 y MAN 1940/27/AA/2568 respectivamente.

$125 \mathrm{Su}$ excavador, el marqués de Cerralbo y A. Schulten, proponen una relación entre este yacimiento y las campañas de Catón en Hispania (195 a.C.), interpretando la parte del yacimiento conocida como «La Cerca» como un campamento militar levantado por aquél. Sin embargo más recientemente se tiende a dudar de tal interpretación (Morillo Cerdán, 2003) considerando en cambio más probable que se trate de una población o fortificación indígena, posiblemente perteneciente al pueblo de los Titos. No obstante aún no hay certeza absoluta que nos permita negar la teoría castramental, y puede que se trate de un poblado indígena reaprovechado como campamento por las legiones romanas. Por tanto ambas posibilidades son compatibles. Igualmente, otros autores (Sánchez-Lafuente, 2007) defienden la interpretación original —castrensedel yacimiento.

${ }^{126}$ Quesada, 1997a: n. ${ }^{\circ}$ cat. 4033 y 4034 respectivamente; Primera referencia: Campano Lorenzo y Sanz Mínguez, 1990: fig. 6.61; García Merino, 2005: 177. Segunda referencia: Campano Lorenzo y Sanz Mínguez, 1990: fig. 6.62; García Merino, 2005: 177.

127 Ulbert, 1984: taf. 25, 195.

${ }^{128}$ Museo Monográfico de La Alcudia de Elche, n. ${ }^{\circ}$ inv. LA - 2030; Ramos Folqués y Ramos Fernández, 1976; Lorrio Alvarado, 2004: 163-164, dibujo en p. 163.

${ }^{129}$ Fernández Ibáñez, 1999: 335-342 y fig. 1; Fernández Ibáñez, 2005b: fig. 1, 2 y 7.

${ }^{130}$ No obstante es más probable que en este caso el puñal hallado pertenezca a la primera ocupación del lugar (15-20 a.C. al 39 d.C.) por la sencilla razón de que el contingente militar era mucho más amplio en ese periodo que en el subsiguiente (la diferencia cuantitativa correspondiente a aquella distinguible entre una legión entera - IIII Macedonica- y un simple Ala de caballería auxiliar - Ala Parthorum-).

${ }^{131}$ El único modelo ya imperial que guarda cierta semejanza con éste es el de pomo cúbico, pero creemos que se trata de una variante o versión inferior, de poca calidad, del modelo de semidisco, no del de pletina plana. En cualquier caso el modelo de pomo cúbico es tan minoritario que no puede tener importancia alguna en la línea evolutiva del puñal.

132 Ver apartado «Empuñadura de aristas». 


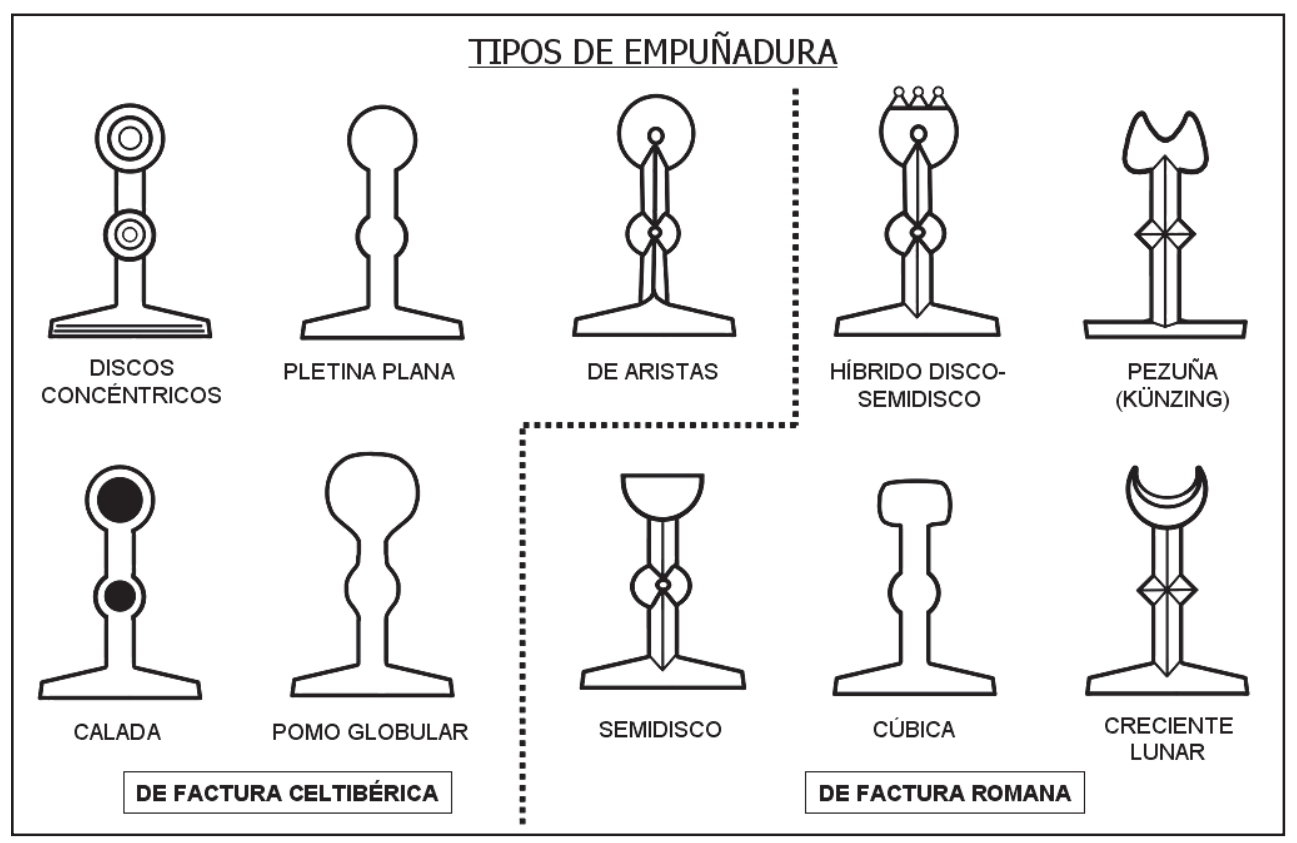

Figura 3. Tipos de empuñaduras de la familia de puñales bidiscoidales.

rante los ss. III y II a.C., y también por suponer el antecedente del modelo de aristas que, según defendemos, protagonizará la transición del puñal celtibérico al romano.

\section{Empuñadura de pomo globular (fig. 3)}

La empuñadura de pomo globular supone una escasa minoría dentro del grupo de bidiscoidales, razón por la que resulta paradójico que el conjunto de todos ellos sea denominado «dobleglobular» ${ }^{133}$. Se define por presentar una forma esférica en el pomo del arma en contraste con las formas discoides, aplanadas, propias del resto de subgrupos. Este subgrupo es representado únicamente por cuatro ejemplares del total analizado, provenientes de los yacimientos de Quintanas de Gormaz ${ }^{134}$ (Soria), Mas de Barberán ${ }^{135}$ (Teruel), Numancia ${ }^{136}$ (Soria) y Punto de Agua ${ }^{137}$ (Valencia). La cronología que ofrecen estas piezas es difusa: circa segunda mitad del III a.C. para Quintanas de Gormaz, fines del III a.C. en adelante para Mas de Barberán y Numancia, fines del III a.C. hasta fines II a.C. para Punto de Agua. Es por tanto posible que se trate de un modelo nacido a fines del III a.C. cuya perduración posiblemente se alargue a lo largo del II a.C. No obstante hemos de admitir la inseguridad que supone datar un modelo con cuatro ejemplares únicamente.

${ }^{133}$ Punto discutido en el apartado acerca de terminología.

134 Tumba 20. Quesada 1997a: n. ${ }^{\circ}$ cat. 4384; Schüle, 1969: taf. 43.1; García Merino, 1973: 31 y ss.; Requejo Osorio, 1978: 227-238; Cabré de Morán, 1990: 205 - 224; Lorrio Alvarado, 1994b: fig. 2.

${ }^{135}$ Izquierdo Peraile, 1999: 97-120 y fig. 5, 2.

${ }^{136}$ Quesada 1997a: n. ${ }^{\circ}$ cat. 4459; Schüle, 1969: taf. 166, 3.

137 Tumba 7. Quesada 1997a: n. ${ }^{\circ}$ cat. 6294; Martínez García, 1990: 79-105, fig. 11 y lám. V.4. 


\section{Empuñadura calada (fig. 3)}

El modelo de empuñadura calada se corresponde únicamente con un yacimiento, Quintanas de Gormaz (Soria), de adscripción cultural celtibérica, y apenas existen dos ejemplares documentados del tipo ${ }^{138}$. Se trata por tanto de un modelo muy minoritario, variante o subtipo del grupo de puñales de pletina plana. Se define por presentar orificios en la lámina metálica de las cachas de la empuñadura, concretamente en el centro del pomo y en el nudo central, traspasando dicha lámina de lado a lado. Estos orificios son circulares, y a través de ellos debía de verse la estructura orgánica del interior de la empuñadura, probablemente lígnea. La cronología de los ejemplares ronda el segundo cuarto del s. III a.C. y mediados de la misma centuria. Por tanto tratamos con un modelo celtibérico, variante del de pletina plana, exclusivo del yacimiento de Quintanas de Gormaz y propio únicamente del s. III a.C.

\section{Empuñadura de discos concéntricos (fig. 3)}

Como tal definimos al modelo de empuñadura que presenta todas las cualidades del modelo de pletina plana más una decoración, tanto en su pomo como en el nudo central, consistente en discos concéntricos ${ }^{139}$. La decoración se desarrolla por igual tanto en el pomo como en el nudo central, no hallando hasta la fecha ningún caso que presente decoración únicamente en uno sólo y no en ambos espacios. Estructuralmente la empuñadura de discos concéntricos es idéntica a la de pletina plana, lo que induce a pensar en una relación entre ambas. Aunque sabemos que durante gran parte de sus respectivas vidas ambos modelos fueron coetáneos, no sabemos con certeza cuál de los dos apareció primero, luego no podemos saber si uno de los dos es una variante del otro o ambos descienden de un modelo común. Los ejemplos más tempranos de este modelo que hemos podido documentar proceden de las necrópolis de Las $\operatorname{Cogotas}^{140}$ (Ávila) y La Osera ${ }^{141}$ (Ávila) ${ }^{142}$. El primero se podría datar en torno a mediados del IV-fines del III a.C., el segundo entre los siglos IV y III a.C. La cercanía física y adscripción cultural idéntica de ambos yacimientos podría indicar un origen vettón para este tipo de empuñadura ${ }^{143}$. A éstos se añaden toda otra serie de ejemplares, pero esta vez provenientes de zona puramente celtibérica, fundamentalmente arévaca, cuya cronología parece ser algo posterior. Tres casos de la necrópolis de Numancia ${ }^{144}$ (fines III a.C.-133 a.C.), otro de la necrópolis de Carratiermes ${ }^{145}$, uno de la necrópolis del Romazal ${ }^{146}$ (ss. II-I a.C.) y los ejemplares difícil-

${ }^{138}$ Primera referencia: Museo Celtibérico de Soria, n. ${ }^{\circ}$ inv. 1428; Quesada 1997a: n. ${ }^{\circ}$ cat. 4419; Schüle, 1969: taf. 36.2; Lorrio Alvarado, 1994b: 212-257 y fig. 2; Segunda referencia: Museo Celtibérico de Soria, n. ${ }^{\circ}$ inv. 1405; Quesada 1997a: n. ${ }^{\circ}$ cat. 4411; Schüle, 1969: taf. 37.2; Lorrio Alvarado, 1994b: 212-257 y fig. 2.

139 A menudo éstos se han ejecutado con una técnica mixta, incluyendo primero la forma en el molde del que se ha fundido la pieza, y añadiendo después decoración por incisión con punzón. En ocasiones sólo se utiliza la incisión, como sucede en los casos en que la pletina de la empuñadura no ha sido fundida sino que se ha creado por martilleo.

140 Tumba 383. Cabré Aguiló, 1932: lám. LXXV, L 75; Cabré Herreros y Morán Cabré, 1991: 341-346; Cabré Aguiló y Cabré Herreros, 1933: 37-47.

141 Cabré de Morán, 1990: fig. 28; Cabré Herreros y Morán Cabré, 1991: 341-346.

142 Según nuestra catalogación se trata de los puñales Cogotas 1 y Osera 2.

143 No obstante, la escasez general de ejemplares nos impide probarlo, siendo en cambio muy insegura cualquier conclusión y en cualquier momento podríamos enfrentarnos al descubrimiento de toda una serie nueva de empuñaduras de este tipo en otras latitudes. Por tanto en principio sugerimos una relación entre el origen de este modelo y la cultura vetona, pero no contamos con suficientes piezas que lo avalen (ni descarten).

144 Jimeno; De la Torre; Berzosa y Martínez, 2005.

145 Carratiermes, tumba 440. Argente oliver, 2001: dibujo en CD adjunto. fig. 54 .

146 Tumba n. ${ }^{\circ} 46$ de la necrópolis de «El Romazal I», n. ${ }^{\circ}$ inv. I-46. Hernández Hernández y Galán Domingo, 1996 : 
mente datables de Arcóbriga ${ }^{147}$. En general este segundo lote nos remite grosso modo a una cronología del s. II a.C. Destacamos la aparentemente total ausencia de empuñaduras de discos concéntricos posteriores al s. II a.C. ${ }^{148}$

Concluimos que la empuñadura de discos concéntricos podría haber aparecido en torno a finales del s. IV o principios del III a.C., experimentando su momento de mayor expansión en el II a.C. para desaparecer inmediatamente después, en torno al año 100 a.C. No habrá, por tanto, ejemplares de este tipo en contexto limetano o extrapeninsular; se trata de un puñal exclusivamente peninsular.

\section{Empuñadura de aristas (figs. 3, 5, 6 y 7)}

Ocupando un lugar privilegiado en nuestro trabajo, incluimos la - a efectos de este trabajo denominada - empuñadura de aristas. Su privilegiada posición la debe a su importancia clave como nexo de unión entre los puñales peninsulares y romanos. Se define por poseer un arriaz ligeramente abatido, pomo y nudo central discoides, normalmente dos remaches sobresaliendo de la estructura. Pero sobre todo ello lo que más define a este modelo es la división en facetas de cada cacha (figs. 6 y 7). Así se genera un vértice central (o arista) en cada cacha que hace particularmente identificable el tipo. La impresión que ofrece el arma es la de haber sido diseñada por unión de toda una serie de formas geométricas perfectas, creándose por tanto unos ángulos muy agudos que contrastan con las formas globulares y uniones suaves entre las piezas tan típicas en los puñales anteriores. Otro aspecto muy importante que distingue a las empuñaduras de aristas del resto de modelos es que sus cachas son fabricadas, sin excepción, enteramente en hierro ${ }^{149}$. Las disposiciones de remaches más típicas a este modelo de empuñadura son las denominadas 5A, 6A y 7A (fig. 9).

Los ejemplares más antiguos con que contamos proceden de la necrópolis de Carratiermes ${ }^{150}$, posiblemente del s. II a.C. ${ }^{151}$, seguidos por los ejemplares de Fuentelaraña ${ }^{152}$. Los más recientes en el ámbito peninsular se corresponden con el gran lote procedente de El Raso (Candeleda, Ávila) ${ }^{153}$, datado con precisión ${ }^{154}$ en la primera mitad del s. I a.C. También contamos

\footnotetext{
${ }_{147}$ Museo Arqueológico Nacional (Madrid), n. ${ }^{\circ}$ inv. 1940/27/ARC - 2282 y 1940/27/ARC - 2288. El yacimiento de Arcóbriga presenta una cronología muy amplia, entre los ss. III-I a.C. por lo que en nada ayuda en nuestra ambición por datar el modelo.

${ }^{148}$ La única excepción a esta aseveración podría ser el caso de Romazal, cuya cronología se puede corresponder a cualquier momento entre los ss. II y I a.C. Por analogía con los demás ejemplares de discos concéntricos pensamos más probable la adscripción de este puñal al s. II a.C., aunque también puede tratarse de una perduración puntual y excepcional. Los ejemplares de Arcóbriga, procedentes de las excavaciones del marqués de Cerralbo, resultan tan difíciles de datar que prudentemente los excluimos del debate cronológico.

${ }_{149}$ En los modelos anteriores la costumbre era realizar la hoja en hierro y rodearla por cachas de bronce, más raramente de hierro. En el caso de la empuñadura de aristas las cachas son siempre, sin excepción, férricas. El resultado es que en estos casos el conjunto del arma resulta — a excepción de las piezas orgánicas, hoy perdidas - enteramente de hierro (hoja, dos cachas y X n. ${ }^{\circ}$ de remaches).

${ }^{150}$ Según nuestro inventario: Carratiermes 1 y 5.

${ }^{151}$ La cronología general del yacimiento oscila entre la segunda mitad del siglo III a.C. y la primera mitad del II a.C. según Argente Oliver y Díaz Díaz (1990). No obstante, según García Soto Mateos (1990: 37) la cronología de la necrópolis perdura hasta el s. I a.C. como demuestra el hallazgo de dos denarios de Sekobirikes.

${ }^{152}$ Según Campano Lorenzo y Sanz Mínguez, 1990, la necrópolis de Fuentelaraña (al norte de Osma, antigua Uxa$m a$ ), debe datarse entre fines de siglo II y fines siglo I a.C.

${ }^{153}$ Fernández Gómez, 1986: figs. 14.20, 89.32, 112.28, 123.2. y 166.15.

154 Gracias a su asociación a numismas romanos (Fernández Gómez, 1986).
} 


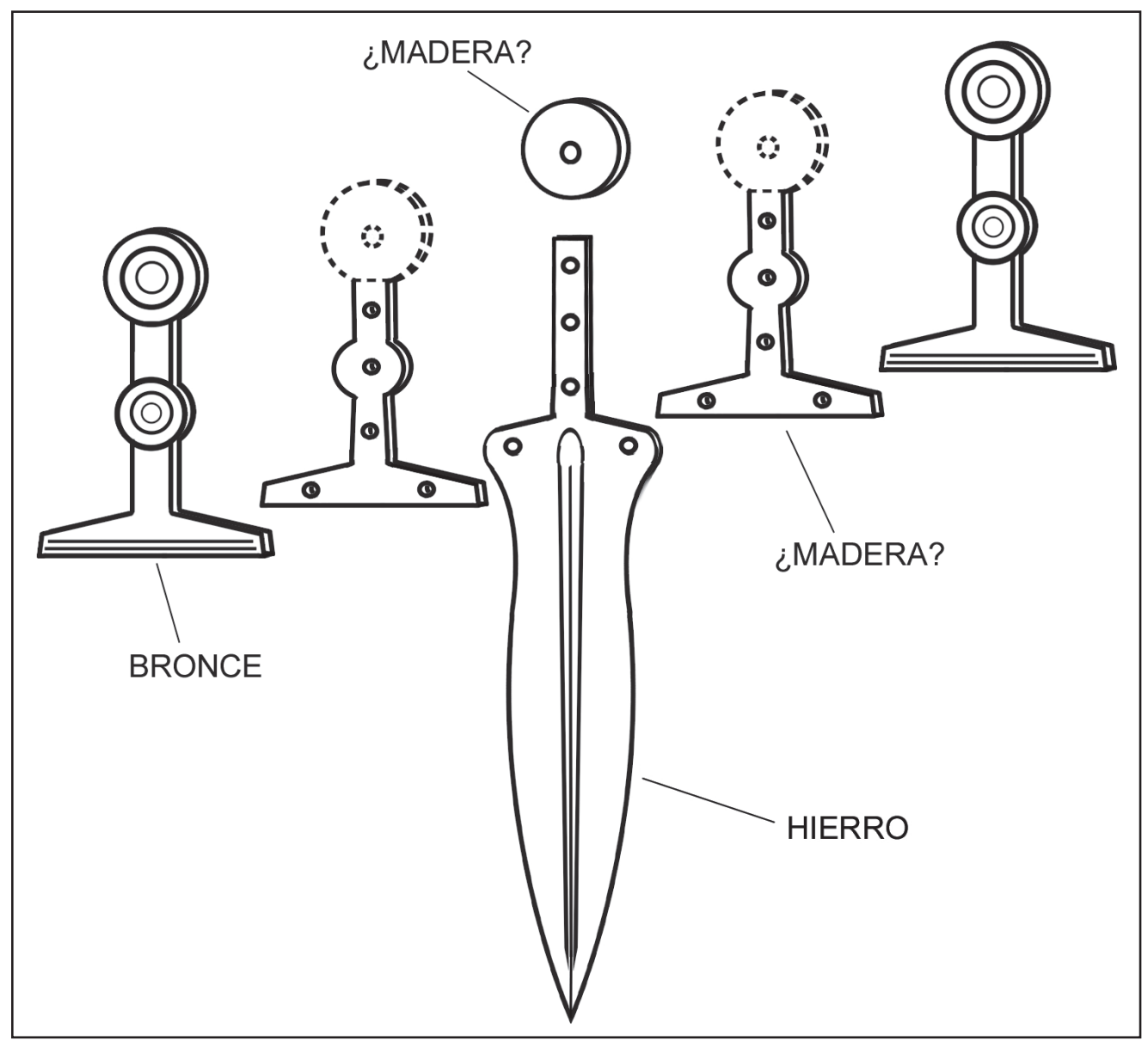

Figura 4. Despiece formal de un puñal bidiscoidal. Modelo de Discos Concéntricos. La espiga de la hoja es abrazada por dos cachas orgánicas (¿de madera?), que a su vez son abrazadas por dos cachas de bronce. Mantenemos en línea discontinua el pomo de las cachas orgánicas pues su forma y división en partes nos es desconocida.

con piezas difíciles de datar procedentes de Osma ${ }^{155}$, La Bienvenida ${ }^{156}$, Termes ${ }^{157}$ y Ciruelos ${ }^{158}$. De éstos, los ejemplares de Osma ${ }^{159}$, entre fines del s. IV y mediados del I a.C. ${ }^{160}$ pueden, o bien tratarse de los primeros ejemplares de empuñadura de aristas, o bien pertenecer al último periodo de uso de la necrópolis. Como información negativa, pero muy significativa, destaca-

${ }^{155}$ Dos ejemplares: A) Museo Arqueológico Nacional, n. ${ }^{\circ}$ inv. 24472. Cabré de Morán, 1990: 205-224, fig. 28.2; García Merino, 2005: 177. B) Museo Arqueológico Nacional, n. ${ }^{\circ}$ inv. MAN 1917/54 - 24.547 cartón 13.

${ }^{156}$ Aún por publicar. Información cortesía de la Dra. Carmen Fernández Ochoa.

157 Ciudad de Tiermes, no su necrópolis de Carratiermes. Schüle, 1969: fig. 46.5.

${ }_{158}$ Museo Arqueológico Nacional, n..$^{\circ}$ inv. MAN 1940/27/C1-1 y 2.

${ }_{159}$ Uno de los cuales deducimos procede de la necrópolis de Portugú́, y no de la de Fuentelaraña, pues entró en el Museo Arqueológico Nacional en 1917 (a juzgar por la lectura de su número de inventario: MAN 1917/54 - 24.547 cartón 13) antes del descubrimiento de la segunda necrópolis.

${ }_{160}$ Según García Merino (2005) la necrópolis de Portuguí (Osma - antigua Uxama) data de finales del siglo IV a.C. y continúa hasta mediados del s. I a.C. 
mos la total ausencia de empuñaduras de aristas en la necrópolis de Numancia ${ }^{161}$ (ante quem 133 a.C.). Dado que Numancia se encuentra en el área nuclear celtibérica, esta ausencia podría indicar la inexistencia de tal género de empuñadura anterior a la destrucción de la ciudad por Escipión. No obstante, otras circunstancias pueden haber jugado un papel en esta ausencia, tales como el particular gusto estético de los numantinos o una eventual simbología cultural adscriptiva de tal género de empuñadura ${ }^{162}$. En cualquier caso, resulta mucho más sensato pensar que la destrucción de Numancia es anterior a la aparición del tipo, lo que nos ofrece una posible fecha post quem para la aparición de la empuñadura de aristas.

También contamos con un ejemplar muy bien datado procedente del yacimiento de Langa de Duero ${ }^{163}$, Soria (entre el último cuarto del s. II y primero del I a.C.) ${ }^{164}$. Contamos con ejemplares hallados en contexto romano castramental de Cáceres el Viejo ${ }^{165}$, campamento pompeyano (circa 80 a.C.) y Monte Cildá166 (26 a.C.-50 d.C.), delatando el contacto de los legionarios con el modelo. Por último, un ejemplar procedente de El Molón (Valencia) ${ }^{167}$, cuya asociación a una vaina romana «tipo A» ${ }^{168}$ nos remite a un periodo entre Augusto y Claudio. Dado que el yacimiento se abandona hacia el c/era proponemos finales del s. I a.C. como fecha verosímil para la pieza.

Ocupa una posición privilegiada en nuestro análisis un caso excepcional de empuñadura de aristas, cuya excepcionalidad radica en el lugar de hallazgo. Se trata del único ejemplar de puñal «de aristas» ${ }^{169}$ hallado en territorio extrapeninsular, concretamente en el campamento de Oberaden ${ }^{170}$, Alemania. El puñal de Oberaden ha sido datado entre los años 11 y 7 a.C. ${ }^{171}$, lo que lo convierte en uno de los primeros ejemplares documentados de pugio romano y al tiempo una de las más sólidas pruebas de la adopción romana del bidiscoidal peninsular ${ }^{172}$. Se puede argüir que en este caso nos encontramos ante una pieza de factura celtibérica llevada hasta territorios limetanos posiblemente por un veterano de campañas peninsulares. Su presencia en el Limes germano delata el conocimiento que las tropas romanas tenían del modelo.

Concluimos por tanto que el puñal de aristas (o con empuñadura de aristas) debió de nacer hacia mediados —o más probablemente último cuarto - del II a.C., ocuparía prácticamente en monopolio ${ }^{173}$ el s. I a.C., experimentaría una drástica reducción tras el conflicto sertoriano

\footnotetext{
161 Jimeno; De la Torre; Berzosa y Martínez, 2005.

${ }^{162}$ Dicho de otro modo, una identificación semiológica de cada tipo de empuñadura con una etnia o incluso ciudad celtibérica. Según esta teoría la empuñadura de aristas podría representar a un pueblo concreto, distinto al de los arévacos o concretamente numantinos, con lo que su uso por parte de éstos no sería imposible pero sí «políticamente incorrecto».

${ }^{163}$ Museo Arqueológico Nacional, n. ${ }^{\circ}$ inv. MAN 1976/48/87; Taracena, 1932: 59 y 60 y lám. XXXVI-28 y 19 (28 puñal, 19 vaina).

${ }^{164}$ Los numismas hallados en Langa de Duero son los siguientes: 1. Denario de C. Servilius Augur (124 a.C.). 2. Denario de la familia Coilia (94 a.C.). 3. N. ${ }^{\circ} 1$ de la ceca 26 de Vives: Denario de Sekobirikes (principios s. I a.C.). 4. Dos ejemplares del n. ${ }^{\circ} 3$ de la ceca 55 de Vives: Denario de Turiasu (entre 100 y 72 a.C.). 5. N. ${ }^{\circ} 1$ de la ceca 29 de Vives: As de Tamaniu (Segunda mitad s. II a.C.). 6. N. ${ }^{\circ} 5$ de la ceca 25 de Vives: Semis de Kese (Finales s. II a.C.).

165 Ulbert, 1984: 196, taf. 25.

166 Alonso Gregorio, 2004: 35-45, figs. 2 y 3.

${ }^{167}$ Pinta; Rovira i Port y Gómez, 1987-88 y Almagro et alii, 1996: 8.

168 «A sheath». Véase Scott, 1985.

${ }^{169}$ No hay duda de que pertenece al tipo «de aristas» peninsular, mostrando una empuñadura facetada, arriaz abatido «tipo B», pomo discoidal y hoja pistiliforme, todo ello características propias del puñal de aristas peninsular. La semejanza se manifiesta incluso en los motivos de su decoración, característicos del mundo celtibérico.

${ }^{170}$ Scott, 1985: 185, n. ${ }^{\circ}$ 3; Helmig, 1990: Abb. 3, c; Bishop y Coulston, 1993: 39.1.

171 Helmig, 1990: Abb. 3, c.

${ }^{172}$ Ver apartado «Decoración en las empuñaduras».

${ }^{173}$ Monopolio generalizado pero no absoluto, pues convivió con algunos ejemplares muy aislados de empuñadura de pletina plana (caso destacado del ejemplar de Herrera de Pisuerga, cuya cronología ha sido precisada en torno a las fechas de 25 a.C. al 50 d.C.).
} 
y desaparecería hacia el c/era, aunque su legado se prolongaría en sus sucesores de semidisco e híbrido disco-semidisco, ambos de factura ya plenamente romana.

\section{Empuñadura híbrida disco-semidisco (fig. 3)}

Hemos bautizado así a este modelo por considerarlo caso intermedio entre los modelos de empuñadura de arista típica, cuyo pomo guarda siempre una forma discoide, y el modelo de semidisco, cuya empuñadura, también de aristas, presenta un pomo semidiscoidal, con el lado curvo enfrentado al resto de la empuñadura. Tanto el modelo que aquí tratamos como sus paralelos (de aristas y semicírculo) comparten todas las demás características formales (idéntico nudo central, idénticos arriaces), a excepción del pomo, en el que difieren los tres modelos. El modelo que aquí tratamos se define por contar con un pomo proto-discoidal, que no llega a cerrar el círculo por su lado superior, donde aparenta tener un corte parcial ${ }^{174}$, y sobre éste una superficie donde asientan tres cabezas de clavo o remaches decoradas.

Ejemplo paradigmático del tipo lo encontramos en el puñal de Utrech ${ }^{175}$ (Holanda), hallado en contexto castramental ${ }^{176}$. Esta pieza es difícil de datar, pues el campamento en que se halló fue ocupado militarmente en sucesivas ocasiones (entre 47 y 69 d.C., y entre 88 y 260 d.C.). Creemos más probable su pertenencia a la primera fase de ocupación, pues formalmente es mucho más cercano a los puñales del s. I d.C. que a los posteriores. También híbridos pero más tendentes al semidisco son los ejemplares de Alleriot ${ }^{177}$ (Francia), con cronología altoimperial, y Mali Drinić ${ }^{178}$ (Croacia), este último acompañado de una vaina de «tipo A» lo que delata su cronología altoimperial ${ }^{179}$. El argumento más poderoso que avala la cronología del s. I d.C. para este minoritario modelo es la forma del nudo central, discoide, en contraste con las empuñaduras de los ss. II y III d.C., cuyo nudo central es, sin excepción, romboidal ${ }^{180}$.

Pero lo más interesante de este híbrido modelo es precisamente su carácter de híbrido, de eslabón intermedio entre los puñales celtibéricos y romanos. Sin duda sabemos que es romano, tanto por su cronología como sobre todo por su contexto. Pero como acabamos de ver guarda una enorme similitud con los modelos celtibéricos, concretamente con el puñal de empuñadura «de aristas». Al tiempo guarda no menos similitud con el modelo de empuñadura «de semicírculo», que sabemos que es un modelo puramente romano. Pero lo más fascinante es que el corte parcial que presenta en la parte más distal del pomo representa sin duda un punto intermedio entre el disco completo celtibérico (de aristas) y el disco cortado por la mitad del modelo romano (de semidisco).

Por tanto desde el punto de vista formal el híbrido disco-semidisco ocupa un punto intermedio entre ambos modelos (aristas y semidisco). Lo que queda por demostrar es si esa posición intermedia, que se observa objetivamente en el campo de lo meramente formal y físico, obedece a una, también posición intermedia, en el campo histórico evolutivo.

\footnotetext{
174 En geometría se denomina «cuerda», en esencia la sección de una porción de un círculo.

${ }^{175}$ N. ${ }^{\circ} 5$ según la clasificación de Thiel y Zanier, 1994: 61. Publicado originariamente en C. A. Kalee en L.R.P. Ozinga et alii, Het Romeinse Castellum te Utrecht. Utrecht, 1989: 159, lám. 104-106.

${ }^{176}$ La moderna Utrech (holandés Utrecht) se asienta sobre una fundación romana de origen castramental con el nombre de Traiectum, perteneciente a la provincia de Germania Inferior.

177 Bonnamour y Fernoux, 1969: 178-185.

178 Jahrbuch des Römisch-Germanischen Zentralmuseum, Mainz (1992) n. ${ }^{\circ}$ 43.2, pp. 733-5 y Abb 55. La pieza se encuentra depositada en el Muzej Cetinske Krajine Sinj, Croacia.

${ }^{179}$ La vaina tipo A se data entre los reinados de Augusto y Claudio (Scott, 1985).

${ }^{180} \mathrm{Tal}$ es el caso de los modelos de empuñadura de creciente lunar y de pezuña, ambos datados entre los ss. II y III d.C. El nudo central romboidal es por tanto indicio seguro de la datación tardía de un ejemplar.
} 
Dificulta esta teoría el hecho de que se han encontrado ejemplares de cronología anterior al que nos ocupa y sin embargo en un estadio evolutivo más avanzado ${ }^{181}$ según el criterio que acabamos de exponer (aristas / híbrido disco-semidisco / semidisco). Podemos por tanto considerar, o bien que hubo modelos híbridos disco-semidisco anteriores pero no se han hallado, o bien que se dieron varias líneas evolutivas paralelas, una, más generalizada, dio lugar inmediatamente al semidisco, y otra, minoritaria, mantuvo tradiciones formales y más parecido con los puñales celtibéricos de los que procedía, conviviendo ambas durante el s. I d.C.

Creemos que efectivamente hay una relación de influencia de un modelo sobre otro, siendo muy probable que el híbrido disco-semidisco ocupara un lugar en la cadena evolutiva entre el puñal celtibérico de aristas y el romano de semidisco, pero no podemos especificar si su posición en la cadena evolutiva es paralela o anterior a la del semidisco. Por añadidura, debemos llamar la atención sobre una particularidad que asemeja a los híbridos disco-semidisco con los de semidisco. Se trata de la tríada de remaches o clavos que sobresalen, proyectando sus cabezas al exterior del pomo en su extremo más distal. Esta particularidad la comparten ambos modelos, demostrando la filiación entre ellos.

Por tanto concluimos señalando que el híbrido disco-semidisco ha de ser sin duda alguna variante del modelo de aristas peninsular, y su cronología documentada pertenece al s. I d.C., pero con toda probabilidad sea algo anterior, coetáneo a la aparición del modelo de semidisco, v.g. a finales del I a.C.

\section{Empuñadura de semidisco (fig. 3)}

Se define por presentar un pomo en forma de medio disco o semidisco cuyo lado plano (correspondiente al diámetro) se dispone opuesto al resto de la empuñadura, hacia el exterior de la misma.

Ejemplos de ello son los puñales de Mainz-Weisenau ${ }^{182}$ (Alemania), dos casos de Kingsholm $^{183}$ (GB), Lorenzberg ${ }^{184}$ (Alemania), S'Gravenvoeren ${ }^{185}$ (Bélgica), Londres ${ }^{186}$ (GB), Alleriot $^{187}$ (Francia), Titelberg ${ }^{188}$ (Luxemburgo), Nida-Heddernheim ${ }^{189}$ (Alemania), Dangstetten ${ }^{190}$ (Alemania), Colchester ${ }^{191}$ (GB), dos casos de Hod Hill ${ }^{192}$ (GB), Velsen ${ }^{193}$ (Holanda) y otros ${ }^{194}$. Todos los ejemplares pertenecientes a este grupo que han podido ser datados han arrojado una datación altoimperial, comprendida entre fines del s. I a.C. y mediados-fines del I d.C. Probablemente el ejemplar más antiguo sea el procedente de Titelberg (Luxemburgo), datado entre

${ }^{181}$ Como tal podemos citar el caso de un puñal procedente de Dangstetten, Alemania [n. ${ }^{\circ} 2$ según la clasificación de Scott, 1985. Véase también Helmig, 1990; y Thiel y Zanier, 1994], con empuñadura de semidisco y una cronología tan temprana como los años 15 a 10 a.C.

${ }_{182}$ Bishop y Coulston, 1993: 75 y fig. 39, 4; Thiel y Zanier, 1994:61, n. 70 y Abb 2, 2.

183 Manning, 1985: Plate 74 V 13 y V15.

${ }^{184}$ Scott, 1985: 193, n. ${ }^{\circ}$ 48. p. 208, fig. 1.

185 Vanden Berghe, 1996: 66-67 y fig. 4.

186 Museum of London, inv. PCD/ER 546; Feugère, 1993: 165.

${ }^{187}$ Bonnamour y Fernoux, 1969: 178-185. Si bien en este caso concreto puede que nos encontremos ante un ejemplar de híbrido disco-semidisco, variante del grupo de semidiscos (ver apartado «Empuñadura híbrido disco-semidisco»).

${ }_{188} \mathrm{Scott}, 1985: 185, \mathrm{n} .{ }^{\circ}$. Este mismo autor propone una cronología para esta pieza entre los años 30 al 10 a. C; Helmig, 1990: 158-164, Abb 3, a; Thiel y Zanier, 1994: 70, n. ${ }^{\circ}$ 14; Vanden Berghe y Simkins, 2001/2: 75-84.

189 Obmann, 1992: 37-40 y taf. 1 .

${ }^{190}$ Helmig, 1990: 160, Abb 3, b.

191 British Museum, n..$^{\circ}$ inv. Colchester 1938; Manning, 1985: Plate 73 V 9.

192 Manning, 1985: Plate 73 V 7 y V8.

${ }_{193}$ Morel, 1989: 93-101; Morel y Bosman, 1989: 177-191; Bishop y Coulston, 1993: 78 y fig. 42; Bosman, 1995.

194 Conocemos dos casos de empuñadura de semidisco sin contextualización arqueológica: n. ${ }^{\circ} 61$ del catálogo de Scott, 1985; Manning, 1985: Plate 73 V 6. 
el 30 y el 10 a.C. ${ }^{195}$ Le sigue de cerca el puñal de Dangstetten, posiblemente entre el 15 y 10 a.C. ${ }^{196}$. El ejemplar de Lorenzberg se sitúa entre el 10 a.C. y el 50 d.C. ${ }^{197}$ El de Velsen ha sido datado con gran precisión en torno al año 28 d.C. ${ }^{198}$.

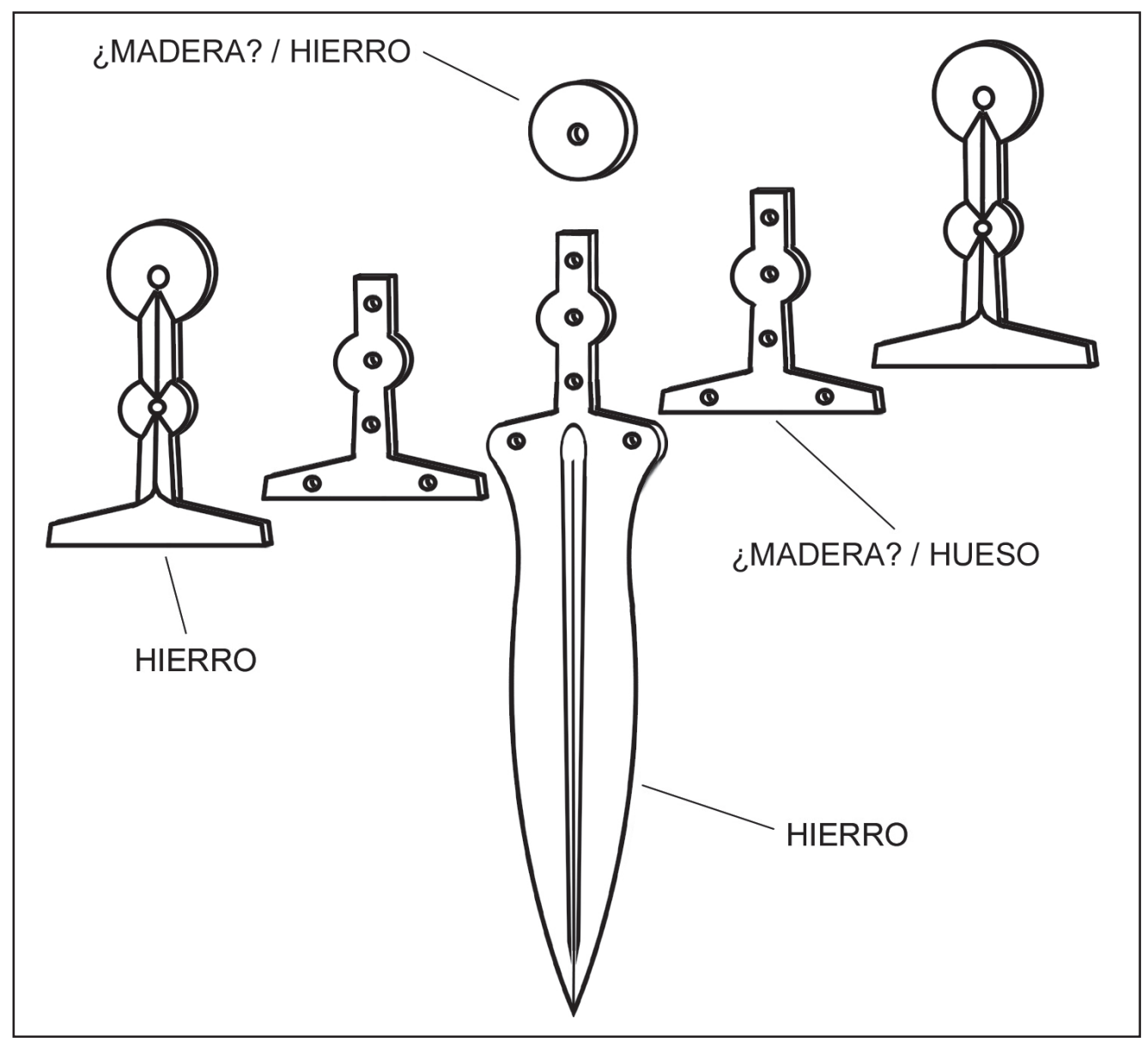

Figura 5. Despiece formal de un puñal bidiscoidal. Modelo de Aristas. La espiga de la hoja es abrazada por dos cachas orgánicas (madera-hueso), que a su vez son abrazadas por dos cachas férricas. Obsérvese que la espiga de la hoja presenta un ensanchamiento a la altura del nudo central, característica exclusiva del modelo de aristas.

Por tanto parece probado que nos encontramos ante un modelo claramente altoimperial, que - quizá no de forma casual - se corresponde grosso modo con la dinastía Julio-Claudia. Su valor en nuestro análisis es por tanto inmenso, pues la conjunción de datos conocidos acerca de la cronología junto con la información de los lugares de hallazgo de esta arma (Limes imperial), supone que nos encontramos ante el primer modelo de puñal militar cuya adscrip-

\footnotetext{
195 Scott, 1985: 185, n. ${ }^{\circ} 1$.

${ }^{196}$ Scott, 1985: 185, n. $^{\circ} 2$.

${ }^{197}$ Scott, 1985: 186, n. ${ }^{\circ} 5$.

198 Morel, 1989: 93-101; Morel y Bosman, 1989: 177-191.
} 
ción es plena y claramente romana. Hasta el momento contábamos con puñales hallados en contextos tanto indígenas como romanos, pero ahora nos encontramos ante un puñal hallado únicamente en contextos romanos ${ }^{199}$.

Insistimos en la importancia de este dato, pues en el caso de ser capaces de rastrear los orígenes de este modelo, podríamos determinar si existe relación con su homólogo celtibérico, como creemos, o no.

No creemos que se trate de una variante del conocido puñal de frontón ${ }^{200}$, a pesar del parecido, por varias razones: en primer lugar el pomo no es exento sino solidario a la hoja del $\operatorname{arma}^{201}$. Por otro lado, el bidiscoidal con remate en semidisco presenta la mitad ausente del disco hacia el exterior, mientras que en el puñal de frontón sucede al revés. Y en tercer lugar porque el puñal de frontón desaparece en el s. II a.C. mientras que el de semidisco nace a finales del I a.C., dejando un hiatus temporal entre ambos demasiado amplio como para permitir una relación evolutiva lineal.

Defendemos que este puñal deriva del modelo de aristas celtibérico, por sus similitudes formales y sucesión cronológica perfecta. La paridad morfológica se evidencia en la idéntica estructura de la longitud interna de la empuñadura, nudo central y arriaces. Los puntos de analogía son los siguientes:

A. Idéntica estructura facetada o «de aristas» a lo largo de la longitud interior de la empuñadura.

B. Idéntico nudo central cruzado por un aspa de aristas.

C. Idéntica disposición de los remaches visibles (en el pomo y nudo central) e idéntica ocultación del resto de remaches ${ }^{202}$.

D. Idénticos arriaces, en ambos casos abatidos (modelo B).

La empuñadura presenta en ambos casos la superficie angulosa, tan típica del puñal de aristas, definida por ofrecer una arista central elevada longitudinal a la empuñadura, lo que provoca la división de la cacha en dos facetas. En resultado final es una empuñadura de seis caras o facetas, dos por cada cacha más dos laterales (fig. 6). Esta especial morfología aparece en Celtiberia a mediados-finales del II a.C., y la hallamos ahora punto por punto repetida en los puñales puramente romanos de fines del I a.C. en adelante. No creemos que se trate de una coincidencia.

También comparten ambos modelos un idéntico nudo central, en ambos casos discoidal y cruzado por un aspa, producto este último de la construcción «facetada»o «de aristas» de la cacha. Ambos modelos de empuñadura presentan una constante muy particular que podemos considerar de función eminentemente estética. Como se indicó en el apartado dedicado a la factura del bidiscoidal, las empuñaduras de éstos presentan una serie de remaches que permiten mantener unidas las diferentes piezas que lo componen. Por lo común estos remaches son

\footnotetext{
199 Ya sea en territorio peninsular o limetano, siempre son contextos pertenecientes a la cultura romana. En su gran mayoría son campamentos militares.

${ }^{200} \mathrm{El}$ puñal de frontón o de frontón exento (ver apartado «Origen y problemática») es una producción meseteña peninsular definida por presentar un pomo en forma de semidisco cuyo lado redondo se opone al resto del arma y el plano al exterior. En el caso romano (de semidisco) ocurre a la inversa, siendo el lado curvo del semidisco el que se enfrenta al arma, y el lado plano al exterior.

${ }^{201}$ Exento en el caso del puñal de frontón (ibérico), solidario en el caso del puñal de semidisco romano. Por exento entendemos que se trata de una pieza independiente, fabricada aparte y aplicada al resto del arma después.

${ }^{202}$ Con excepciones. En algunos casos (p. ej. Titelberg) se muestran visibles otra serie de remaches cuya disposición no se corresponde con el pomo o nudo central.
} 


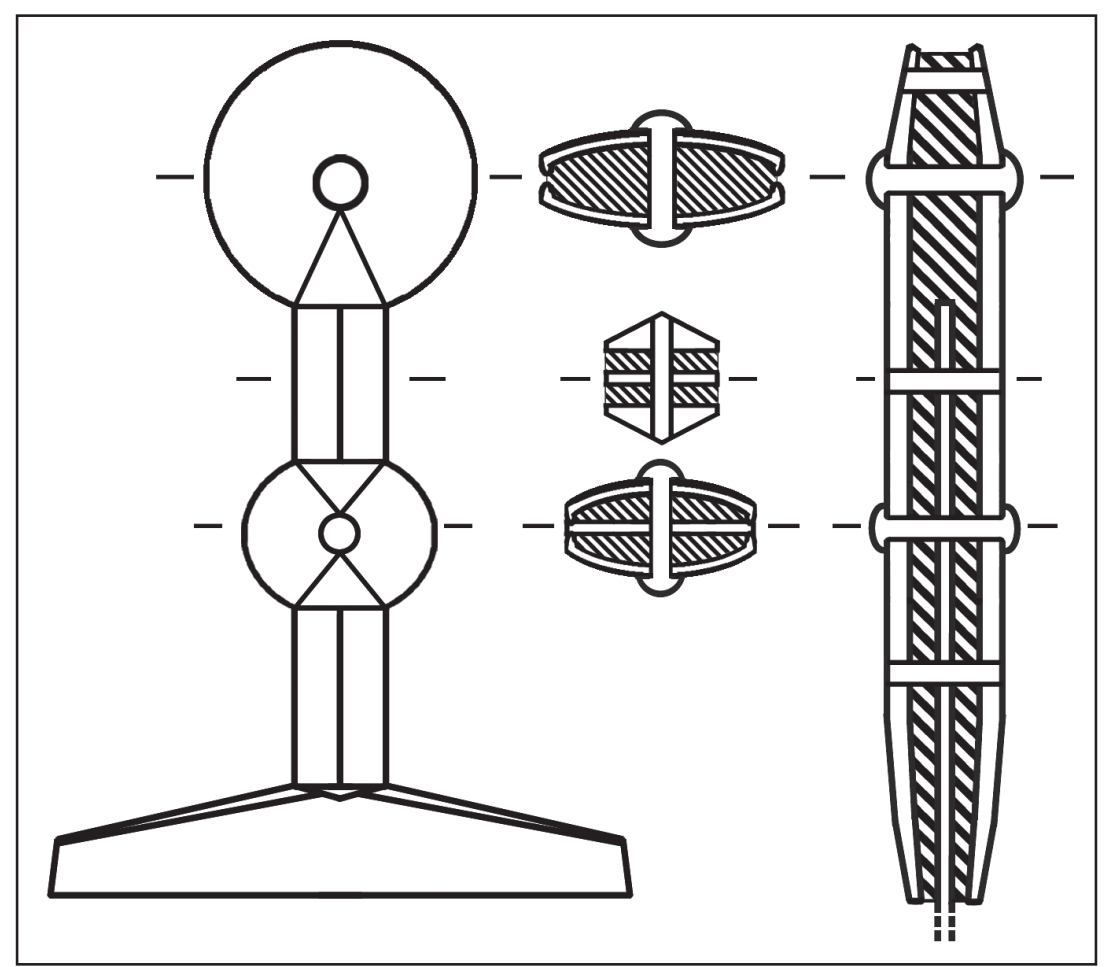

Figura 6. Frente y sección de una empuñadura bidiscoidal. Modelo de Aristas. El trazado diagonal representa el material orgánico, probablemente lígneo, del interior de la empuñadura.

intencionadamente disimulados merced a la lima de sus cabezas, que al no sobresalir de la estructura, permanecen camuflados. En cambio una excepción a esta práctica son los remaches localizados en el pomo y nudo central de la empuñadura. En estos casos los remaches no son limados, permaneciendo sus cabezas sobresalientes de la superficie y por tanto bien visibles. Creemos que esto es debido a cuestiones estéticas, aunque posiblemente también se buscara el facilitar la prensión del arma. En cualquier caso tanto en la elección concreta de los clavos a disimular - como la excepción en los dos casos mentados - coinciden plenamente el puñal celtibérico de aristas y el romano semicircular. La única diferencia que se observa en este caso es que los puñales de semidisco, al presentar un pomo distinto, algo más dilatado, requieren no de dos sino de tres o más remaches en el mismo. Éstos suelen distribuirse sin excepción ordenados linealmente en sentido transversal al arma. En último extremo podemos considerar menor este punto de diferencia, puesto que la norma general de presentar remaches visibles tanto en el nudo central como en el pomo se mantiene.

Por último, los modelos de aristas celtibérico y de semidisco romano se asemejan en la forma de la guarda o arriaces. En ambos casos nos encontramos ante lo que podríamos llamar «arriaces abatidos» $\mathrm{O}$ «tipo $\mathrm{B} »^{203}$, v. g., arriaces cuyo lateral superior (i.e. hacia el interior de la empuñadura) presenta una inclinación hacia la punta del arma. En algún caso excepcional nos

${ }^{203}$ Ver apartado «Evolución de los arriaces». 
encontramos ante otro tipo de arriaz asociado a la empuñadura semidiscoidal ${ }^{204}$, pero la norma es la asociación con el modelo B.

El resultado es una guarda en forma aproximadamente triangular, aunque sin vértices ${ }^{205}$. En propiedad el polígono al que más se asemeja es el pentágono, siendo el lado inferior el de mayor dimensión, los laterales inmediatos aproximadamente verticales ${ }^{206}$ y los lados superiores casi completamente horizontales. Esta especial morfología, que hemos acordado denominar «de arriaces abatidos» o arriaz tipo «B», es compartida tanto por el puñal de aristas como por el de semidisco, avalando una vez más la probable relación evolutiva entre ambos.

Por todo ello concluimos defendiendo la fortísima influencia celtibérica que muestra el puñal de semidisco, lo que en nuestra opinión demuestra el origen celtibérico del puñal legionario romano.

\section{Empuñadura de creciente lunar (fig. 3)}

Conformando el caso probablemente más problemático del conjunto, el modelo de empuñadura de creciente lunar supone un unicum histórico que por su exclusividad amenaza con permanecer en el misterio. Se define por contar con un pomo en forma de creciente lunar con los picos hacia arriba, v. g. señalando en la dirección opuesta al resto del arma. Tan sólo conocemos dos ejemplares del tipo: uno lamentablemente descontextualizado pero con gran probabilidad peninsular ${ }^{207}$, el segundo procedente de Julióbriga ${ }^{208}$ (Retortillo, Cantabria). El puñal fue hallado, no en el yacimiento, sino en sus cercanías, pero lo más probable es que su cronología corra pareja a la de la urbe (15/13 a.C. ${ }^{209}$-mediados s. III d.C.), lapso temporal muy amplio que dificulta enormemente la adscripción cronológica de la pieza. Lo que nos llama la atención de este ejemplar es su cercanía formal con el modelo denominado «de pezuña» o tipo Künzing ${ }^{210}$, sin llegar a pertenecer al tipo. Al mismo tiempo, reconocemos en el modelo de creciente lunar un motivo decorativo digno de ser utilizado como pomo de puñal, mientras que en el muy similar modelo de pezuña no se reconoce ninguna forma identificable. Podemos interpretar este hecho de varias maneras:

En principio sugiere que el modelo con simbología fácilmente identificable (la luna) es el original, mientras que el motivo «amorfo» (pezuña) es una evolución del anterior tendente a simplificar o esquematizar un motivo de sobra conocido ${ }^{211}$. Sin embargo, para ello tendría que haber habido gran cantidad de ejemplares (al menos más de dos), y la arqueología demuestra

\footnotetext{
${ }^{204}$ Así parece ser el caso del ejemplar de Herrera de Pisuerga, de tipo semidisco pero cuyo arriaz se asemeja más al modelo «C».

${ }^{205}$ Los vértices de este proto-triángulo son seccionados antes de converger en una punta, creando nuevos laterales. Por esta razón decimos que no se trata propiamente de un triángulo sino de un pentágono de lados y ángulos muy irregulares.

${ }^{206}$ Con ligeras inclinaciones hacia el interior o exterior según los casos.

${ }^{207}$ Cabré Herreros y Morán Cabré, 1991: fig. 2, C. Según testimonio de estos autores, el puñal fue visto en el mercado de antigüedades de la Plaza Mayor de Madrid.

${ }^{208}$ Antigua Iuliobriga. García Bellido, 1963: 200-201 y fig. 19. Cabré Herreros y Morán Cabré, 1991: 341-346 y fig. 3; Fernández Ibáñez, 2005a: 210 y fig. 13, A.

${ }^{209}$ La ciudad de Iuliobriga se fundó ex-novo tras las Guerras Cántabras con el fin de asentar en ella a los veteranos de aquel conflicto, al tiempo que participar activamente en la política de pacificación del territorio emprendida por el emperador Augusto.

${ }^{210}$ Ver apartado «Empuñadura de Pezuña».

211 Este fenómeno es recurrente en la evolución semiótica. Un ejemplo paradigmático del proceso lo supone el caso de las figuras que representan al dios Horus en el Antiguo Egipto. Éstas evolucionaron tanto a lo largo del tiempo que, lo que en origen era una figura antropomorfa con alas desplegadas y como tal identificable, degeneró hasta convertirse en una silueta plana con protuberancias laterales y completamente inidentificable para quien no conociera la figura en que se inspira.
} 
lo contrario. Y lo que es más, para que un artesano pueda permitirse el lujo de simplificar un motivo o símbolo, es absolutamente imprescindible que este motivo sea completamente popular y reconocible por toda la sociedad. Sin embargo el motivo del creciente lunar no fue nunca tan popular como para poder ser simplificado o modificado con éxito, v.g., manteniendo su significado simbólico, por lo que no creemos en esta posibilidad.

Que se trate de una variante local del popular puñal de pezuña, que, quizás por la especial vinculación del artesano o dueño por la luna, o quizás, como defienden Cabré y Morán ${ }^{212}$, como consecuencia de algún género de culto lunar - pero ya local y no genéricamente romano- al que simbólicamente alude ${ }^{213}$.

O bien, que no aluda a simbología alguna y se trate de un mero elemento decorativo ${ }^{214}$, variante de la familia de los puñales de pezuña.

Por último, que el motivo del creciente lunar contenga algún contenido simbólico para la cultura romana y no indígena peninsular. Hallamos crecientes lunares como remates (o pesas) del vexillum o estandarte militar, en los signa o estandartes sólidos verticales legionarios, acompañado de discos (¿símbolos lunares y solares o acaso astrales?); igualmente en forma de pequeños crecientes lunares metálicos decorando el extremo del cingulum $^{215}$ del legionario romano altoimperial, e incluso decorando los calcei senatorius o botas del senador romano ${ }^{216}$. Independientemente de la identificación del símbolo con el astro lunar o no, la recurrente presencia del motivo en contexto militar romano no deja de ser sospechosa. De ello podemos deducir que se trata de un motivo puramente romano que quizá aluda de alguna manera al mundo militar, razón por la cual lo hallamos decorando el pomo de un arma.

En cualquier caso, y volviendo al campo puramente formal, la relación del creciente lunar con el puñal de pezuña es innegable, no sólo por la cercanía formal entre los pomos sino, lo que es mucho más decisivo tipológicamente, la coincidencia absoluta entre sus nudos centrales, en ambos casos romboidales ${ }^{217}$. Se trata por tanto de los dos únicos modelos de puñal que presentan esa peculiaridad, lo que sin duda demuestra una relación entre ambos. Por último, hemos de señalar la similitud del puñal de creciente lunar con aquel representado en la estela de Beleño ${ }^{218}$ (Ponga, Asturias), estela funeraria en honor a un individuo de nombre latino. La cercanía geográfica, cronológica y morfológica entre la representación epigráfica y el hallazgo de Julióbriga no deja de plantear interesantes interrogantes ${ }^{219}$.

Por todo ello concluimos que el modelo de creciente lunar con toda probabilidad pertenece a la familia del modelo de pezuña, por tanto no es anterior al s. II d.C., y posiblemente tampoco

212 Cabré Herreros y Morán Cabré, 1991.

${ }^{213}$ La localización en territorio astur del único ejemplar de puñal con empuñadura de creciente lunar contextualizado (puñal de Julióbriga) nos inclina a relacionar el motivo con los cultos lunares tan insistentemente referidos por los autores clásicos para los pueblos del septentrión peninsular. Cultos lunares por otra parte confirmados por la arqueología, destacadamente en el caso de los motivos «decorativos» — entre los que el creciente lunar es recurrente- de las estelas funerarias de época romana del norte peninsular.

${ }^{214}$ Dado que se trata de un motivo muy simple, podríamos desechar toda especulación en torno a su significado bajo la base de que su presencia es puramente casual, y al contrario, podríamos argüir que lo que sería extraño es la ausencia de un motivo tan sencillo y por tanto fácil de representar.

${ }^{215}$ Como se puede observar en la estatua de legionario hallada en Camomile Street, Londres (Museum of London).

216 Sabemos que las botas del senador eran uno de los distintivos de los que eran más celosos, y éstas se ataban con correas (corrigiae) de las que pendía un creciente lunar de marfil. Es evidente que, al menos en este último caso, el creciente lunar denotaba una diferenciación social.

${ }^{217} \mathrm{La}$ importancia de esta coincidencia radica principalmente en que se trata de los dos únicos modelos de empuñadura que cuentan con nudo central romboidal. El monopolio que comparten de esa característica tan específica delata la muy probable relación cronológica y tipológica entre ambos modelos de empuñadura. Según creemos, ambos modelos pertenecen a los s. II y III d.C.

218 Fernández Ibáñez, 2005a: 211 y fig. 13, B y C.

219 Este tema se debate en extenso en el apartado «documentación iconográfica». 
sea posterior a mediados del s. III d.C., momento en que el yacimiento de Julióbriga decae sensiblemente.

\section{Empuñadura cúbica (fig. 3)}

Este minoritario modelo se define por presentar una forma aproximadamente cúbica, algo más ancha que alta, haciendo las veces de pomo. Se trata de un modelo cuya existencia se corresponde exclusivamente con la época altoimperial, principalmente a lo largo del s. I d.C., y posiblemente en exclusiva, sin perduración más allá de ese siglo. Casi con toda probabilidad se trata de una variante, o sencillamente bien burda imitación, del modelo de semicírculo que según parece le precede ligeramente en el tiempo. Esta segunda opción nos parece más probable, pues la empuñadura cúbica muestra una factura mucho más sencilla y tosca que su coetáneo modelo de semicírculo. Esto se demuestra fundamentalmente en el hecho de que el modelo cúbico carece de las características «aristas» en su empuñadura que el puñal de semidisco ha heredado del propiamente denominado «de aristas ${ }^{220}$.

Encontramos ejemplares de este modelo únicamente en territorio peninsular, y en cualquier caso debemos interpretarlo como un género minoritario. Ejemplos del mismo son dos casos de la ciudad de Palencia ${ }^{221}$ y uno de Numancia ${ }^{222}$. En este último caso sin duda se trata de un arma perteneciente a las fases altoimperiales de la ciudad, momento en que ésta aún era ocupada.

\section{Empuñadura de pezuña (o «tipo Künzing») (fig. 3)}

La empuñadura que nosotros denominamos «de pezuña» recibe distintos nombres: Monteverde ${ }^{223}$ la denomina «de doble pezuña de gacela», pero en la historiografía europea se denomina «tipo Künzing», en alusión al yacimiento germano donde se halló una gran concentración de ejemplares. Se define por un pomo cuya silueta aparenta la pezuña que le da nombre ${ }^{224}$. Son tres por tanto los rasgos característicos que permiten identificarlo con claridad:
A. Pomo en forma de Pezuña.
B. Arriaces completamente rectos y transversales a la longitud del arma («en T invertida» o arriaz «tipo $C »)$.
C. Nudo central romboidal.

De los tres, el último rasgo es el único que puede variar, apareciendo totalmente ausente en una subvariante, minoritaria ${ }^{225}$. Los otros dos rasgos (pomo de pezuña y arriaces rectos en T) son universales al género de puñales de pezuña.

\footnotetext{
${ }^{220}$ La ausencia de aristas simplifica enormemente el modelo y, en la misma medida, la factura del mismo. Por eso pensamos que la ausencia de aristas es un indicio de la tosquedad de su factura con miras a una producción mucho menos costosa. Para una definición de «aristas», ver apartado «Empuñadura de Aristas».

${ }^{221}$ Primer ejemplar: Cabré Aguiló, 1931: lám. XX, 4. Segundo ejemplar: Schüle, 1969: taf. 165.1; Fernández Ibáñez, 2005a: 209 y fig. 8.

${ }^{222}$ Schüle, 1969: taf. 166, 6.

223 Monteverde, 1957: 792.

${ }^{224}$ V.g. una forma cercana a la de un creciente lunar con los picos redondeados y la base ampliada. Se asemeja por tanto a la pezuña de un animal de la familia de los cápridos.

${ }^{225}$ Se trata de la variante Künzing «tipo C» según Reuter, 1999: 121. Es una variante idéntica a las demás salvo por la ausencia de nudo central de ningún tipo y de la misma se han hallado ejemplares en Niederbieber, Künzing y Carnuntum.
} 
Se trata de un modelo de cronología muy avanzada. Tradicionalmente datado únicamente en el s. III d.C. ${ }^{226}$, más recientemente se tiende a $\operatorname{creer}^{227}$ que el origen de este modelo podría corresponder con los inicios del s. II d.C. - coincidiendo con la aparición de la dinastía Antonina- y perviviendo hasta el ocaso del III d.C. Los ejemplares de Bar Hill (GB) son igualmente de Pezuña y han sido datados en época Antonina, corroborando la teoría del origen trajaneo de este género de puñal. Parece, en cualquier caso, que nos encontramos ante el último eslabón en la cadena evolutiva del puñal bidiscoidal, separándose y distinguiéndose ya mucho de su modelo de origen. El pomo discoide se ha transformado en pezuña, mientras que el nudo central ha adoptado una forma romboidal. El arriaz ha terminado de completar su tendencia a aplanarse, llegando a convertirse, en asociación a los puñales de pezuña, en una pieza completamente rectangular y transversal al conjunto del arma. Este fenómeno ha sido bautizado por la historiografía sajona como empuñadura en $« \mathrm{~T}$ invertida» ${ }^{228} \mathrm{y}$, a efectos de este trabajo, como arriaz tipo «C».

Aunque fundamentalmente limetano, en la P. Ibérica también contamos con algunos representantes del modelo, caso de Pinilla de Toro $^{229}$ (Zamora), hallado en el contexto de una villa tardorromana, Sotopalacios ${ }^{230}$ (Burgos), Aroche ${ }^{231}$ (Huelva) y Torre de Palma ${ }^{232}$ (Monforte, Portugal), en el contexto de una villa romana tardía ${ }^{233}$. Por tanto se trata de un modelo tardío, último representante de la línea de bidiscoidales, pues tras de sí no deja heredero alguno. En la segunda mitad o finales del s. III d.C. parece abandonarse definitivamente el puñal militar ${ }^{234}$.

Los ejemplares limetanos de empuñadura de pezuña como son los casos procedentes de Buciumi $^{235}$ (Rumanía), Bar Hill1236 (GB), Copthall Court ${ }^{237}$ (Londres) Tuchyňa ${ }^{238}$ (Eslovaquia) y Künzing ${ }^{239}$ (Alemania) se asocian casi sin excepción a hojas destacadamente pistiliformes ${ }^{240}$. Por esta misma razón llama la atención que en el caso peninsular la asociación de este modelo de empuñadura sea tanto a hojas fuertemente pistiliformes (en armonía con la costumbre romana) como de base ensanchada ${ }^{241}$ (¿peculiaridad hispana?). Con reservas ${ }^{242}$ planteamos la

\footnotetext{
226 Bishop y Coulston, 1993.

227 Reuter, 1999.

${ }^{228}$ Traducción libre del original T shaped dagger handle. Bishop y Coulston, 1993: 112. Ver apartado «Evolución de

229 Varia, 1975: 461-463.

${ }^{230}$ Monteverde, 1957: 792-795; Cabré Herreros y Morán Cabré, 1991: 341-346; Fernández Ibáñez, 2005a: 211

${ }^{231}$ Museo de Huelva n. ${ }^{\circ}$ inv. 5085; Quesada, 2000: 100-101.

${ }^{232}$ Museu Arqueologico Nacional (Lisboa), n. ${ }^{\circ}$. inv. 2001.5.9. Este ejemplar presenta una interesante decoración a base de una fina lámina de oro recubriendo los arriaces, refrendo del carácter relativamente valioso o de prestigio del puñal

${ }^{233}$ Villa de Basilii o Villa de Torre de Palma, ocupada entre los siglos II y IV d.C., fecha coherente por tanto con la cronología propuesta para este modelo de empuñadura.

${ }^{234}$ Hecho tras el cual tal vez podamos distinguir la voluntad del emperador Diocleciano, gran reformador del panorama militar en todos sus aspectos -incluidos los armamentísticos- a caballo entre los ss. III y IV d.C. Los puñales posteriores, caso destacado de aquel denominado «tipo Simancas» serán de carácter más cinegético y de prestigio que militar.

${ }^{235}$ Chirila, Gudea, Lucacel y Pop, 1972; Feugère, 1993: 164.

236 Bishop y Coulston, 1995: 112 y fig. 73.

237 Bishop y Coulston, 1995: fig. 95, 1; Feugère, 2002: 165.

${ }^{238}$ Kreković, 1994: 211-225 y fig. 7, 14.

${ }^{239}$ Reuter, 1999: 121-124; Scott, 1985; Bishop \& Coulston, 1995: 112 y fig. 73.

240 Pistiliforme: semejante a la silueta de una hoja vegetal. Concretamente hace referencia a una forma alargada, terminada en punta y con un ensanchamiento central.

${ }^{241}$ Se asocian a hoja pistiliforme los ejemplares de Sotopalacios y Aroche, y a hoja de base ensanchada los casos de Torre de Palma y Pinilla del Toro.

${ }^{242}$ Habida cuenta el limitado número de ejemplares de pezuña peninsulares documentados.
} arriaces». y fig. 1.11 . militar. 
posibilidad de que nos hallemos ante una pervivencia local de la tradición celtibérica que se manifiesta en el mantenimiento de la hoja de base ensanchada ${ }^{243}$.

\section{PIEZAS ORGÁNICAS EMBUTIDAS}

La empuñadura del bidiscoidal originariamente presentaba pletinas orgánicas ocupando una posición intermedia entre la espiga y las cachas metálicas (figs. 4-7). Su existencia la conocemos más en negativo que por documentación física ${ }^{244}$.

\section{Hueso y cuerno}

El ejemplar hallado en Monte Cildá ${ }^{24}$ (Palencia) presenta dos piezas intermedias de hueso entre las dos cachas y el nervio de la hoja. En el ámbito limetano hallamos bastantes más ejemplos, caso de Londres ${ }^{246}$, Nida-Heddernheim ${ }^{247}$ (Frankfurt am Main), Vindonissa ${ }^{248}$ (Austria), Colchester $^{249}$ (GB), S'Gravenvoeren ${ }^{250}$ (Bélgica). La presencia de empuñaduras de hueso es una práctica común en el mundo romano, especialmente documentada en asociación a espadas. Es probable, a la luz de los ejemplares citados, que esta práctica fuera igualmente común al conjunto de las armas cortas, puñales incluidos.

\section{Madera}

Conocemos dos ejemplares que conservan un disco de madera que ocupa el espacio entre las cachas correspondiente al pomo: Capote ${ }^{251}$ (Badajoz) y El Raso ${ }^{252}$ (Candeleda, Ávila). En otros casos la pieza es de hierro ${ }^{253}$. Por último nos resta especular con otros materiales que hubieran servido de relleno entre las cachas. Una opción válida podría haber sido el cuero, pero su relación con el bidiscoidal no ha sido aún sancionada por ningún hallazgo y permanece en el universo de las hipótesis. En conclusión, afirmamos que la empuñadura del bidiscoidal exige la presencia de dos láminas de material orgánico como piezas indispensables en su factura, y

243 Un tipo de hoja totalmente ajena al mundo romano y en cambio muy típica del celtibérico.

244 El espacio de separación que presentan, sin excepción, la espiga de la hoja respecto a las cachas metálicas nos permite inferir la existencia pretérita en el lugar señalado de algún género de láminas de algún material orgánico, hoy perdido. De los ejemplares analizados, únicamente tres han conservado restos que nos permiten conocer la existencia y materia concreta de que estaban fabricados.

245 Alonso Gregorio, 2004: 35-45, figs. 2 y 3.

246 Cacha tallada en marfil. Museum of London PCD/ER 546; Feuguère, 1993: 165. En este caso parece que la empuñadura carecía e cachas metálicas, siendo éstas enteramente óseas, puesto que la pieza que describimos contiene decoración en su superficie, sugiriendo que ésta no era cubierta por ninguna otra pieza. Por su tipología deducimos una cronología del s. I d.C.

247 Que presenta una estructura enteriza de marfil. Datado en el s. I d.C. por Obmann, 1992: 37-40.

248 Vaina, a excepción de la espiga, enteramente de hueso. Se especula con que se trate de una amortización de empuñadura proveniente de una espada. Scott, 1985: fig. 1, 32.

249 Cuya tipología ubica la pieza en el s. I d.C. British Museum, inv. Colchester 1938; Manning, 1985 : Plate 73 V 9.

${ }^{250}$ Cuerno animal embutido. Su cronología es altoimperial, concretamente anterior al reinado de Tiberio [Según Vanden Berghe, 1996: 66, siguiendo las teorías de Scott, 1985] Koninklije musea voor Kunst en Geshiedenis (Bruselas), n. ${ }^{\circ}$ inv. B1309; Vanden Berghe, 1996: 66 y fig. 4.

251 Berrocal Rangel, 1993: 366.

${ }^{252}$ Que conserva un disco de madera carbonizada ocupando el espacio entre las cachas de la empuñadura; Fernández Gómez, 1986: fig. 89.32.

253 Puñal de La Bienvenida (Ciudad Real), aún por publicar. 
también afirmamos que al menos la madera y el hueso han sido documentados como materia prima para la fabricación de estas piezas.

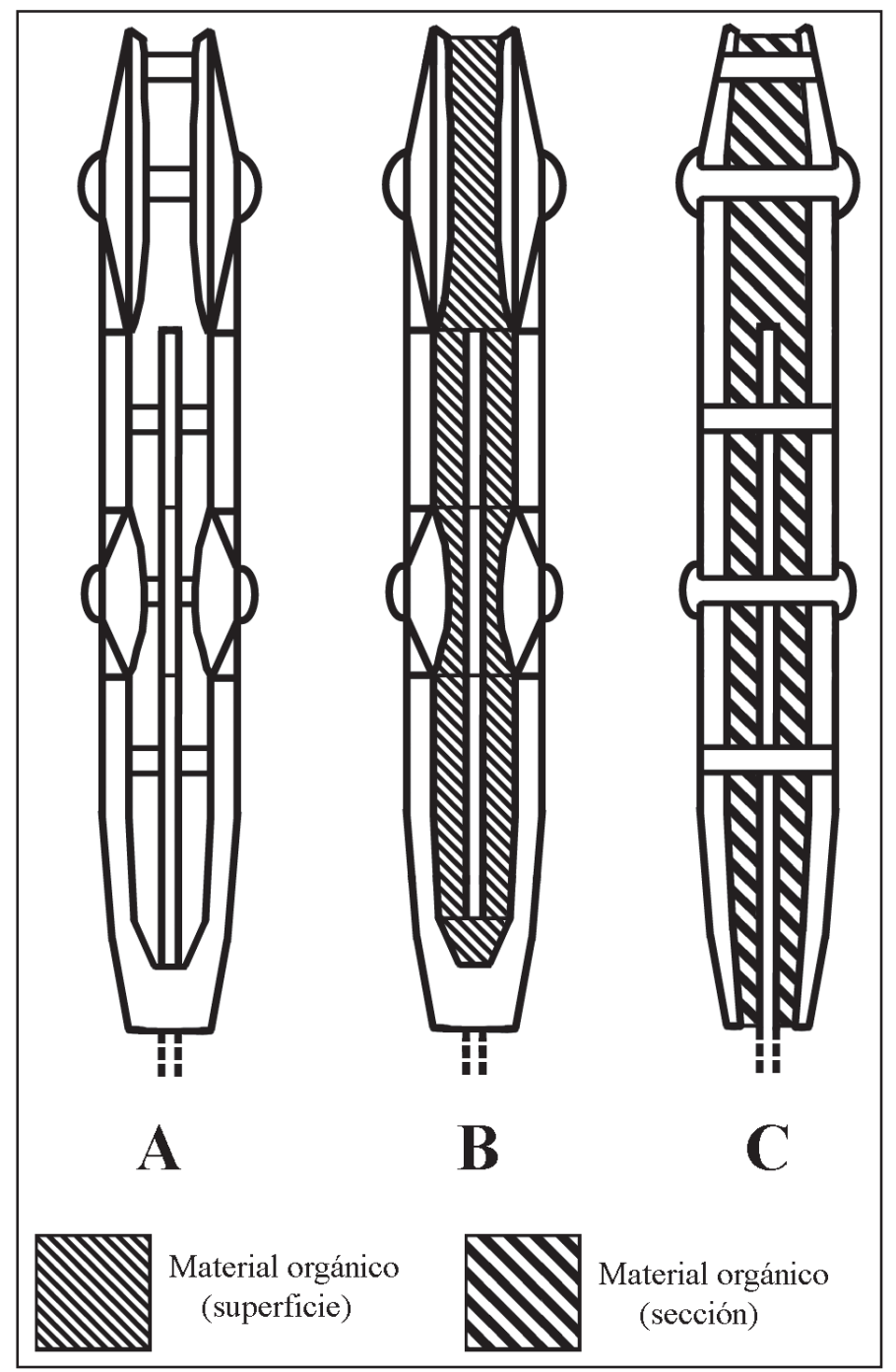

Figura 7. Perfil de la empuñadura de puñal bidiscoidal. Modelo de Aristas. A: Tal y como se conserva hoy día; B: aspecto que ofrecería en origen; C: sección.

\section{EVOLUCIÓN DE ARRIACES}

Se aprecian básicamente tres variantes de arriaz (fig. 8):
A. Arriaz recto y corto.
B. Arriaz Abatido (triangular).
C. Arriaz «en T invertida». 
El modelo «A» se define por presentar arriaces relativamente cortos y completamente rectos $^{254}$. Se relaciona a menudo con la empuñadura de discos concéntricos, puramente peninsular, y acostumbra a presentar decoración consistente en líneas rectas longitudinales al arriaz (y transversales al arma) ${ }^{255}$. Pertenecen a este subgrupo ejemplares de Cogotas ${ }^{256}$, Osma ${ }^{257}$, Numancia ${ }^{258}$, Turó del Vent ${ }^{259}$ y Quintanas de Gormaz ${ }^{260}$. Estos ejemplos nos remiten todos ellos a los siglos III y II a.C.

El segundo modelo («B») o «arriaz abatido» es con diferencia el mayoritario ${ }^{261}$. Se define por su perímetro grosso modo triangular pero sin vértices ${ }^{262}$. Inmensamente popular en el ámbito celtibérico y donde se documenta desde el siglo III a.C., cuenta también con representación en el ámbito limetano, casos de Titelberg ${ }^{263}$ (Luxemburgo), Velsen ${ }^{264}$ (Holanda), Maguncia-Weisenau $^{265}$ (Alemania), Maguncia ${ }^{266}$ (Alemania), Allèriot ${ }^{267}$ (Francia), Dangstetten $^{268}$ (Alemania), Hod Hill'269 (GB), Sisak ${ }^{270}$ (Croacia), Leeuwen ${ }^{271}$ (Holanda), Oberaden ${ }^{272}$ (Alemania), Risstissen ${ }^{273}$ (Alemania) y Mali Drinićc74 (Croacia). Estos ejemplares ofrecen, en conjunto, una cronología claramente altoimperial, en torno a fines I a.C. y a lo largo del I d.C. ${ }^{275}$. Por tanto, los primeros ejemplares romanos presentan el mismo arriaz que los celtibéricos, lo que constituye una prueba más de la filiación entre ambas armas.

El tercer subgrupo («C») lo componen los arriaces «en T invertida» ${ }^{276}$, definidos por presentar un perfil completamente recto, arriaces muy desarrollados ${ }^{277}$ y una altura de guarda ${ }^{278}$ muy reducida. Su asociación más común es con empuñaduras de pezuña lo que sugiere una cronología bastante tardía. Ejemplos peninsulares del tipo los hallamos en Herrera de Pisuer-

\footnotetext{
${ }^{254}$ Creando en conjunto un rectángulo transversal al arma.

${ }^{255}$ Aunque en un caso procedente de Uxama (Museo Arqueológico Nacional, n. ${ }^{\circ}$ inv. 1917/54 - 24.512) la decoración se compone por un disco sobreelevado en el eje del arriaz con círculos concéntricos en su interior.

256 Tumba 383. Quesada, 1997a: n. ${ }^{\circ}$ cat. 4654; Cabré Aguiló, 1932: lám. LXXV, L 75; Cabré Herreros y Morán Cabré, 1991: 341-346; Cabré Aguiló y Cabré Herreros, 1933: 37-47.

${ }^{257}$ El primero: MAN, n. ${ }^{\circ}$ inv. 1917-54-24.512. El segundo: tumba 10, Quesada 1997ª: n. ${ }^{\circ}$ cat. 4321; Schüle, 1969: taf. 57.8; García Merino, 2005: 177.

258 Tumba 60. Jimeno; De la Torre; Berzosa y Martínez, 2005: 106 y fig. 64, 5.

259 Rovira Hortalá, 1999: 20-22 y lám. 4; López Mullor; Rovira Port y Sanmartí Greco, 1983: 615; Quesada, 1997a: 294, n. ${ }^{\circ}$ cat. 6177

${ }^{260}$ Museo Celtibérico de Soria, n. ${ }^{\circ}$ inv. 1428; Schüle, 1969: taf. 36.2; Lorrio Alvarado, 1994b: 212-257 y fig. 2.

${ }^{261}$ Tanto entre el conjunto bidiscoidal, como entre los primeros pugiones romanos.

${ }^{262}$ Los vértices de este proto-triángulo son seccionados antes de converger en una punta, creando nuevos laterales. No se trata por tanto de un triángulo sino de un pentágono de lados y ángulos muy irregulares.

${ }^{263}$ Scott, 1985: 185, n. ${ }^{\circ} 1$; Helmig, 1990: 158-164, Abb 3, a; Thiel y Zanier, 1994: 70, n. ${ }^{\circ}$ 14; Vanden Berghe y Simkins, 2001/2: 75-84.

${ }^{264}$ Morel, 1989: 93-101; Morel y Bosman, 1989: 177-191; Bishop y Coulston, 1993: 78 y fig. 42; Bosman, 1995.

${ }^{265}$ Bishop y Coulston, 1993: 75 y fig. 39, 4; Thiel y Zanier, 1994: 61, n. ${ }^{\circ} 70$ y Abb 2, 2.

${ }^{266}$ Lindenschmidt, 1900: taf. 52.3.

267 Bonnamour y Fernoux, 1969: 178-185.

${ }^{268}$ El primero Helmig, 1990: 160, Abb 3, b; el segundo Bishop y Coulston, 1993: fig. 39, 2.

${ }^{269}$ Manning, 1985: Plate 73, V7, V8 y Plate 74, V12.

270 VVAA, 2003: 677 y Abb. 19.

271 Scott, 1985: fig. 1, 53.

272 Bishop; Coulston, 1993: fig. 39, 1; Helmig, 1990: Abb 3, c; Scott, 1985: 185 y n. ${ }^{\circ}$ cat. 3.

273 Bishop; Coulston, 1993: fig. 39, 3.

274 VVAA, 1993a: 733 y Abb. 55.

275 Se asocian, además, a empuñaduras de semidisco, lo que refuerza la validez de la datación.

276 Traducción libre de la expresión alglosajona T shaped handle que leemos en obras como Scott, 1985; Bishop y Coulston, 1993, y otros.

277 En general más desarrollados longitudinalmente que el resto de modelos de arriaz.

278 Altura de Guarda: distancia medida transversalmente al arriaz (longitudinalmente al arma en su conjunto) v. g., entre la base de la hoja y el arranque de la empuñadura. Suele ser un espacio de apenas uno o dos centímetros.
} 
ga $^{279}$ (Palencia) Numancia ${ }^{280}$ (Soria), Palencia ${ }^{281}$ (Palencia), Pinilla de Toro 282 (Zamora), Sta. Cruz de Camazos ${ }^{283}$ (Valladolid), Sotopalacios ${ }^{284}$ (Burgos) y Torre de palma ${ }^{285}$ (Monforte, Portugal). Prácticamente todos asumen una cronología tardía, correspondiente a los ss. II y

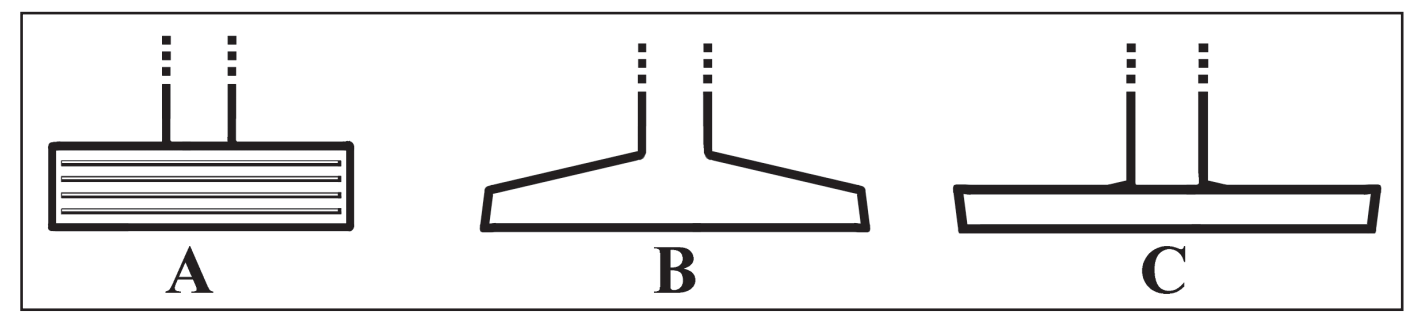

Figura 8. Tipos de arriaz. A: primitivo; B: «arriaz abatido»; C: en «T invertida».

III d.C. ${ }^{286}$. Los casos limitaneos son también numerosos: Buciumi ${ }^{287}$ (Rumanía), Bar Hill288 (GB), Londres 289 (GB), Copthall Court ${ }^{290}$ (GB), Tuchyňa ${ }^{291}$ (Eslovaquia), Künzing ${ }^{292}$ (Alemania), Leiden ${ }^{293}$ (Holanda), Maguncia ${ }^{294}$ (Alemania), todos ellos tardíos, correspondientes como muy pronto a fines del I d.C., más comúnmente a los ss. II y III d.C. ${ }^{295}$. A medio camino entre el modelo B y el C contamos con algunos ejemplos, entre ellos el de Lorenzberg ${ }^{296}$, Alemania (10

279 Pérez González, 1996: 91-102, fig. 3; Fernández Ibáñez, 2005b: fig. 1.1 y 7.

${ }^{280}$ Un primer ejemplar: Schüle, 1969: taf. 166, 5. Un segundo ejemplar: Schüle, 1969: taf. $166,7$.

281 Quesada, 1997a, n. ${ }^{\circ}$ 3881; Schüle, 1969: taf. 165.1; Fernández Ibáñez, 2005: 209 y fig. 8.

282 VARIA, 1975: 461-463.

283 Mañanes; Gutierrez y Agúndez, 2002; Fernández Ibáñez, 2005a: 209 y fig. 9, C.

284 Monteverde, 1957: 792-795; Cabré Herreros y Morán Cabré, 1991: 341-346; Fernández Ibáñez, 2005 : 211 y fig. 1.11.

285 Museu Arqueologico Nacional (Portugal) n. ${ }^{\circ}$ inv. 2001.5.9.

286 La duda recae sobre el ejemplar de Herrera de Pisuerga, que podría pertenecer tanto a la primera como a la segunda ocupación del lugar, lo que significa la diferencia entre pertenecer a un periodo entre el 15-20 a.C. al 39 d.C. o bien al 50-107 d.C. La primera ocupación se corresponde con la Legio IIII Mac. Mientras que la segunda con el Ala Parthorum; Pérez González, 1996: 91-102. En cualquier caso anterior al resto de ejemplares, por lo que podría tratarse de uno de los primeros modelos que presenten este tipo de arriaz.

287 Chirila, Gudea, Lucacel y Pop 1972; Feugère, 1993: 164.

288 Reuter, 1999: 121 y Abb 2.

289 British Museum n. $^{\circ}$ inv. 1934.12-10.70; Manning, 1985: Plate 74 V14.

290 Museum of London n. ${ }^{\circ}$ inv. 59.94/1.

291 Kreković, 1994: 211-225 y fig. 7, 14.

292 Bishop y Coulston, 1993: fig. 95, 2 y 3.

293 Sumner, 1997: 106.

294 Baatz, 1962: taf. 19, 9.

295 El ejemplar de Bar Hill probablemente pertenezca al s. II d.C. [ha de ser posterior al año 85 d. C; Bishop y Coulston, 1993], el de Buciumi al II d.C. [Según Feugère, 2002: 166], los casos de Künzing probablemente al III d.C., así como el de Tuchyňa [En atención a las similitudes de este puñal con aquellos hallados en Künzing, se ha datado la pieza en el siglo III d.C. (según Kreković, 1994: 211-25). Dado que recientemente (Reuter, 1999) se ha propuesto adelantar la cronología del modelo tipo Künzing hasta principios. del II d.C., es posible que el ejemplar de Tuchyňa pertenezca tanto al II como al III d.C.].

296 Scott, 1985: 193, n. ${ }^{\text { }}$ 48. p. 208 fig. 1. 
a.C.-50 d.C. ${ }^{297}$ ) o el de Utrecht ${ }^{298}$, Holanda (47 d.C. -260 d.C. ${ }^{299}$ ). Por tanto la transición entre el modelo «B» y el «C» acontece en el I d.C., probablemente a lo largo de su primera mitad.

Concluimos que la tendencia de los arriaces romanos era a aplanarse progresivamente a lo largo del tiempo, transformación que se evidencia en la transición entre el modelo «B», originariamente celtibérico pero adoptado por Roma, y el «C», puramente romano ya.

Condensamos los datos crono-tipológicos relativos a los arriaces en esta tabla ${ }^{300}$ :

\begin{tabular}{|c|c|c|c|c|c|c|}
\hline & s. III a.C. & s. II a.C. & s. I a.C. & s. I d.C. & s. II d.C. & s. III d.C. \\
\hline Tipo A & & & & & & \\
\hline Tipo B & & & & & & \\
\hline Tipo C & & & & & & \\
\hline
\end{tabular}

REMACHES (fig. 9)

Con el fin de mantener unidas todas las piezas de la empuñadura, los artesanos se sirvieron de clavos con los extremos remachados ${ }^{301}$. Éstos atraviesan transversalmente la estructura por distintos puntos, afianzando las distintas piezas entre sí (figs. 6 y 7). En ocasiones estos remaches se manifiestan al exterior, en forma de cabeza de clavo, más comúnmente permanecen ocultos.

\section{Remaches visibles ${ }^{302}$}

Hemos podido reconocer hasta catorce combinaciones distintas de remaches visibles en virtud de dos variables: su número y disposición en la empuñadura (fig. 9). La combinación visible destacadamente más común $(2 \mathrm{~A})$ se define por contar con dos remaches, dispuestos exactamente en el centro tanto del nudo central como del pomo. Esta variante representa el $40.8 \%$ del total analizado ${ }^{303}$, con diferencia el grupo mayoritario del conjunto, dado que el segundo grupo más numeroso (6A) corresponde únicamente al $12 \%$ del total ${ }^{304}$. Colegimos que la presencia de más de un remache ubicado en el pomo de la empuñadura es un rasgo inequívocamente romano-imperial, no hallándose ejemplo alguno cuya cronología no sea posterior al cambio de era. Los ejemplares celtibéricos, en cambio, muestran sin excepción uno o ningún

297 Scott, 1985: 186, n. ${ }^{\circ} 5$.

298 Thiel y Zanier, 1994: 59-81 y Abb. 2-1.

299 El campamento de Traiectum (Utrech, Holanda) fue fundado a mediados del s. I d.C. (posiblemente en el 47 d.C.) por el gobernador de Germania Inferior, Cneo Domicio Corbulón. Este campamento fue destruido durante la revuelta bátava (69-70 d.C.). Entre 88/89 d.C. y 260 d.C. el lugar fue ocupado por la Cohors II Hispanorum Peditata. En 210 d.C. se reforzaron las defensas con muros de ladrillo de un metro de espesor. Se siguió utilizando hasta al menos el siglo IV d.C.

${ }^{300}$ Hemos excluido de ella la información referente al s. IV a.C., pues no tenemos seguridad sobre el tipo de arriaces pertenecientes a esa centuria.

301 Que hemos venido a denominar genéricamente como «remaches».

302 Sólo remaches visibles desde el exterior, no se corresponde por tanto con el total de remaches.

303 El modelo de dispersión de remaches visibles «2A» se manifiesta en 20 de un total de 49 casos analizados.

304 Correspondiente a 6 de un total de 49 casos analizados. 
remache en el pomo, en ningún caso más. Son por tanto disposiciones de remaches visibles típicamente romano-imperiales ${ }^{305}$ las denominadas 2C, 3C, 4B (fig. 9); y el resto inequívocamente indígenas.

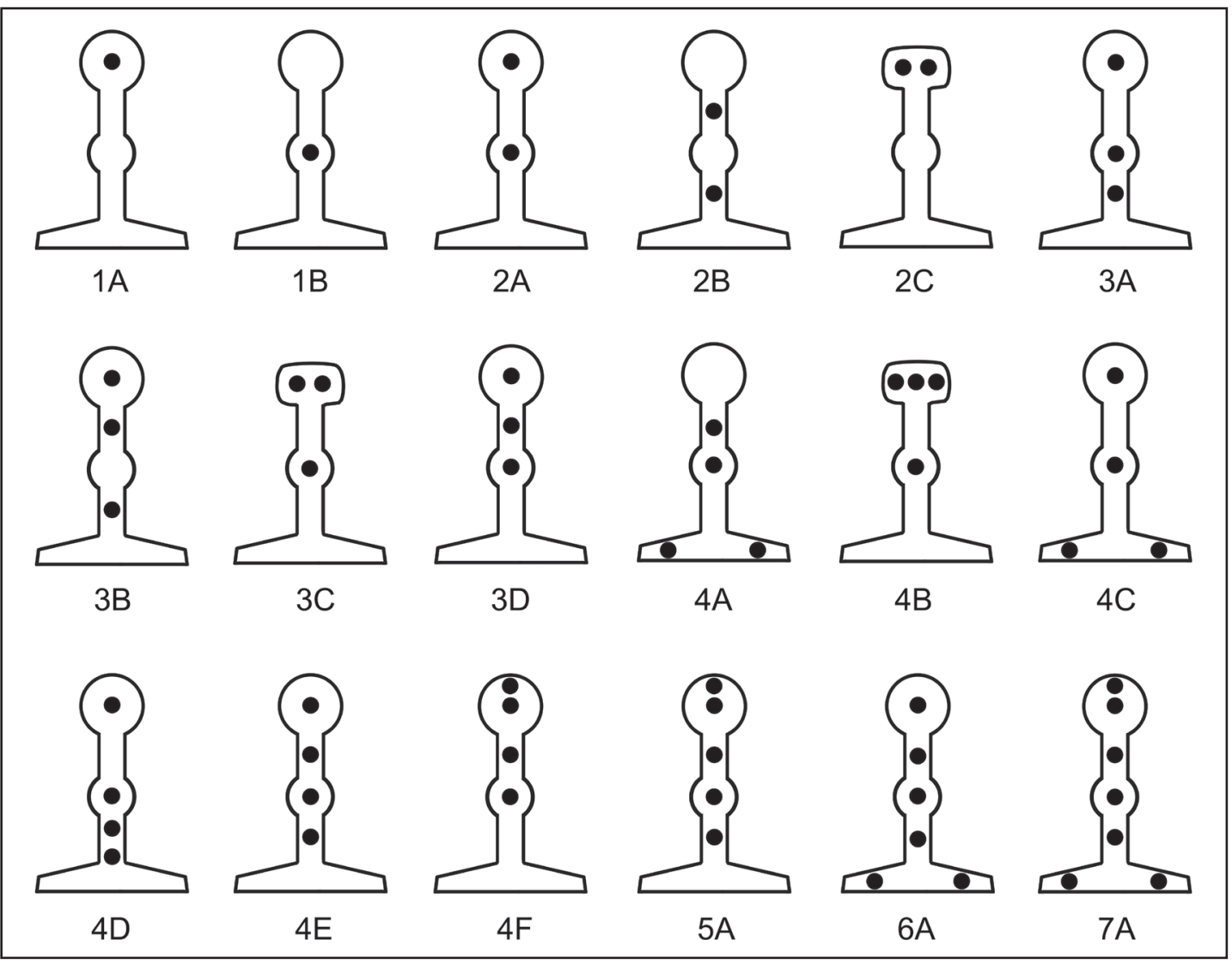

Figura 9. Patrones de distribución de remaches a lo largo de la empuñadura.

\section{Total de remaches ${ }^{306}$}

Gran número de remaches, en torno al 50\%, fueron deliberadamente ocultados mediante la limadura de sus cabezas, haciéndolas solidarias con la superficie de la empuñadura ${ }^{307}$. Lamentablemente, sólo hemos podido comprobar el número total de remaches en diecinueve ejemplares cuya empuñadura no presentaba pérdidas de volumen y de la que, o bien en la publicación, o bien en análisis físico de la pieza, fuimos capaces de reconocer el interior de la

305 Y propias de finales del I a.C. en adelante

306 Cifra que incluye visibles y no visibles desde el exterior.

307 El éxito de esta labor de disimulo es tal que en gran número de ocasiones nos es muy difícil descubrir los remaches ocultos. Lamentablemente esta lacra se ha manifestado también en numerosas publicaciones, cuyos dibujos y representaciones tampoco incluyen los remaches ocultos. 
misma $^{308}$. Se observa que, por lo general, el número total de remaches es superior al número visible, existiendo casos de incluso siete remaches, de los que apenas alguno es visible desde el exterior. En cualquier caso en el ámbito peninsular las disposiciones más comunes de remaches reales (combinando visibles y ocultos) son las denominadas 4C, 5A y 6A (fig. 9).

\section{DECORACIÓN EN LAS EMPUÑADURAS}

Gran número de los puñales de tipo bidiscoidal ${ }^{309}$ presentan diversos dibujos y motivos de carácter puramente ornamental, sin función práctica. En cuanto a la técnica empleada distinguimos dos grupos principales:

- Motivos incisos ${ }^{310}$.

— Motivos incisos y damasquinados ${ }^{311}$.

En ocasiones la decoración se aplica no directamente sobre las cachas de la empuñadura sino sobre una fina lámina metálica - fácilmente repujable — que a su vez se afianza sobre la empuñadura por medio de remaches ${ }^{312}$.

\section{Motivos decorativos}

Hemos podido reconocer una breve lista de motivos decorativos que encontramos en la superficie de las empuñaduras. A continuación las definimos:

A. Círculos concéntricos: se define por dos o más dibujos circulares de distinto tamaño, dispuestos en torno al mismo eje. Este tipo de decoración se concentra siempre bien en el pomo, bien en el nudo central, salvo en un caso excepcional donde se dispone en el centro del arriaz ${ }^{313}$. Hallamos ejemplares de este modelo en yacimientos como Arcóbriga (Zaragoza), Carratiermes ${ }^{314}$ (Soria), $\operatorname{Cogotas}^{315}$ (Ávila) y Numancia ${ }^{316}$ (Soria).

${ }^{308}$ De estos diecinueve ejemplares susceptibles de análisis interno, tres de ellos (procedentes de Carratiermes, Ucero y en ejemplar descontextualizado) presentaban únicamente dos remaches, otros tres presentaban tres remaches (Cuesta del Burro, Capote y Termes), siete ejemplares se mantenían unidos por cuatro remaches (Arcobriga, Osma, Raso, dos ejemplares de Numancia y otros dos descontextualizados), dos casos de cinco (uno de Osma y otro descontextualizado), cuatro de seis (Cerro de las Balas, Romazal y dos de Numancia) y hasta un caso de siete (Osma). La media que hace el conjunto es por tanto de 4,15 remaches por empuñadura.

$309 \mathrm{Y}$ en mayor número sus vainas, como analizaremos en el apartado correspondiente.

310 Concavidades lineales en la superficie del metal, ejecutadas mediante incisión directa sobre el material.

${ }^{311}$ Damasquinado: técnica consistente en la realización de figuras y dibujos mediante la introducción, ataujía o embutido, de finos hilos de oro y plata sobre una superficie de acero o hierro. Para ello se produce una incisión en dicha superficie, dentro de la cual se introduce el material precioso (oro o plata).

312 Como demuestran algunos ejemplares procedentes de Numancia, Soria (Ref. Numancia 14), Monte Cildá, Palencia (Alonso Gregorio, 2004: 35-45, figs. 2 y 3), Romazal, Cáceres (Tumba 46; n. ${ }^{\circ}$ inv. I-46; Quesada, 1997a: n. ${ }^{\circ}$ cat. 5391; Hernández Hernández y Galán Domingo, 1996: fig. 54.) y Castellares de Herrera, Zaragoza (Quesada, 1997a: n. ${ }^{\circ}$ cat. 3062; Burillo Mozota y Sus Giménez, 1988: foto en pág. 67).

${ }^{313}$ MAN 1917/54/24.512; La excepcionalidad decorativa de esta pieza demuestra el alto grado de libertad del artesano que la fabricó, y por ende hasta qué punto por esta causa el grupo de bidiscoidales es heterogéneo.

314 Tumba 440. Argente Oliver, 2001: CD adjunto.

315 Cabré Aguiló, 1932: lám. LXXV, L 75; Cabré Herreros y Morán Cabré, 1991: 341-346; Cabré Aguiló y Cabré Herreros, 1933: 37-47.

316 Tumbas 60, 123 y 80. Jimeno; de la Torre; Berzosa; Martínez, 2005: 106 y fig. 64, 5. Tumba 80. Museo Numantino 95/5/1119/c-80. 
B. Líneas radiales: dispuestas en torno a un eje imaginario, se distribuyen con un ángulo o separación idéntica entre los radios. Únicamente presente en el pomo del arma.

C. Líneas perimetrales: se definen por seguir, unos milímetros detrás del borde, la silueta del perímetro de la pieza sobre la que descansan. El resultado es que resaltan y hacen más visible la silueta de la pieza a la que decoran.

D. Líneas transversales: cualquier línea decorativa dispuesta en sentido transversal a la longitud del arma. Son muy comunes en el espacio interior de la empuñadura y en el arriaz.

E. Líneas longitudinales: son aquellas que, inversamente a las anteriormente citadas, se disponen en sentido longitudinal al conjunto del arma. Son mucho más excepcionales, habiéndose documentado sólo dos casos.

F. Celosía y zigzagueo: se trata de uno de los más bellos motivos, así como interesante por su valor histórico (vid infra). Su factura es incisa y a menudo damasquinada en plata. Se define por presentar una incisión en forma lineal pero zigzagueante ${ }^{317}$. Cuando dos motivos zigzagueantes inversos se superponen aparece lo que denominamos «celosía», o sucesión de rombos ${ }^{318}$. Ambos motivos, zig-zag y celosía, son en esencia un mismo motivo bien en singular o repetido. Pueden aparecer en cualquiera de las distintas partes de la empuñadura, aunque con especial recurrencia en la longitud interior de la misma.

G. Gotas o Punteado: referimos aquí la decoración a base de pequeñas incisiones o excisiones $^{319}$ aparecidas en la superficie de la empuñadura. Suelen presentarse en grupos, organizadas linealmente o circularmente, y preferentemente a lo largo de la longitud interna de la empuñadura, o en el frontal del pomo.

H. Línea ondulante: hemos encontrado un único caso ${ }^{320}$ que presenta este tipo de decoración, demostrando una vez más la libertad de los artesanos para «individualizar» cada arma.

I. Chapa de oro: al igual que en el caso anterior, sólo contamos con un ejemplar que responda a esta clasificación ${ }^{321}$. En este caso, el metal áureo se localiza decorando el arriaz. La excepcionalidad del caso podría sugerir que se trate de un añadido posterior a la factura del arma, ejecutado por el dueño, no por el artesano.

J. Chapa de Plata: el único caso conocido presenta chapa de plata en el perímetro del pomo $^{322}$. Contamos con un posible segundo ejemplar ${ }^{323}$ que posiblemente también presente una lámina de metal plateado en el arriaz, pero no lo podemos precisar.

\footnotetext{
317 Como se observa en el puñal de Las Cogotas (Ávila), tumba 383. Quesada 1997a: n. ${ }^{\circ}$ cat. 4654; Cabré Aguiló, 1932: lám. LXXV, L 75. O también en la pieza descontextualizada depositada en el Römisch-Germanischen Zentralmuseum, Mainz con n. ${ }^{\circ}$ inv. O.40559 y O.40504 ; Egg, 1986: 906.

318 Como ocurre en un caso descontextualizado (Cabré Herreros y Morán Cabré, 1991: fig. 2, C.) y también en la pieza proveniente de la tumba 1386 de La Osera (Ávila). Quesada, 1997a: n. ${ }^{\circ}$ cat. 5997; Cabré Herreros y Morán Cabré, 1991: fig. 28.

319 Excisión: abultamiento o protuberancia de una superficie. A menudo resulta difícil distinguir entre incisiones y excisiones debido a las limitaciones del dibujo en que se publican.

${ }^{320}$ Proveniente de Termes, Soria. Schüle, 1969: fig. 46,5. (Este autor la denomina Termancia, vocablo moderno erróneo creado por homofonía con Numancia. El nombre correcto es Termes o en último extremo Termessos, siendo esta última la denominación que hace Apiano de la misma).

${ }^{321}$ Puñal de Torre de Palma, Villa de Basilii, tardorromana; Museu Arqueologico Nacional (Portugal), n. ${ }^{\circ}$ inv. 2001.5.9

322 Ejemplar hallado en Monte Cildá; Alonso Gregorio, 2004: 35-45, figs. 2 y 3.

${ }^{323}$ Ejemplar hallado en Castellares de Herrera. Burillo Mozota y Sus Giménez, 1988: foto en pág. 67.
} 
K. Remaches: si bien su función principal es práctica, también se observa que en gran número de ocasiones algunas cabezas de remache son conservadas con fin decorativo ${ }^{324}$.

En la presente tabla cruzamos las variables de tipo de decoración con el lugar que ocupan en la empuñadura. Cada aspa representa un ejemplar en el que concurren ambas variables:

\begin{tabular}{|c|c|c|c|c|c|}
\hline & $\begin{array}{l}\text { Frontal del } \\
\text { Pomo }\end{array}$ & $\begin{array}{l}\text { Perímetro } \\
\text { del Pomo* }\end{array}$ & $\begin{array}{c}\text { Empuñadura } \\
\text { (Longitud interior) }\end{array}$ & $\begin{array}{l}\text { Nudo } \\
\text { central }\end{array}$ & Arriaz \\
\hline $\begin{array}{l}\text { Círculos } \\
\text { concéntricos }\end{array}$ & $\mathrm{xxxxxxxx}$ & & & $\operatorname{xxxxxxx}$ & $\mathrm{x}$ \\
\hline Líneas radiales & $\mathrm{xx}$ & & & $\mathrm{x}$ & \\
\hline Líneas perimetrales & & & & & $\mathrm{xxx}$ \\
\hline Líneas transversales & & & $\operatorname{xxxxxxx}$ & & $\operatorname{xxxxxx}$ \\
\hline $\begin{array}{c}\text { Líneas } \\
\text { longitudinales } \\
\end{array}$ & & & $\mathrm{x}$ & & $\mathrm{x}$ \\
\hline Celosía y/o Zig-Zag & $\mathrm{x}$ & $\mathrm{xx}$ & $\mathrm{xxxx}$ & $\mathrm{x}$ & $\mathrm{x}$ \\
\hline Gotas o Punteado & $\mathrm{xx}$ & & $\mathrm{xxx}$ & & $\mathrm{x}$ \\
\hline Línea ondulante & & & & & $\mathrm{x}$ \\
\hline Chapa de oro & & & & & $\mathrm{x}$ \\
\hline Chapa de plata & & $\mathrm{x}$ & & & \\
\hline
\end{tabular}

* Por perímetro del pomo entendemos el borde exterior del mismo, generalmente de materia orgánica, pero ocasionalmente abrazado por una lámina metálica susceptible de albergar motivos decorativos.

** Longitud interior de la empuñadura: se corresponde con la parte de la empuñadura destinada estrictamente a la función prensil, (v.g. exceptuando por tanto pomo, nudo central y arriaz).

Del análisis conjunto se colige que las decoraciones más recurrentes son aquella de círculos concéntricos y de líneas transversales. Les sigue la decoración en celosías o zig-zag. También se observa cómo gran parte de la decoración se concentra en los arriaces, siendo además ésta extremadamente heterogénea, pues cubre prácticamente todas las modalidades decorativas. A menudo hallamos empuñaduras que únicamente presentan una de las cachas decoradas, demostrando que la forma de pender el arma del costado permitía que sólo fuera visible una de las caras de la empuñadura, quedando la otra enfrentada al cuerpo del usuario, ergo oculta.

Destacamos un motivo que es compartido tanto por las armas peninsulares como por las romanas: el damasquinado «en celosía» o en zig-zag. Ejemplares peninsulares del mismo se encuentran en ejemplares tan tempranos como Las $\operatorname{Cogotas}^{325}$ y La Osera ${ }^{326}$ (en torno a fines del s. IV-siglo III a.C.) así como dos casos descontextualizados ${ }^{327}$ (el uno circa 100 a.C., el otro de los ss. II-III d.C.) delatando la dilatada vida del motivo ${ }^{328}$. Pero lo que llama poderosamen-

324 Para más información sobre el valor decorativo de los remaches, ver apartado sobre «Remaches».

${ }^{325}$ Las Cogotas (Ávila), tumba 383. Quesada 1997a: n. ${ }^{\circ}$ cat. 4654; Cabré Aguiló, 1932: lám. LXXV, L 75.

326 Tumba 1386 de La Osera (Ávila). Quesada, 1997a: n. ${ }^{\circ}$ cat. 5997; Cabré Herreros y Morán Cabré, 1991: fig. 28.

327 A) Cabré Herreros y Morán Cabré, 1991: fig. 2, C; B) Römisch-Germanischen Zentralmuseum, Mainz, n. ${ }^{\circ}$ inv. O.40559 y O.40504; Egg, 1986: 906.

${ }^{328}$ Este mismo modelo decorativo se aprecia en multitud de objetos distintos a los puñales, caso de los broches de cinturón celtibéricos, vainas de espada laténica, pinzas de bronce, etc., delatando el protagonismo que llegó a tener en la protohistoria peninsular. 
te la atención de este motivo decorativo es la existencia de puñales romanos limitaneos que presentan idéntico motivo. El motivo «de celosía» se verifica en ejemplares indiscutiblemente romanos provenientes de Alleriot ${ }^{329}$ (Francia), Mali Drinić ${ }^{330}$ (Croacia), Maguncia ${ }^{331}$ (Alemania) y Utrecht ${ }^{332}$ (Holanda). Insistimos, no se trata sólo de una coincidencia en la técnica elegida (damasquinado), sino también en el motivo decorativo concreto y en el lugar exacto de la empuñadura donde se dispone. Es evidente por tanto que no nos encontramos ante una coincidencia, sino ante una influencia, que por su mayor antigüedad, ha de proceder del mundo celtibérico en dirección al romano.

Tal vez debamos interpretar este tipo de piezas, con damasquinados de plata, como armas de especial valor de representación y prestigio, lo que nos remite a conceptos como el denominado parazonium, propio de los tribunos y altos militares, así como al gran valor que podía llegar a tener un puñal o su vaina, extremo que evidencia el papiro de L. Caecilius Secundus ${ }^{333}$.

\section{Caso Oberaden - La Osera (fig. 10)}

Contamos con un caso paradigmático que expone como ninguno la influencia decorativa indígena sobre la romana. En este caso la coincidencia afecta a dos ejemplares concretos, el uno peninsular, el otro romano. Nos referimos a los puñales de la tumba 1387 de La Osera ${ }^{334}$ (Ávila) y el ya mencionado de Oberaden ${ }^{335}$ (Alemania).

Ambos puñales coinciden en la forma pistiliforme de sus hojas, empuñaduras de aristas y la misma forma de sujeción del enmangue mediante remaches visibles que coinciden con el centro de los nudos del mismo. Pero el elemento común más sorprendente es la prácticamente idéntica decoración geométrica que comparten sus empuñaduras. Se trata de una incisión lineal en forma de círculos concéntricos ocupando toda la superficie del pomo. Sobre esta decoración se superpone un motivo radial en forma de 6 haces de líneas que surcan el pomo desde su centro hasta su perímetro. El resultado final es un dibujo de ritmo giratorio, protoesvastiforme. El parecido llega hasta detalles nimios como la coincidencia entre el número de líneas que forman cada una de las seis haces radiales (tres en ambos casos).

El resultado es que nos encontramos ante dos puñales virtualmente idénticos, que podrían haberse adjudicado al mismo horizonte cultural sin mayores consideraciones. No obstante, a ambos les separa una inmensa distancia cronológica. En el ejemplo de la Osera nos encontramos con un arma cuya cronología ha sido precisada en torno al siglo III a.C. ${ }^{336}$, mientras que en el caso de Oberaden se baraja una datación altoimperial, correspondiente al lapso entre los años 11 y 7 a.C. ${ }^{337}$. Por tanto distan cerca de tres centurias si bien formalmente son prácticamente idénticos.

\footnotetext{
329 Bonnamour y Fernoux, 1969: 178-185.

330 Jahrbuch des Römisch-Germanischen Zentralmuseum, Mainz (1992) n. ${ }^{\circ}$ 43.2, pp. 733-5 y Abb 55. La pieza se encuentra depositada en el Muzej Cetinske Krajine Sinj, Croacia.

${ }^{331}$ Baatz, 1962: taf. 19, 9 .

${ }^{332}$ N. ${ }^{\circ} 5$ según la clasificación de Thiel y Zanier, 1994: 61. Publicado originariamente en C. A. Kalee (véase nota 175): 159, lám. 104-106.

333 Tanto para la discusión sobre el parazonio como sobre el papiro, ver apartado «Documentación literaria».

334 Tumba 1386 de La Osera (Ávila). Quesada, 1997a: n. ${ }^{\circ}$ cat. 5997; Cabré Herreros y Morán Cabré, 1991: fig. 28.

${ }^{335}$ Scott, 1985: 185, n. ${ }^{\circ}$ 3; Helmig, 1990: Abb. 3, c; Bishop y Coulston, 1993: 39.1.

336 En atención a la zona de la Necrópolis en que fue hallada, concretamente la «zona V».

337 El campamento militar de Oberaden (Alemania) fue ocupado únicamente entre las fechas del 11 y 7 a.C., luego por fuerza esa ha de ser la cronología ante quem de esta pieza.
} 


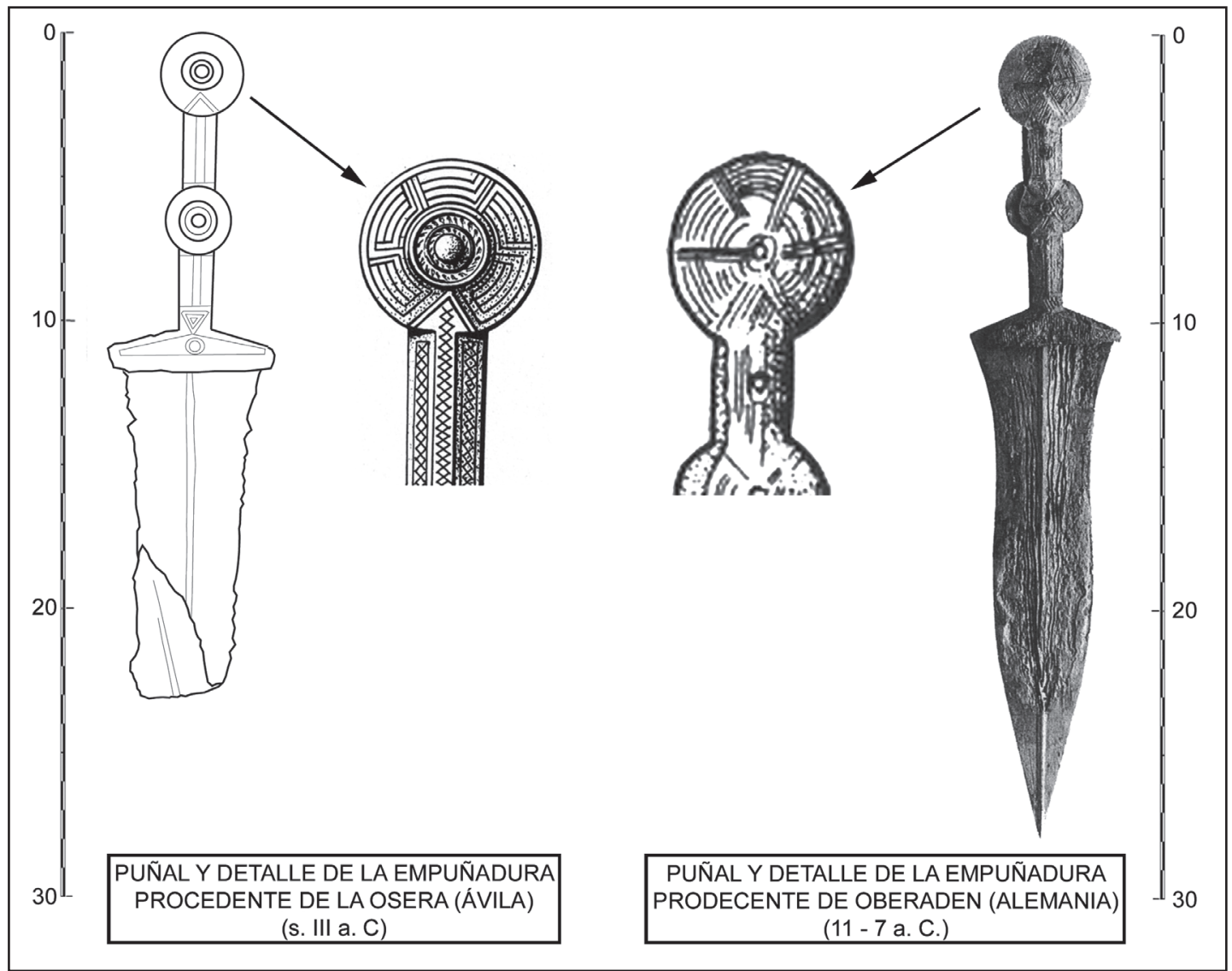

Figura 10. Paralelismos decorativos: casos de La Osera (Ávila) y Oberaden (Alemania).

\section{Evolución temporal decorativa}

Se aprecia que la decoración, tanto de vainas como de empuñaduras, presenta dos picos de popularidad, el primero a comienzos de la existencia del bidiscoidal, y el segundo durante el s. I d.C., en manos romanas. En las piezas peninsulares tardías, en torno a fines del II a.C., principios del I a.C. la decoración se hace más discreta, consistente en remaches y formas geométricas, pero con el Alto Imperio regresan los motivos más vistosos y llamativos, particularmente los damasquinados. De ello quizá se pueda deducir, aunque con reservas, que en un primer momento el bidiscoidal era un arma con mayor valor simbólico que práctico, situación que se invierte en el s. II a.C. a causa de las necesidades bélicas y la gran difusión del objeto ${ }^{338}$. Este hecho parece corroborarse por la aparente concentración de poder existente en los siglos IV y III a.C. en contraste con la —más homogénea en cuanto a jerarquía social y económicasociedad de los siglos II y I a.C.

${ }^{338}$ Una vez que el puñal se fabrica en masa, se hace accesible a las masas, perdiendo con ello su valor simbólico de prestigio. 
LÍNEA EVOLUTIVA DE LAS EMPUÑadURAS (figs. 11-13)

Concluimos que la línea evolutiva, tanto del bidiscoidal celtibérico como del pugio romano, si bien con algunas breves lagunas, es perfectamente rastreable y documentable. Simplificando enormemente el proceso, y reduciéndolo a sus hitos principales (fig. 12), podríamos concluir que el primitivo modelo celtibérico de Pletina Plana (ss. IV-II a.C.), con todas sus variantes ${ }^{339}$,

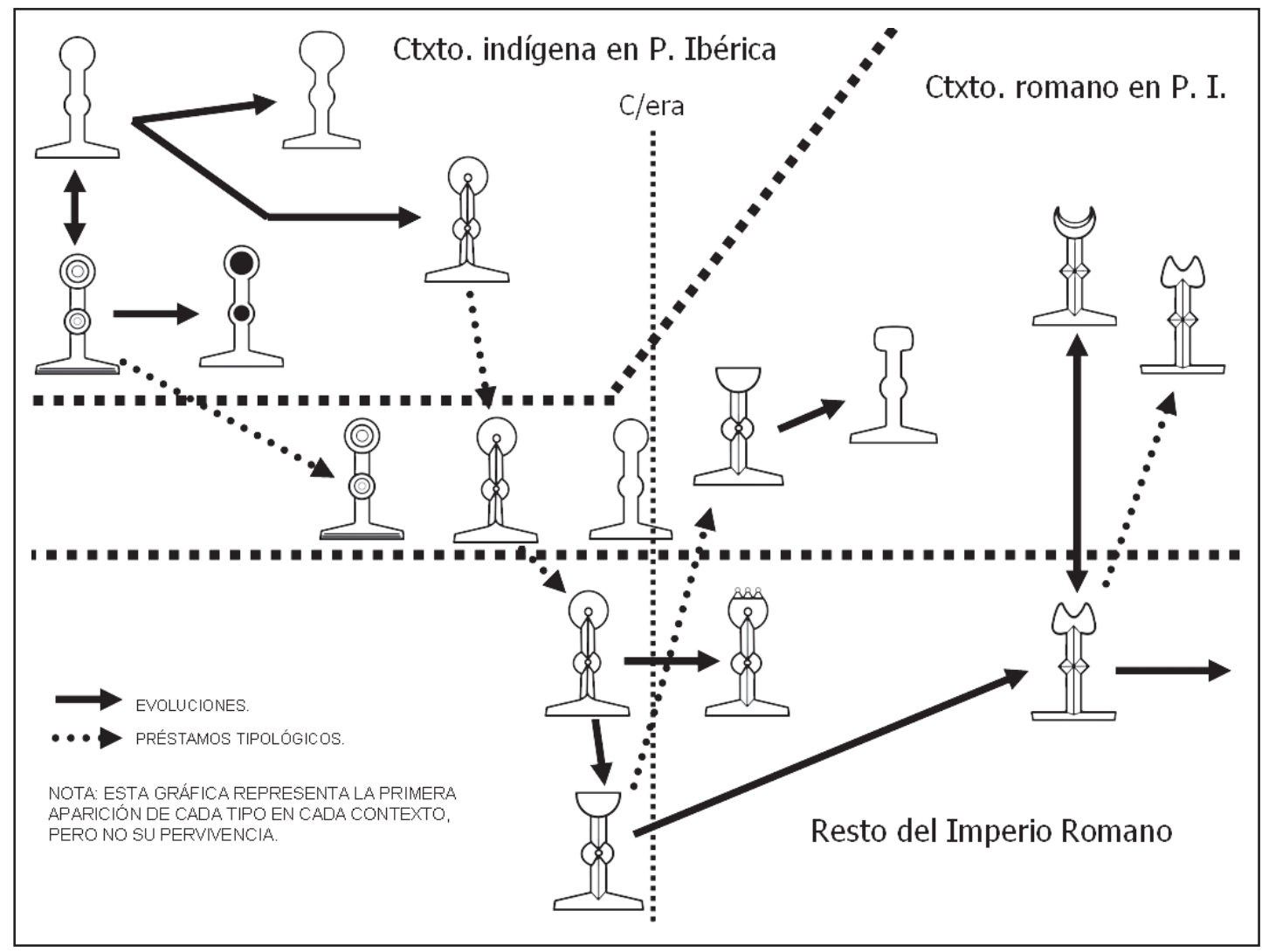

Figura 11. Esquema evolutivo general de las empuñaduras del puñal bidiscoidal celtibérico y pugio romano mostrando las relaciones, influencias y variantes de los distintos modelos.

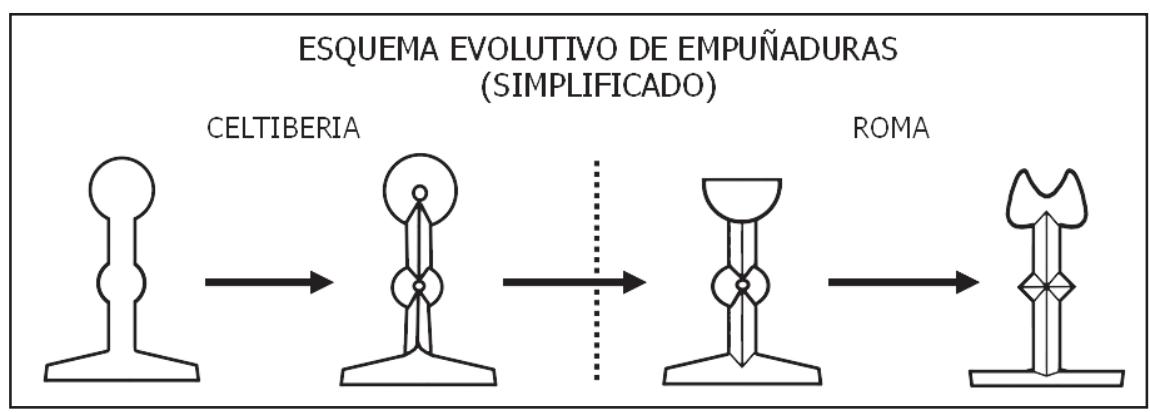

Figura 12. Esquema evolutivo de empuñaduras simplificado.

339 Modelo de Discos Concéntricos, de Empuñadura Calada y de Pomo Globular. 
dará lugar a finales del II a.C. al, igualmente celtibérico, modelo de Aristas. Este modelo de aristas - conocido pero probablemente no fabricado por los romanos - a su vez evolucionará a fines del I a.C. en los modelos Híbrido disco-semidisco y de Semidisco, ya plenamente romanos. El modelo de Semidisco eventualmente dará lugar al, también romano, modelo de Pezuña (Trajano en adelante), que cierra finalmente la serie de bidiscoidales. Las cronologías del conjunto de bidiscoidales son las siguientes:

Tabla crono-tipológica de empuñaduras (por siglos): (fig. 13)

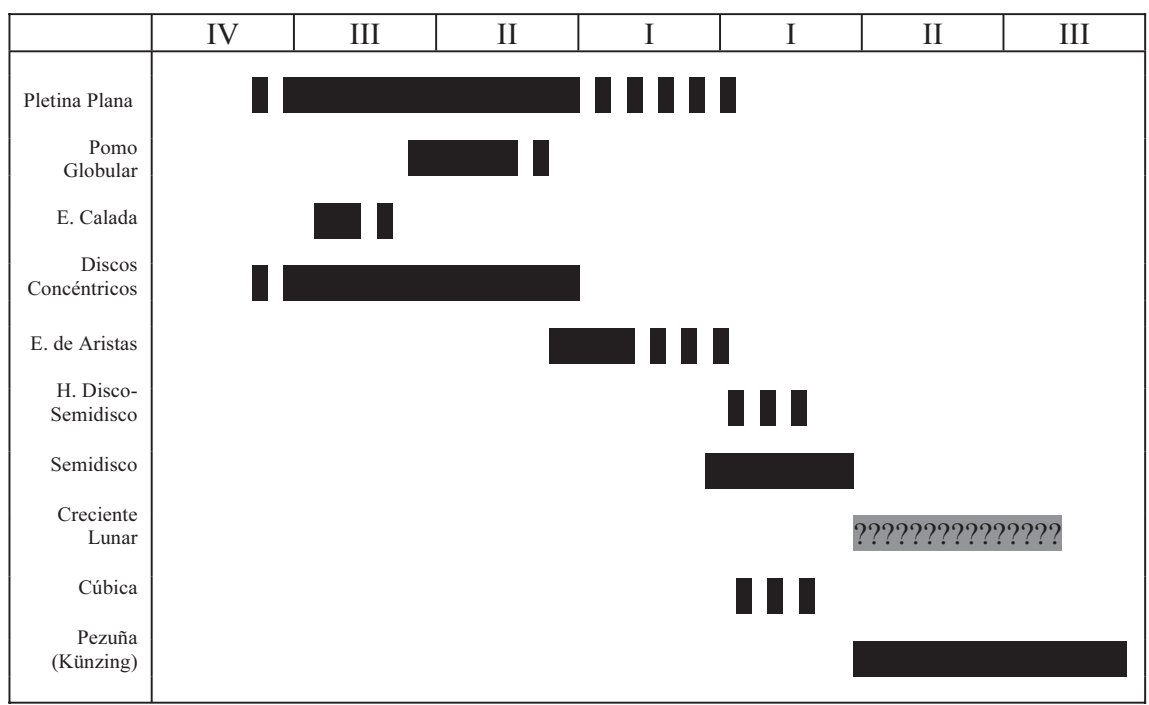

Leyenda: las franjas continuas indican periodos en los que se fabricaba el tipo, las discontinuas hallazgos aislados y el gris datación dudosa.

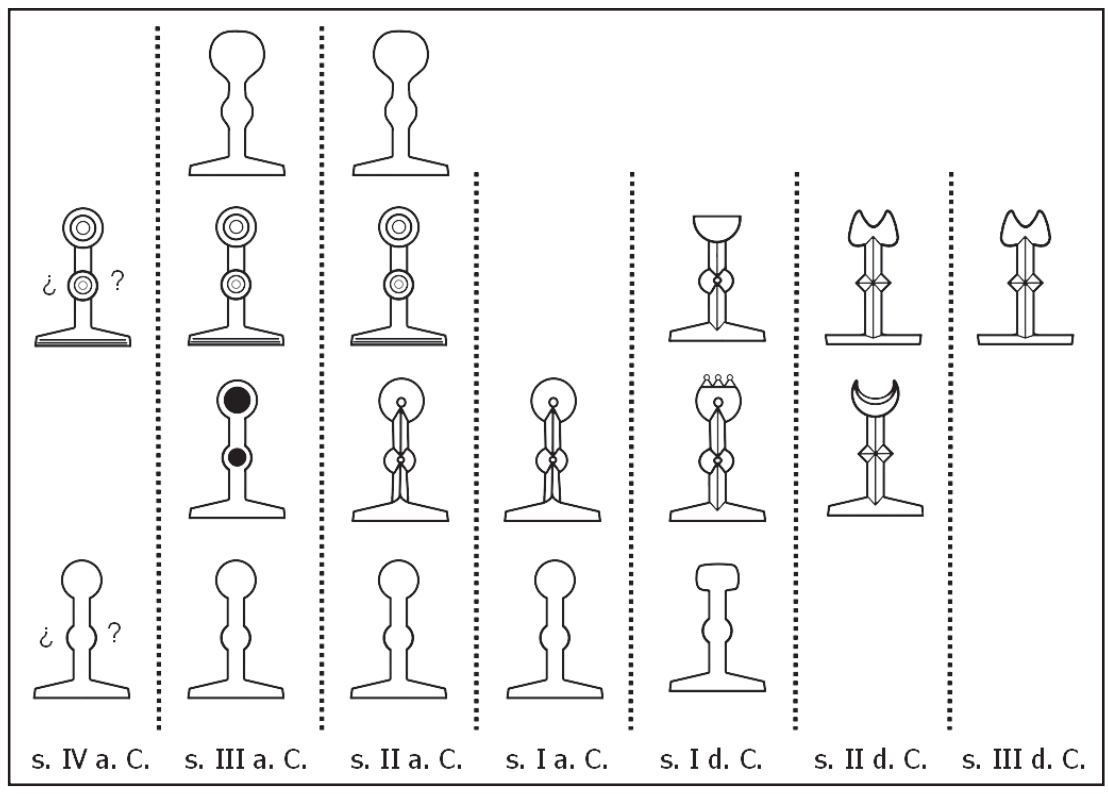

Figura 13. Tipos de empuñadura por siglos. 


\section{TIPOLOGÍA DE HOJAS}

Generalidades de las hojas (figs. 14 y 15)

El puñal bidiscoidal presenta en la práctica totalidad de los $\operatorname{casos}^{340}$ un nervio central que recorre la hoja longitudinalmente, desde su base hasta la misma punta del arma ${ }^{341}$. Excepcionalmente hallamos ejemplares con nervadura doble, lo cual es indicio inequívoco de romanidad $^{342}$ y cronología siempre posterior al cambio de era. Tal es el caso de Julióbriga ${ }^{343}$ (Cantabria) y, — con dos o incluso más nervios en cada lado de la hoja - de Hod Hill ${ }^{344}$ (GB), Leeuwen $^{345}$ (Holanda), Maguncia ${ }^{346}$ (Alemania) y Risstissen ${ }^{347}$ (Alemania). La longitud media de hoja de los bidiscoidales peninsulares es de $18,18 \mathrm{~cm}^{348}$ (fig. 15).

\section{Hoja pistiliforme (fig. 14)}

Género de hoja así bautizada en honor a su peculiar silueta, semejante al pistilo de una flor. Se define por presentar un estrechamiento (waist o «cintura» en terminología sajona ${ }^{349}$ ) en la anchura de la hoja entre el primer y segundo tercio de la misma. Cuantitativamente es, junto con el modelo de base dilatada, uno de los modelos más populares, representando un $35 \%$ del total ${ }^{350}$.

Su cronología, al igual que en el caso de la hoja de base dilatada, se desarrolla por un lapso muy amplio, desde los ejemplares tempranos de Ucero (anterior al s. II a.C.), Osma (s. III a.C.), Quintanas de Gormaz (s. III a.C.), hasta los más tardíos de Palencia ciudad (probablemente del s. I d.C. ${ }^{351}$ ), Julióbriga y Aroche (con toda probabilidad a partir de Trajano). Con dataciones intermedias entre estos dos extremos citamos los casos de Castillejo (s. II a.C.), Arcóbriga (ss. II-I a.C.), Langa de Duero (fines II inicios I a.C.) y el Raso (primera mitad I a.C.).

Se trata por tanto de un género de hoja documentado al menos desde el III a.C., con una gran perduración temporal que enlaza con los ejemplares romanos imperiales. Y es ahí, precisamente, donde este género de hoja halla su peculiaridad que le distingue del resto: en los umbrales del cambio de era la hoja de base dilatada sufre un drástico descenso que le llevará a desaparecer casi por completo. En el caso de la hoja pistiliforme, por el contrario, el advenimiento del cambio de era no tiene ningún efecto sobre su popularidad, lo que le permite seguir existiendo a lo largo de los ss. I-III d.C., ya en contextos puramente romanos. Es más, obser-

\footnotetext{
${ }^{340}$ Correspondiente al 93,5\% del total, o lo que es lo mismo, 72 casos de entre 77.

${ }^{341}$ En contraste con la práctica moderna habitual de retrasar el nervio unos milímetros hacia el interior.

342 No existe ejemplar alguno de factura peninsular con este rasgo salvo el puñal de Julióbriga, ya de época romana.

${ }^{343}$ Probablemente datado entre el s. II y mediados del III d.C.; García Bellido, 1963: 200-201 y fig. 19. Cabré Herreros y Morán Cabré, 1991: 341-346 y fig. 3; Fernández Ibáñez, 2005a: 210 y fig. 13, A.

344 Manning, 1985: Plate 73 V 7 y V8.

345 Scott, 1985: fig. 1, 53.

${ }^{346}$ Bishop y Coulston, 1993: 75 y fig. 39, 5.

347 Bishop y Coulston, 1993: fig. 39, 3.

348 Sobre 61 ejemplares. Esta medida se ha tomado desde el arranque de la hoja bajo los arriaces (no desde el origen verdadero de la hoja), hasta su punta.

${ }^{349}$ La expresión exacta usada por la terminología sajona para referirse a este tipo de hoja es waisted blade (hoja con cintura).

${ }^{350}$ Concretamente con las proveniencias: Ucero, Osma, Más de Barberán, Castillejo, Ciruelos, Julióbriga, Espinal, Osma, El Raso, Aroche, Cuesta del Burro, Cueva de Cofresnedo, Las Ruedas, Santa Cruz de Camazos, Palencia, Arcóbriga, Dehesa del Rosarito, El Romazal, Sotopalacios, Langa de Duero y Quintanas de Gormaz.

351 Aunque el contexto no nos permite precisar demasiado la cronología, el remate semidiscoidal del pomo los asemeja tipológicamente a los puñales limetanos del s. I d.C.
} 
vamos que será en este último periodo cuando experimente un reforzamiento de las características formales que le definen, v. g. una acentuación en su pistiliformidad. Al mismo tiempo acontece un aumento en las dimensiones de la hoja, fenómeno que se da en el s. I d.C. En el caso peninsular las hojas pistiliformes oscilan entre los 17 y los $23 \mathrm{~cm}$, cifras que contrastan ligeramente con las de las hojas de base ensanchada, que en cambio pueden llegar a ser tan cortas como $13 \mathrm{~cm}$ (fig. 15).

\section{Hoja de base dilatada o ensanchada (fig. 14)}

Se trata de uno de los dos modelos más comunes de hoja que, junto al modelo pistiliforme, encabezan la lista de hojas asociadas a empuñaduras bidiscoidales ${ }^{352}$. Se trata de una hoja ancha, de filos relativamente paralelos, en cuya base (o extremo más próximo a la empuñadura) se aprecia un ensanchamiento, apenas uno o dos centímetros antes de buzar bajo los arriaces o guarda. Los numerosos ejemplares de hoja de base dilatada se distribuyen homogéneamente por todo el área cubierta por el puñal bidiscoidal ${ }^{353}$. El conjunto se corresponde con el $37 \%$ del total. Destacamos la recurrente asociación de este modelo de hoja a la empuñadura de aristas, más raramente a empuñaduras de Pletina Plana. El modelo se desarrolla predominantemente durante el los ss. II-I a.C., relacionándose con mayor fuerza con los yacimientos puramente celtibéricos o en cualquier caso indígenas, no tanto a los romanos ${ }^{354}$. Por tanto se puede decir que a grandes rasgos se trata de un género de hoja típicamente celtibérico y cuya cronología raramente sobrepasa el ecuador del s. I a.C.

\section{Hoja de filos paralelos (fig. 14)}

Se define por el carácter rectilíneo y paralelo de sus dos filos, que convergen en un espacio comprendido entre el segundo y tercer - último - tercio, de modo que el ángulo de convergencia se revela muy acusado, resultando en una punta poco aguda. En cuanto a sus longitudes, éstas parecen bascular entre los 17 y 18,9 cm de longitud. (fig. 15). Se trata del género más minoritario de cuantos modelos de hojas aparecen asociadas al bidiscoidal. Sólo hallamos ejemplares de este modelo en los yacimientos de Uxama ${ }^{355}$, Numancia ${ }^{356}$, Carratiermes ${ }^{357}$, La Azucarera $^{358}$, Quintanas de Gormaz ${ }^{359}$ y un caso descontextualizado ${ }^{360}$. Las cronologías de estos ejemplares nos indican un espacio temporal relativamente concreto. Los casos de Quintanas de Gormaz (mediados III a.C.) y Uxama (fines III a.C.) pueden ser los más antiguos del conjunto, seguidos de cerca por los ejemplares de Numancia (s. II a.C.) y los difícilmente

352 Ver gráfica adjunta n. ${ }^{\circ} 3$.

353 El modelo se documenta en Numancia, La Osera, Osma, Ucero, Punto de Agua, Carratiermes, Cáceres el Viejo, El Raso, Arcóbriga, Torre de Palma y Pinilla de Toro.

${ }^{354}$ Sólo dos casos del total se relacionan con yacimientos romanos y posteriores al c/era: Pinilla de Toro (Zamora) y Torre de Palma (Monforte, Portugal). El ejemplar de Pinilla de Toro se halló en superficie sobre una villa tardorromana (Las Minas), posiblemente de los siglos III-IV d.C., al igual que el ejemplar de Torre de Palma, también hallado en el contexto de una villa romana (Villa de Basilii o Villa de Torre de Palma) ocupada esta vez entre los siglos II y IV d.C.

355 Tumba 8. Quesada 1997a: n. ${ }^{\circ}$ cat. 4314. Schüle, 1969: taf. 56.9; García Merino, 2005: 177.

356 Schüle, 1969: taf. 166, 14.

357 Primer caso: Tumba 440. Argente Oliver, 2001: CD adjunto. Segundo caso: Museo Numantino, n. ${ }^{\circ}$ inv. P/256; Chaín Galán y De la Torre, 2005: n. ${ }^{\circ}$ 67. Tercer caso: Museo Numantino, n. ${ }^{\circ}$ inv. 87/3/2238; Chaín Galán y De la Torre, 2005, n. ${ }^{\circ} .307$.

358 Quesada: n. ${ }^{\circ}$ cat. 6260; Iriarte; García; Filloy; Gil y Sesma, 1996: 173-154; Iriarte; Gil; Filloy y García, 1997: 233 250 y fig. 21.

${ }^{359}$ Museo Celtibérico de Soria, n. ${ }^{\circ}$ inv. 1343; Quesada, 1997a: n. ${ }^{\circ}$ cat. 4428; Schüle, 1969: taf. 33.7; Lorrio Alvarado, 1994b: fig. 2.

360 Álvarez Gracia; Cebolla Berlanga y Blanco Morte, 1990: fig. 7. 


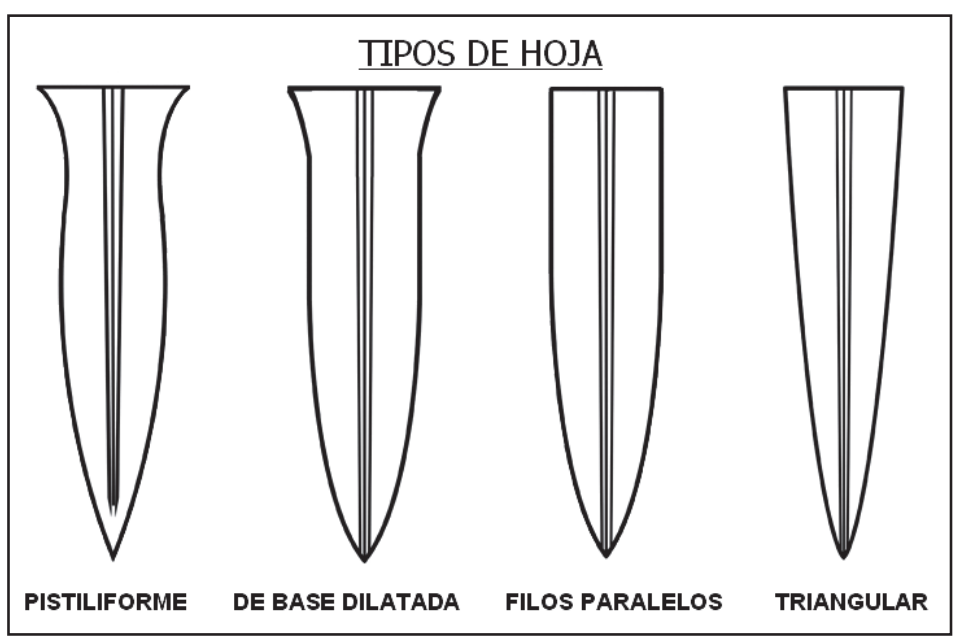

Figura 14. Tipos de hoja asociadas al puñal bidiscoidal.

datables de Carratiermes (ss. III-I a.C.). Finalmente el caso de La Azucarera, de discutida cronología (fines II-principios I a.C.) puede ser el caso más tardío, de no serlo en mayor grado alguno de Carratiermes o el ejemplar descontextualizado.

Por tanto, estos ejemplares nos ofrecen una cronología — para la hoja de filos paralelos — de entre mediados del III a.C. y principios del I a.C. Carece de paralelos extrapeninsulares, se trata por tanto de una hoja eminentemente peninsular.

\section{Hoja triangular (fig. 14)}

Se trata de un género relativamente minoritario entre los modelos de hoja, suponiendo escasamente un $18 \%$ del total ${ }^{361}$. Destaca la relativa concentración en Uxama (cuatro ejemplares) ${ }^{362}$. Del conjunto aparentemente los dos ejemplares de La Osera 1 (s. III) y Osera 3 (ss. IV-III a.C.) son los más antiguos, seguiros tal vez por el ejemplar de Osma (segundo cuarto s. III a.C.). posteriormente los de Numancia (fines III, fines II a.C.) y Castillejo (tercer cuarto s. II a.C.). Por último contamos con los casos tardíos de La Caridad (fines del II, principios del I a.C.) y Cáceres el Viejo (principios I a.C.). El conjunto nos refiere una cronología completamente coincidente con el periodo de existencia del bidiscoidal, por lo que no nos sirve como herramienta para datar. Las hojas triangulares son heterogéneas en cuanto a sus dimensiones $^{363}$. La mayoría se mueven entre los 15 y $17,9 \mathrm{~cm}$ de longitud, con excepciones ${ }^{364}$. En cuanto a la anchura ${ }^{365}$, ésta se limita generalmente en torno a los $4-4,5 \mathrm{~cm}^{366}$.

${ }^{361}$ Porcentaje correspondiente a 14 ejemplares, hallados en Osma, Castillejo, Osera, Capote, La Caridad, Cáceres el Viejo y Numancia.

${ }_{362}$ Que podría responder a la pertenencia de todos ellos a un mismo taller ubicado en esa ciudad.

363 Véase la gráfica «Longitud de hoja por tipos».

${ }^{364}$ Notablemente una procedente de Cáceres el Viejo, que presenta hasta $28 \mathrm{~cm}$ de longitud

${ }^{365}$ Medida en su base, v.g. en el punto más ancho.

366 De nuevo, hay excepciones notables de un mínimo de $3,5 \mathrm{~cm}$ hasta $6 \mathrm{~cm}$ de anchura. 
DiMENSIONES DE HOJAS

\section{Longitud de hoja (fig. 15)}

El conjunto de hojas de bidiscoidal peninsular presenta una gama de dimensiones longitudinales comprendida entre los 13 y $29 \mathrm{~cm}$. Es, por tanto, un conjunto fuertemente heterogéneo, como corresponde a su igualmente heterogéneo origen y cronología. La longitud media de las hojas bidiscoidales es de $18,18 \mathrm{~cm}^{367}$. La mediana (no media) de longitud de hoja se encuentra en torno a los $21 \mathrm{~cm}$, que no se corresponde con la media. Donde sí se observa correspondencia es entre la media y la moda, que se sitúa esta última entre los $18-18,9 \mathrm{~cm}$ con un pico de quince casos contabilizados. Según todo indicio, los puñales más primitivos son también los más he-

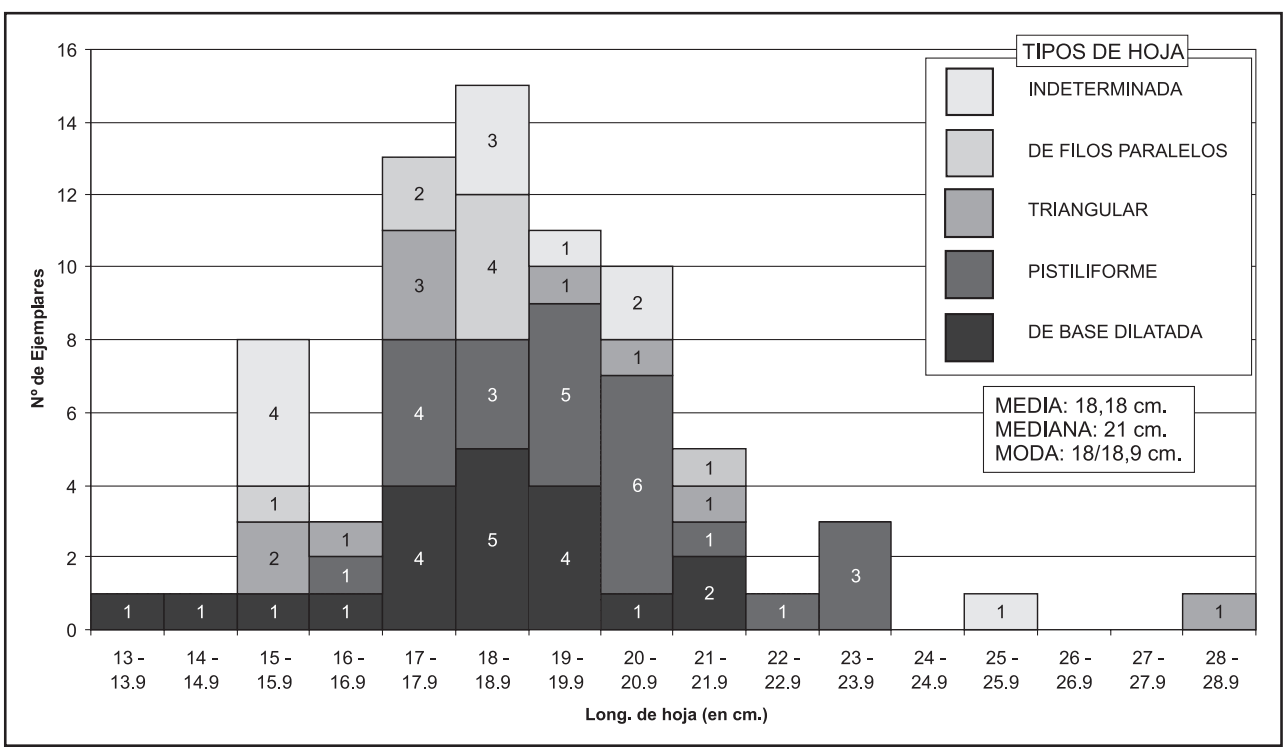

Figura 15. Tabla donde se muestran las diferentes longitudes de hojas clasificadas según la tipología a la que pertenecen (véase también fig. 5).

terogéneos en cuanto a sus dimensiones ${ }^{368}$. Es posible que esto se deba al poco contacto entre los diferentes talleres en fechas tan tempranas, así como al carácter artesanal y único de cada pieza, circunstancias que se invertirán en los siglos II y I a.C. como consecuencia de las necesidades bélicas. A esto debemos añadir que en los ss. IV y III a.C. el puñal contenía un fuerte carácter como elemento de prestigio, lo que inevitablemente redundaría en la individualizad de cada pieza. En periodos posteriores el puñal se «democratiza» y generaliza, convirtiéndose en un objeto fabricado prácticamente «en serie». Si lo primero favorecía la heterogeneidad, lo segundo la homogeneidad.

\footnotetext{
367 Sobre 61 ejemplares analizados.

368 Encontramos algunos con longitudes de hoja de entre 15-15,9 cm, pero también hay casos entre 18-18,9 cm e incluso algún ejemplo aislado procedente de Uxama (Schüle, 1969: taf. 55.2; Lorrio Alvarado, 1994; Cabré de Morán, 1990: 205-224; García Merino, 2005: 177) de hasta 20-20,9 cm.
} 
En cualquier caso se aprecia cómo generalmente los puñales propios de los siglos IV y III a.C. presentan longitudes algo inferiores a las de sus sucesores. Las armas datadas en el s. II a.C. por el contrario, tienden a mantenerse entre las dimensiones de 17 y $17,9 \mathrm{~cm}$ de longitud de hoja ${ }^{369}$. En el s. I a.C. asistimos a un renovado proceso de heterogeneización de las dimensiones, tal y como ocurrió en los Ss. IV y III a.C. Este fenómeno viene acompañado de un destacado desarrollo longitudinal ${ }^{370}$.

En cuanto a la relación entre tipos de hojas y sus respectivas dimensiones se observan algunos fenómenos interesantes (fig. 15). En primer lugar, se aprecia cómo los puñales de base dilatada se desarrollan entre las dimensiones más pequeñas del conjunto (13 $\mathrm{cm}$ de longitud) hasta los $21 \mathrm{~cm}^{371}$. Asimismo, las hojas de filos paralelos abarcan dimensiones generalmente comprendidas entre los 17 y $19 \mathrm{~cm}$ de longitud mientras que las pistiliformes destacan por su tamaño claramente superior, con una dimensión comprendida generalmente entre los 17 y $21 \mathrm{~cm}$. Este fenómeno se explica si consideramos que los puñales tardíos tienden tanto a aumentar sus dimensiones como el grado de pistiliformidad. No obstante, la tendencia de las hojas pistiliformes a presentar un tamaño superior a la media es un hecho constatable desde el periodo celtibérico $^{372}$. Por último, las hojas de tipo triangular parecen representar un papel especialmente heterogéneo, comprendiendo desde dimensiones muy reducidas $(15 \mathrm{~cm})$ hasta un extraño ejemplar de $28 \mathrm{~cm}$ de longitud. La moda parece corresponderse con los 15-17 cm Como conclusión, apreciamos que, independientemente del tipo al que pertenezca, la mayoría de las hojas presenta una longitud entre los 17 y los $20 \mathrm{~cm}^{373}$, siendo la media absoluta de $18,18 \mathrm{~cm}$.

En el caso romano las dimensiones son sensiblemente superiores. Según hemos podido ver la longitud media de hoja romana ronda $\operatorname{los} 22,05 \mathrm{~cm}^{374}$, lo que supone una diferencia de unos cuatro centímetros con sus homólogos peninsulares. Es evidente por tanto que la hoja experimenta un desarrollo longitudinal a lo largo de su evolución temporal.

\section{Ancho de hoja}

El ancho medio de hoja de bidiscoidal es de 4,62 $\mathrm{cm}^{375}$. No obstante la gama de tamaños se dilata desde los escasos $3 \mathrm{~cm}$ hasta $\operatorname{los} 7 \mathrm{~cm}$ en un caso excepcional. La mediana ronda los 5-5,4 cm, que no se corresponde con la media, ya citada. Tampoco se corresponde con la moda, que se sitúa entre los 4-4,4 cm, cifra más cercana a la media, con un pico de diecinueve casos contabilizados.

Se observa un interesante, aunque sutil, fenómeno en cuanto a la correlación entre el ancho máximo de las hojas y la evolución temporal ${ }^{376}$. En primer lugar observamos que el grupo de hojas más antiguo, aquel correspondiente con los siglos IV y III a.C., presenta un ancho de hoja preferentemente en torno a los 4,5-5,9 cm. En el s. II a.C. en cambio, descollan los puña-

\footnotetext{
${ }^{369}$ Con ejemplos aislados entre los 19 y $20,9 \mathrm{~cm}$.

370 Es posible que el aumento de las dimensiones sea obra de Roma en su intento por emular las armas indígenas, pues los ejemplares más voluminosos proceden precisamente del campamento romano de Cáceres el Viejo. Véase Ulbert, 1984.

371 De hecho, las dimensiones más reducidas de entre todas las hojas de bidiscoidales (aquellas entre 13 y $15 \mathrm{~cm}$ ) se corresponden siempre a hojas de tipo de base dilatada.

372 Puesto que los ejemplares posteriores, de época imperial, se corresponden únicamente con cuatro piezas del total de 24 hojas consideradas en esta estadística.

373 Dimensiones entre las que se comprenden 43 de los 61 ejemplares analizados, es decir, el 70,4\% del total

374 Sobre 38 ejemplares limetaneos analizados.

375 Medida tomada sobre 75 ejemplares.

376 Como método de estudio se ha optado por dividir las muestras en grupos según su tamaño, con $5 \mathrm{~mm}$ de diferencia de ancho de hoja entre cada grupo.
} 
les con un ancho de entre 5-5,4 cm y fundamentalmente aquellos entre 4 y 4,4 cm. El siglo I a.C. no presenta ningún canon de medidas pero parece mantener muy similares dimensiones al s. II a.C. En cuanto a la relación entre los tipos de hoja y sus dimensiones transversales, acusan cierta tendencia las hojas de base dilatada o ensanchada a comprender tamaños ligeramente más dilatados que la media pero sin llegar a superar los 5,4 cm. En cuanto a las hojas pistiliformes, éstas muestran unas dimensiones completamente heterogéneas, representándose a lo largo de toda la gama. Las hojas triangulares son por lo general menores, en torno a los 4-4,4 $\mathrm{cm}$ de anchura, mientras que las hojas de filos paralelos, se muestran como las más reducidas del conjunto, no sobrepasando jamás los $4,9 \mathrm{~cm}$ de ancho.

\section{SECCIONES DE HOJA (fig. 16)}

Hemos podido identificar una tipología de secciones de hoja ${ }^{377}$ relacionadas con el bidiscoidal que hemos venido a denominar:

A. De cuatro mesas ${ }^{378}$ (o sección «A»): perfil formado por cuatro superficies planas. El resultado es una forma netamente romboidal, losángica.

B. Esteliforme $(« B »)$ : formado por cuatro superficies cóncavas. Su perfil se asemeja a la visión distorsionada que a menudo nos llega de una estrella, formada por un aspa de cuatro haces de luz. Es el inverso al lenticular.

C. Lenticular $(« C »)$ : se define por presentar dos superficies convexas, unidas por sus extremos. Su nombre hace referencia a la lente convergente ${ }^{379}$ de un cristal, a cuyo perfil se asemeja. Es el inverso al esteliforme.

D. Lámina plana («D»): que mantiene un grosor similar tanto en el centro como cerca de los filos.

La primera deducción que extraemos es la neta superioridad (46\%) del modelo de cuatro mesas (A) sobre el resto ${ }^{380}$. Asimismo verificamos que las hojas de sección «tipo A» $\mathrm{y}$ «tipo D» presentan mayoritariamente un perfil pistiliforme, mientras que los ejemplares de hoja de base ensanchada se reparten de forma homogénea entre todos los grupos, a excepción del de lámina plana ${ }^{381}$. Destacamos el interesante hecho de que las hojas de filos paralelos presentan exclusivamente una sección de cuatro mesas (A), no habiendo ningún caso de asociación de una hoja de filos paralelos con otro tipo de sección. Independientemente de la forma de la sección, el 93,5\% del conjunto de bidiscoidales presenta nervadura central de algún tipo, y únicamente el $6,4 \%$ carece de ella ${ }^{382}$.

Todos nuestros intentos por precisar una evolución cronológica de secciones han fracasado $^{383}$. La única característica de diferenciación cronológica que hemos podido detectar es la

377 La identificación de estas cuatro variantes (fig. 16) se ha hecho sin tomar en cuenta la nervadura central o acanaladura, cuya presencia o ausencia no tiene ninguna relación con la sección ni determina su clasificación

378 También denominada «losángica».

379 La lente convergente, o bicóncava es más gruesa por el centro que por el borde.

380 Contabilizando 24 ejemplares sobre un total de 52.

381 Con el que no se documenta asociación alguna.

382 De un total de setenta y siete ejemplares susceptibles de análisis, únicamente cinco presentaron una hoja carente de nervadura alguna.

383 Por lo que consideramos que posiblemente no exista ningún patrón ni proceso evolutivo, sino que la elección del tipo de hoja obedeciera a los gustos del herrero o su cliente, o simplemente a la técnica de forja propia del artesano concreto. 


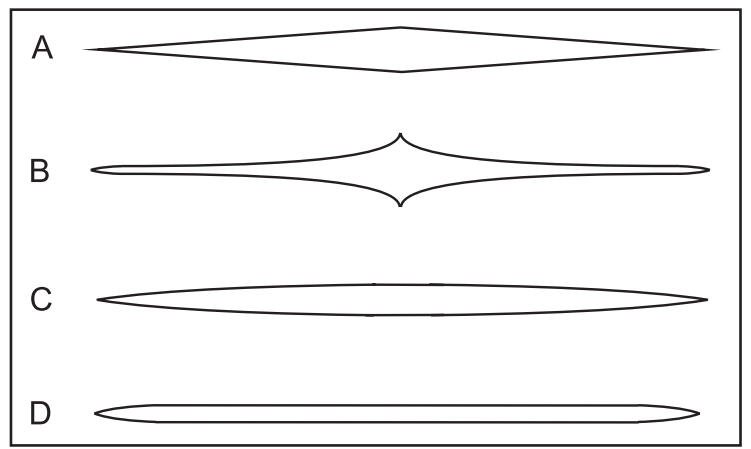

Figura 16. Secciones de hoja. A: cuatro mesas; B: esteliforme; C: lenticular; D: chapa plana.

tendencia de las armas romanas a contener acanaladuras, un rasgo prácticamente ausente en la Península antes de la romanización ${ }^{384}$ pero relativamente usual entre las armas limetanas. Por tanto la presencia de acanaladuras en un bidiscoidal suele ser indicio de su romanidad y cronología tardía, posterior al cambio de era.

\section{TIPOLOGÍA DE VAINAS}

Tipos DE VAINAS ASOCIADAS AL BIDISCOIDAL (fig. 17)

Los puñales de tipo bidiscoidal se asocian, según la fecha y la identidad cultural del fabricante, a uno u otro tipo de vaina. Distinguimos tres grandes grupos de vaina asociadas al bidiscoidal o a sus variantes:

A. De cañas (celtibérica).

B. De chapa metálica (romana).

C. De chapa orgánica (romana).

Clasificación general de vainas asociadas al bidiscoidal y a sus variantes:

\begin{tabular}{|c|c|c|c|}
\hline FILIACIÓN & ESTRUCTURA & SUSPENSIÓN / TIPO & CRONOLOGÍA \\
\hline \multirow{3}{*}{ CELTÍBERA } & \multirow{2}{*}{ DE CAÑAS } & ASAS LATERALES & ss. IV-III a.C. \\
\cline { 3 - 4 } & & 2 ANILLAS DIAGONALES & ss. IV-c/era \\
\cline { 3 - 4 } & & 2 ANILLAS ISOLATERALES & s. II a.C. \\
\hline \multirow{2}{*}{ ROMANA } & \multirow{2}{*}{ DE CHAPA METÁLICA } & 4 ANILLAS / TIPO A & Augusto-Claudio \\
\cline { 3 - 4 } & & 4 ANILLAS / TIPO C & ss. II-III d.C. \\
\cline { 2 - 4 } & DE CHAPA ORGÁNICA & 4 ANILLAS / TIPO B & Tiberio - fines I d.C. \\
\hline
\end{tabular}

\footnotetext{
${ }^{384}$ Entre los bidiscoidales peninsulares anteriores a la romanización sólo hemos podido distinguir un único caso que presenta acanaladuras, procedente de la necrópolis de Portuguí (Uxama, Osma, Soria); MAN 1917/54 - 24.506 A y B, cartón 2; Quesada, 1997a: n. ${ }^{\circ}$ cat. 5993.
} 


\section{Vaina de cañas}

Modelo típico del ámbito peninsular, de relativa complejidad estructural. Lo forman las piezas:

A. Dos «cañas»: presentan una sección en forma en «U», y tienen la función de cubrir el filo de la hoja a lo largo de todo su perímetro. Son dos, una por cada filo, y se unen en sus extremos superior y medio por los puentes, y en sus extremos inferiores por medio de la contera.

B. Dos «puentes» o abrazaderas: láminas metálicas (generalmente de bronce), con una anchura variable, que abrazan transversalmente la estructura de la vaina uniéndose en sus extremos a las dos cañas laterales. De este modo fijan la separación entre las cañas en una medida estática correspondiente al ancho de hoja del arma correspondiente ${ }^{385}$. La unión de los puentes con las cañas se ejecuta merced al uso de clavos o remaches, en número de cuatro ${ }^{386}$. En ocasiones, y según el modelo de vaina que tratemos, los puentes se funden en un único «puente completo» ${ }^{387}$ que recorre toda la superficie entre las cañas cubriendo por completo la hoja del arma ${ }^{388}$.

C. Contera ${ }^{389}$ : pieza metálica, generalmente férrica (excepcionalmente broncínea), ubicada en el extremo inferior de la vaina, en el punto donde ambas cañas convergen. Su forma es cónica en su mitad superior y plana y discoide en el inferior. Ocasionalmente aparece decorada con apliques de bronce discoides en cada cara ${ }^{390}$. Su función es cubrir, al tiempo que unir, los extremos inferiores de las cañas y evitar su separación. Secundariamente, esta pieza sirve de protección para el usuario de la vaina ${ }^{391}$.

D. X Remaches: generalmente cuatro, uniendo puentes y cañas.

Y destinadas a la suspensión son las piezas:

E. Dos goznes ${ }^{392}$ : no son piezas independientes sino prolongación del puente o abrazadera en forma de «U» que sobresale horizontal y transversalmente de los laterales de la vaina. Unen la vaina con las anillas de suspensión, a las que abrazan con holgura.

F. Dos anillas: sostenidas por los goznes, de los que penden con holgura. Unen los goznes con el correaje.

G. Dos asas laterales: en la variante que lleva su nombre sustituyen a las anillas en la función de suspensión.

385 Cada puente rodea completamente la estructura de la vaina en sentido transversal, de modo que da una vuelta completa alrededor de la misma. No obstante, lo común es que cada puente esté formado a su vez por dos piezas, una por cada «cara» o lateral.

${ }^{386}$ Uno por cada unión entre cada uno de los extremos de los dos puentes con las dos cañas.

387 Información extendida en el apartado «Modelo de puente completo».

388 A menudo los puentes, al presentar la única superficie algo amplia del conjunto de la vaina, son elegidos como campo decorativo. Véase apartado «decoración en las vainas».

$389 \mathrm{O}$ «extremo distal discoide».

390 Como tal se aprecia en un ejemplar perteneciente a la colección Axel Guttmann (Museo Arqueológico Nacional).

${ }^{391} \mathrm{~A} 1$ sustituir con una superficie discoide y roma, el vértice afilado y punzante que presenta la unión de los extremos inferiores de las cañas. De este modo se evita que el usuario sufra daño por rozamiento con una superficie cortante como habría supuesto el haber dejado visibles los extremos inferiores de las cañas.

392 Loop en terminología anglosajona (p. ej. en Scott, 1989). 
Las piezas «E»y «F» (goznes y anillas) tienen como objeto la suspensión del conjunto de la vaina. Los goznes unen la vaina a las anillas, mientras estas últimas se ligan a algún género de correaje probablemente orgánico ${ }^{393}$. Este conjunto formado por gozne y anilla se repite de dos a cuatro veces a lo largo del perímetro de la vaina, dando lugar a las diferentes variantes de vaina que conocemos según su número y posición ${ }^{394}$.

— Vaina de cañas con dos anillas diagonales

Se trata del modelo más recurrente de la Celtiberia. Se define por contener únicamente dos anillas con finalidad suspensiva, cada una a un lado de la vaina, pero dispuestas a diferente altura $^{395}$.

Se distinguen dos subgrupos, por un lado aquellas vainas en las que las anillas se disponen la superior ${ }^{396}$ a la derecha, y la inferior ${ }^{397}$ a la izquierda, y por otro aquel en el que, inversamente, la superior se dispone a la izquierda y la inferior a la derecha. El detalle no es baladí, pues determina el lado de la cadera del que se suspenderá el arma ${ }^{398}$. En el mundo celtibérico la proporción se inclina claramente a favor de los ejemplares de anilla superior diestra e inferior siniestra, v. g., aquellos que suponemos se colgaban de la cadera derecha del cuerpo. Esto se prueba en la elección de la cara a decorar, demostrando el sentido en que debía sostenerse de modo que la decoración quedara a la vista ${ }^{399}$. Especulamos con una suspensión diagonal desde cinturón o bien vertical desde bandolera para este tipo. La cronología del conjunto dista desde el s. IV a.C. hasta el c/era aproximadamente ${ }^{400}$.

Entre los ejemplares romanos limitaneos encontramos un único caso de suspensión por dos anillas diagonales ${ }^{401}$, delatando que se trata de un género de suspensión extraño al ámbito extrapeninsular ${ }^{402}$. Además observamos que la situación es exactamente la inversa en cuanto a

${ }^{393}$ Lo que deducimos de la total ausencia de documentación arqueológica del mismo.

394 Es preciso llamar la atención sobre el peligro que entraña confundir los clavos, remaches y sus correspondientes (de haberlas) arandelas (entendemos como arandela aquella pieza metálica en forma de disco plano horadada en su centro, cuya función es servir de extensión de la cabeza del clavo o remache que la atraviesa, afirmando la función de este último), propio todo ello del sistema de unión de los puentes con las cañas, con eventuales arranques de sistemas de suspensión. De este modo, se puede pensar, erróneamente, que una vaina cuenta con determinado número de anillas de suspensión, al interpretar como arranques propios de éstas lo que en realidad son simples remaches de unión entre las diferentes piezas que componen la vaina. Esto se debe a que, en la totalidad de los ejemplos analizados hasta el momento, los arranques de los sistemas de suspensión se afianzan a las vainas haciendo uso de los mismos clavos o remaches que previamente han servido de unión entre los puentes y las cañas.

${ }^{395} \mathrm{Si}$ suponemos un correaje vertical como medio de suspensión, el resultado es que la vaina, una vez colgada del mismo, pendería no de forma vertical, como sería de suponer, sino con una fuerte inclinación, producto de la diferente altura de sus anillas de suspensión (ver imagen propuesta A). Esta inclinación creemos que tiene como objeto el facilitar el acceso con la mano a la empuñadura, y facilitar así la extracción del puñal de la vaina (en la misma línea, Idoia Filloy Nieva, 1997).

396 V.g. aquella dispuesta junto a la boca de la vaina.

397 V.g. aquella dispuesta a media distancia entre la boca y la contera de la vaina.

398 Si la anilla superior se dispone a la derecha y la inferior a la izquierda, entonces la vaina se inclinará hacia la derecha al suspenderla, delatando que su lado de la cadera desde el que se suspendía ha de ser el derecho. Si la posición de las anillas es la inversa, la vaina se suspenderá del costado izquierdo.

${ }^{399}$ Son tres vainas las que demuestran claramente este extremo, una primera descontextualizada (Álvarez Gracia; Cebolla Berlanga y Blanco Morte, 1990: fig. 4) y dos procedientes de Carratiermes: A) Tumba 103. Museo Celtibérico de Soria, n. ${ }^{\circ}$ inv. 87/3/3459; Argente Oliver, 2001; Argente Oliver y Díaz Díaz, 1990; y B) Tumba 440. Argente Oliver, 2001: $\mathrm{CD}$ adjunto.

${ }^{400}$ Con excepción de la vaina de dos anillas diagonales de Palencia (Ref. Palencia 2) cuya asociación a una empuñadura de semidisco es indicio de su cronología tardía, en torno al s. I d.C.

${ }^{401}$ Puñal de Titelberg, Luxemburgo. Scott, 1985; Vanden Berghe y Simkins, 2001/2: 75-84; Helmig, 1990; Bishop y Coulston, 1993.

${ }^{402}$ El ejemplar coincide también con el único caso de vaina de cañas documentado en el extranjero. 
la ubicación de las anillas ${ }^{403}$. Defendemos que la opción por este sistema de suspensión, pero invertido, deriva de la tradición romana de pender la espada del costado derecho del cuerpo ${ }^{404}$, obligando así a su inferior en la panoplia, el puñal, a desplazarse a un lugar secundario, el costado izquierdo. El puñal romano adopta el sistema de suspensión de dos anillas diagonales, típicamente celtibérico, pero modificándolo en virtud de sus tradiciones, de modo que invierte la posición de las anillas para con ello invertir la posición del arma en la cadera. Si en el caso celtibérico la tendencia era a colgar el arma del costado derecho, en el caso romano lo es del izquierdo. Ninguna de las dos tendencias es universal, pero sí generalizada.

Según Vanden Bergue ${ }^{405}$ el puñal de Titelberg conoció en su momento la suspensión por medio de cuatro anillas ${ }^{406}$, pues así parecen demostrarlo los cuatro remaches ${ }^{407}$ que sobresalen ligeramente de la estructura de los puentes, lo que sugiere que en su momento contuvieron una tercera y cuarta anilla, hoy inexistentes ${ }^{408}$. No obstante, nos permitimos plantear la duda de que así sea. El conjunto de características de esta vaina ofrecen la impresión de que se trata de una pieza de factura genuina y plenamente celtibérica, no romana, quizá adquirida por algún militar romano o llevada por algún auxiliar hispano a las fronteras septentrionales del imperio. Como decimos, la costumbre romana disponía el puñal del costado izquierdo del cuerpo. Dado que los puñales celtibéricos penden casi sin excepción del costado derecho, el soldado se vería obligado a invertir la suspensión de su arma para adecuarlo a las normativas castrenses romanas. Esto explicaría que aparezcan todo tipo de indicios de que la vaina tuvo anillas de suspensión en los puntos inversos a los que la presentan actualmente ${ }^{409}$. Este mismo autor esgrime como prueba de la presencia de cuatro anillas la prolongación de la pieza del gozne de suspensión a lo largo de la longitud del puente, como si tuviera la ambición de alcanzar el extremo opuesto para formar un segundo gozne. Sin embargo el mismo extremo se constata en ejemplares peninsulares cuya suspensión es indiscutiblemente de dos anillas ${ }^{410}$.

Debemos señalar que el puñal de Titelberg es destacadamente temprano (circa 30-12 a.C.) ${ }^{411}$ coetáneo al desarrollo del modelo de vaina, que luego será canónico en Roma, consistente en una suspensión por medio de cuatro anillas. Por tanto, y según nuestra interpretación, este puñal sería un interesante caso de «romanización» de un puñal originariamente celtibérico. Romanización ésta, que tan sólo exigiría invertir la suspensión para pender el arma del costado izquierdo, y no derecho como originariamente estaba diseñado ${ }^{412}$.

${ }^{403}$ Disponiendo la superior a la izquierda y la inferior a la derecha, como parece ser el caso del ejemplar romano procedente de Titelberg, Luxemburgo. Scott, 1985; Vanden Berghe y Simkins, 2001/2: 75-84; Helmig, 1990; Bishop y Coulston, 1993.

${ }^{404}$ De esta práctica se eximían los oficiales, particularmente centuriones, así como los portaestandartes de todo tipo (signiferes, aquiliferes e imaginiferes). De ello se deduce que este grupo de exentos se corresponde con aquellos que no usaban escudo para combatir. (Explicación ampliada en el capítulo de Iconografía).

405 Vanden Berghe y Simkins, 2001/2: 75-84.

406 Vanden Berghe y Simkins, 2001/2: 80.

$407 \mathrm{Si}$ la suspensión se proyecta desde los puntos de arriba a la izquierda y abajo a la derecha, entendemos como puntos sin suspensión sus inversos, v.g. arriba a la derecha y abajo a la izquierda.

${ }^{408}$ A su vez este autor aduce que uno de los extremos sin anilla de suspensión muestra melladuras propias del proceso de afirmar una lámina metálica sobre su superficie, lámina hoy perdida, así como el hecho de que la anilla de suspensión se proyecta longitudinalmente a lo largo de todo el puente, lo que sugiere la idea de que buscara alcanzar el extremo opuesto del puente para continuar allí abrazando una segunda anilla.

${ }^{409}$ Pero de ello no debemos deducir que su suspensión fuera de cuatro anillas.

410 Destacadamente en el ejemplar de la tumba 512 de Carratiermes. Argente Oliver, 2001: CD adjunto.

${ }^{411}$ Esta es la fecha que ofrecen Vanden Berghe y Simkins, 2001/2: 75. Según Scott, 1985, la pieza pertenece al periodo 30-10 a.C. Ambas propuestas son muy similares.

412 Otra opción mucho más sencilla hubiera consistido en voltear horizontalmente la vaina, pero eso hubiera supuesto renunciar a la rica decoración incisa que ésta presenta por una de sus caras. 
— Vaina de cañas y anillas isolaterales (fig. 17)

La vaina de anillas isolaterales ${ }^{413}$ se define por presentar únicamente dos anillas, ambas dispuestas en el mismo lateral de la vaina. Merced a un ejemplar, cuya decoración se desarrolla sólo por una de sus caras ${ }^{414}$, conocemos cuál de ambas caras era expuesta, y cual oculta. De ello deducimos el sentido concreto en el que se disponían las anillas de suspensión: en el lateral derecho de la vaina ${ }^{415}$.

Se trata de un modelo eminentemente celtibérico ${ }^{416}$, documentado en los yacimientos de Carratiermes $^{417}$ y Numancia ${ }^{418}$. En total se contabilizan cinco ejemplares ${ }^{419}$. La cronología de estas piezas parece corresponderse con el s. II a.C., si bien la asociación en tres casos a empuñaduras de aristas podría sugerir una datación algo más tardía ${ }^{420}$. Concluimos que la presencia de este modelo de vaina queda probada para el siglo II a.C., quedando abierta la posibilidad de que se perpetuase hasta principios del siguiente. En cuanto a su posible extensión a la cultura romana, contamos con los enigmáticos casos de las lápidas funerarias de Gnaeus Musius ${ }^{421}$ y Minucius Lorarius $^{422}$. Aunque no sabemos si por medio de una vaina similar a la nuestra, ambos muestran puñales suspendidos de forma horizontal ${ }^{423}$. Es posible, por tanto, que la práctica celtibérica correspondiente al uso de este género de vainas de puñal fuera, al igual que la romana, en sentido horizontal sobre el vientre (figs. 17 y 18).

— Vaina de cañas y asas laterales ${ }^{424}$ o pontet doble ${ }^{425}$ (fig. 17)

Este sistema de suspensión se define por contar la vaina con dos asas metálicas que se proyectan por ambos laterales en sentido vertical. De las asas cuelgan holgadamente sendas piezas metálicas terminadas en disco plano. A través del conocimiento que tenemos de otros

413 (del gr. Issos, igual, mismo, y lateral).

414 Perteneciente a la Colección «Pérez Aguilar», lamentablemente descontextualizado.

${ }^{415}$ De ello se podría deducir a su vez que este modelo de puñal se suspendía de algún género de cinturón, o bien en la cadera izquierda del usuario, de modo que la empuñadura se prolongara hacia el frente, facilitando su extracción, o bien horizontalmente sobre el vientre, de modo que la empuñadura se prolongara hacia la derecha del usuario.

${ }^{416}$ Una única excepción a esto podría ser un caso extrapeninsular procedente de Nimega (Holanda), de cronología posiblemente altoimperial.

${ }^{417}$ Un caso proveniente de su necrópolis (Museo Numantino, n. ${ }^{\circ}$ inv. 87/3/3459; Chaín Galán y De la Torre, 2005: n. ${ }^{\circ}$ 316) y otro de la propia ciudad (Quesada, 1997a: n. ${ }^{\circ}$ cat. 4454; Schüle, 1969: fig. 46.5).

418 Dos ejemplaes: El primero hallado en la tumba 123; Jimeno; De la Torre; Berzosa y Martínez, 2005; el segundo hallado en la tumba 80, Museo Numantino, n. ${ }^{\circ}$ inv. 95/5/1119/c-80.

${ }_{419}$ Uno de los casos provenientes de Numancia [Tumba 80; Museo Numantino 95/5/1119/c-80; Jimeno; De la Torre; Berzosa y Martínez, 2005] supone un ejemplo problemático, pues según la publicación de Jimeno et alii, 2005, se trata de una vaina de anillas isolaterales, mientras que según el catálogo de la exposición "Celtíberos, tras la estela de Numancia», aparece fotografiada con las anillas dispuestas en diagonal. Parece evidente que el puente inferior se halló separado del resto, con lo que la reconstrucción es hipotética, y como tal debemos tomarla.

${ }^{420}$ Aunque no tiene por qué suponer una contradicción, puesto que el puñal de aristas nace en el último cuarto del s. II a.C. y en último extremo es posible que se trate de una asociación de dos piezas de cronología desigual.

${ }^{421}$ Hallado en Maguncia, Alemania. CIL XIII 6901.

422 Hallado en Padua, Italia. AE 1982, 395.

${ }^{423}$ El primer caso muestra el puñal suspendido horizontalmente del costado derecho. En el segundo caso, — datado ante quem 42 a. C (Este militar perteneció a la Legio Martia, un contingente destruido en 42 a.C.) fecha muy temprana y cercana a la de sus paralelos celtibéricos - el puñal es suspendido de forma completamente horizontal sobre el vientre.

${ }^{424}$ El término no es acuñación nuestra, sino que ya aparece como tal mencionado en Filloy Nieva y Gil Zubillaga, 1997: 148 y nota 11.

${ }^{425}$ Denominamos también de «pontet doble» a este modelo de suspensión en alusión al sistema céltico (fundamentalmente de la Galia, aunque con exportaciones) de suspensión de armas denominado pontet, y definido por un único asa vertical colocado en la parte posterior de la vaina. A través de este asa se cruzaría la correa del cinturón, quedando vaina y cinturón unidas. La similitud entre ambos sistemas nos permite establecer la comparativa nominal. 
paralelos del mundo clásico, fundamentalmente romanos ${ }^{426}$, podemos afirmar que la finalidad de estas piezas rematadas en disco es la de unirse a algún género de correa, probablemente un cinturón $^{427}$. El sistema no resultará especialmente popular, documentándose hasta el momento tan sólo cuatro asociaciones ${ }^{428}$. La cronología del conjunto de estas piezas es muy elevada, rondando la segunda mitad del IV y el III a.C., no sobrepasando el fin del siglo III a.C., por lo que no influirá en modo alguno en la tradición armera romana.

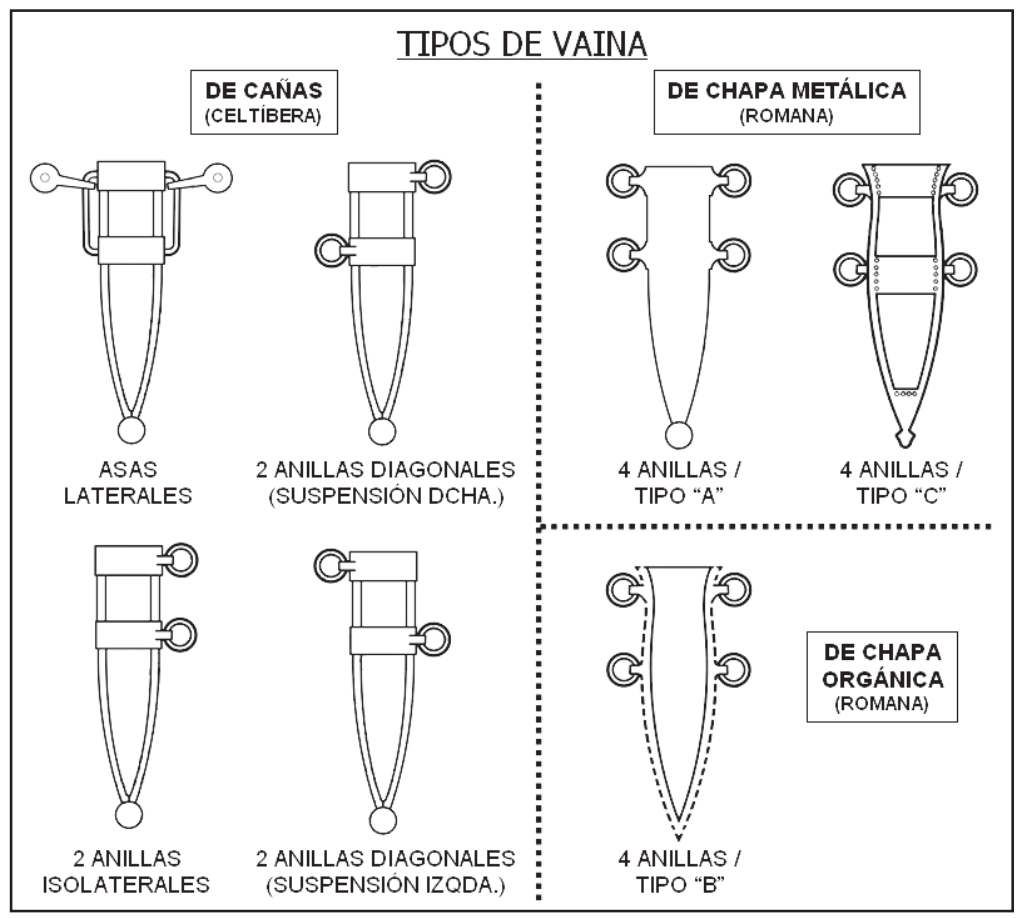

Figura 17. Tipos de vaina asociadas al puñal bidiscoidal.

\section{Vaina de chapa metálica (fig. 17)}

De factura plenamente romana, se define por estar formada por dos chapas metálicas unidas en sus extremos. No requiere, por tanto, de cañas ni puentes como sus homólogos celtibéricos. La suspensión - al igual que en el caso hispano - se soluciona merced a anillas metálicas, pero en número de cuatro y no dos. La unión de éstas con la vaina se sirve de «goznes»,

${ }^{426}$ Caso de los ejemplos iconográficos (ver apartado iconográfico). También documentos arqueológicos como el puñal de Velsen (Holanda), o el tahalí de Herrera de Pisuerga (Palencia).

${ }^{427}$ Si bien aún desconocemos con precisión el modelo seguido, contamos con dos posibles interpretaciones: bien por medio de un remache permanente que atraviesa tanto el correaje como el remate discoide del gancho, con el resultado de afianzar ambas piezas entre sí, o bien siguiendo un sistema cercano al de nuestros modernos botones, de modo que el gancho metálico atraviese un ojal en el correaje para pender de éste.

428 Caso de los ejemplares de Cogotas (tumba 383. Cabré Aguiló, 1932: lám. LXXV, L 75; Cabré Herreros y Morán Cabré, 1991: 341-346; Cabré Aguiló y Cabré Herreros, 1933: 37-47), La Osera (Tumba 321. Museo Arqueológico Nacional, n. ${ }^{\circ}$ inv. 86/81/II/311/4; Baquedano Beltrán, 1980: 285 y fig. 4.) y dos casos de Osma (El primero: Museo Arqueológico Nacional / MAN 245441; Cabré de Morán, 1990: 205-224. fig. 29; García Merino, 2005: 177; el segundo: MAN 1917/54 - 24.547 cartón 13). 
pequeñas piezas metálicas independientes en forma de «U» que se afirman en los laterales de la vaina por medio de remaches, tres por cada gozne. Nótese que los goznes en este caso son piezas independientes, y no prolongación de los puentes como en el caso peninsular. Aún desconocemos la forma exacta en que este sistema de anillas se relacionaba con los correajes ${ }^{429}$.

Dos son los modelos que se definen por esta estructura: tipos $« A »^{430} \mathrm{y}\left\langle\mathrm{C} »^{431}\right.$. La vaina tipo $\langle\mathrm{A}\rangle^{432}$ nace hacia mediados del s. I a.C. y desaparece en tiempos del emperador Claudio, mientras que el tipo «C», representado por los ejemplares de $\operatorname{Londres}^{433}$ (GB), Künzing ${ }^{434}$ (Alemania), Tuchyna ${ }^{435}$ (Eslovaquia), nos remite a época antonina en adelante ${ }^{436}$. Formalmente se distinguen por los calados y contera cilíndrica del tipo «C» en contraste con la chapa predominantemente continua y contera discoide del tipo «A». Son modelos muy comunes en el Limes septentrional, pero muy excepcionales en el ámbito peninsular ${ }^{437}$.

Como decimos el modelo «C» presenta huecos o calados en cada cara, suponemos que con el fin, sin duda estético, de mostrar un segundo nivel, probablemente lígneo - orgánico en cualquier caso - bajo la chapa metálica. Llama la atención, en cualquier caso, la disposición de estos huecos en la chapa que coinciden plenamente con aquellos que presentaban las vainas de cañas celtibéricas, al menos un siglo anteriores. La estructura es por tanto completamente distinta pero exteriormente se asemeja enormemente a los modelos celtíberos en lo que podríamos considerar un sutil arcaísmo estético.

\section{Vaina de chapa orgánica (fig. 17)}

$\mathrm{Al}$ igual que los precedentes, se trata de un modelo genuinamente romano, académicamente denominado «tipo $\mathrm{B} »{ }^{438}$. Se define por una estructura orgánica — probablemente maderaque forma la estructura de la vaina. Sobre una de sus caras se aplica una fina lámina metálica plana, generalmente decorada. La suspensión se soluciona de forma idéntica a los modelos «A» $\mathrm{y}$ «C $»$, mediante cuatro goznes de los que penden cuatro anillas. Señalamos que los remaches destinados a sostener los goznes atraviesan lámina metálica y cuerpo orgánico de la vaina a un tiempo, resultando en una disposición típica de doce agujeros de remache ${ }^{439}$ en la lámina metálica, que nos permite identificar el tipo. La cronología del tipo ha sido establecida entre el reinado de Tiberio y fines del s. I d.C. Sólo conocemos un ejemplar peninsular ${ }^{440}$ en contraste con la gran cantidad de ejemplares limitaneos ${ }^{441}$ del tipo.

${ }^{429}$ Peter Connolly (1997) ha propuesto un sistema por el cual una tira de cuero traspasa sucesivamente las cuatro anillas y se cruza en la cara oculta de la vaina, formando así un aspa de cuero. Entre el aspa y la vaina se introduciría el cinturón, quedando así suspendida la vaina del mismo.

${ }^{430}$ Según Scott, 1985

431 Según terminología propia.

432 Podemos hallar representantes limitaneos de este género de vaina en Alleriot, Francia (Bonnamour y Fernoux, 1969: 178-185), Dangstetten, Alemania (Helmig, 1990: 160, Abb 3, b), Maguncia (Alemania).

${ }^{433}$ Bishop y Coulston, 1993: fig. 95, 1.

${ }^{434}$ Bishop y Coulston, 1993: fig. 95, 7.

435 Kreković, 1994: 211-25 y fig. 7, 13.

${ }^{436}$ El primer caso ha sido datado en fecha no anterior al s. II d.C., los dos siguientes en el s. III d.C.

${ }^{437}$ Sólo conocemos un caso de vaina posiblemente «tipo A» en la P. Ibérica, caso de El Molón (Valencia). Pinta; Rovira i Port; Gómez, 1987-88: 306, fig. 11; Almagro et alii, 1996.

438 «B sheath», Scott, 1985.

$439 \mathrm{O}$ tres agujeros de remache por cada uno de los cuatro goznes destinados a su vez a sostener las cuatro anillas de suspensión.

${ }^{440}$ Cabré Aguiló, 1931: lám. XX, 4.

${ }^{441}$ Leeuwen, Holanda (Feugère, 1994: 164), Nijmegen, Bélgica (Gerhartl-Witteveen y Hubrecht, 1990: 99-107. Vainas de las figs. 9, 10, 11, 12 y 15) entre muchos otros. 


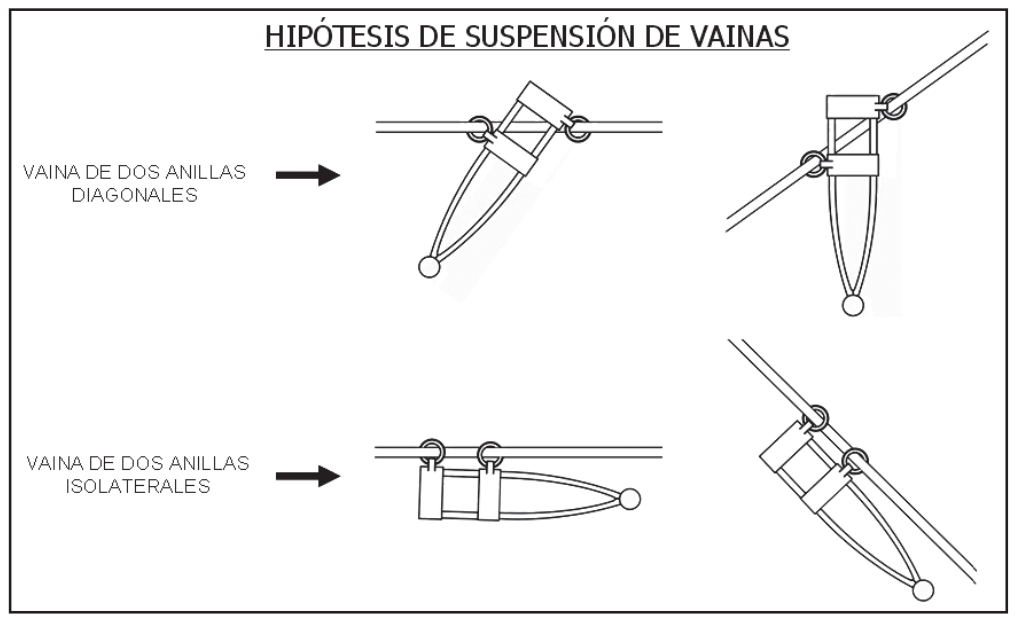

Figura 18. Distintas hipótesis de suspensión de vainas.

\section{DECORACIÓN EN LAS VAINAS}

Dada la exigua superficie sobre la que trabajar, la decoración del conjunto se concentra en los puentes o abrazaderas ${ }^{442}$. Los motivos decorativos aparecen en una sola de las caras de la vaina, dando a entender que sólo existía una posición de suspensión ${ }^{443}$.

La decoración de los puentes es sin excepción transversal al conjunto de la vaina. Destaca especialmente por su predominio un motivo concreto: la batería de líneas paralelas que recorren el puente de uno a otro extremo en sentido transversal a la vaina. Este motivo es con diferencia el más recurrente, $\mathrm{y}$, cuando lo hace, suele presentarse tanto en el puente superior como en el inferior. En el caso de las vainas con puente completo hallamos a menudo motivos decorativos de distinto tipo. Es probable por tanto que estos motivos no sean sino copias en metálico de los motivos que decoraban las vainas semiorgánicas ${ }^{444}$. Dos son los tipos principales de decoración en los puentes completos:

\section{Guilloca $^{445}$}

Únicamente aparece representado en la superficie de los puentes completos de las vainas ${ }^{446}$ y difiere según la parte de la vaina que ocupe: en el espacio entre los dos puentes encontramos guillocas simples (de un nudo, o dos lazos), mientras que en el espacio entre el puente inferior y la contera hallamos guillocas dobles (dos nudos o tres lazos). Posiblemente se trate de una evolución del —algo más simple- motivo de círculos superpuestos. Ejemplos de guilloca

\footnotetext{
442 Podemos especular con que del mismo modo las superficies entre los puentes — cubiertas por materiales orgánicos - fueran objeto de trabajos de decoración, pero no se ha conservado ejemplar alguno.

${ }^{443} \mathrm{Y}$ una de las caras de la vaina quedaba siempre oculta, enfrentada al cuerpo de su usuario. Esto nos permitirá saber en qué lado de la cadera y sentido se suspendía cada género de vaina (ver «Sistemas de suspensión»).

${ }^{444}$ Los puentes completos son sin excepción de bronce, por tanto observamos que los motivos decorativos difieren según la ubicación en la vaina pero también en virtud del tipo de material sobre el que se aplican.

${ }^{445}$ Motivo geométrico formado por una serie de lazos que se entrecruzan sucesivas veces al tiempo que avanzan en una misma dirección, formando así una especie de cuerda holgadamente trenzada y con continuidad longitudinal.

446 Es por esto último por lo que pensamos que se trata de un motivo muy típico pero del que nos han quedado escasas muestras al dibujarse generalmente sobre la madera o cuero que, obviamente, no se ha conservado.
} 
son: Osera ${ }^{447}$ (Soria), Numancia ${ }^{448}$ (Soria), Capote ${ }^{449}$ (Badajoz) y Descontextualizado 3 ; mientras que de círculos superpuestos son: Quintanas de Gormaz ${ }^{450}$ (Soria) y Numancia ${ }^{451}$ (Soria). Las cronologías cruzadas de estos ejemplos sugieren que ambos motivos eran aproximadamente coetáneos.

\section{Escaqueado ${ }^{452}$}

Decoración que, al igual que la Guilloca, aparece únicamente en las vainas con puente completo. Este sistema irá cobrando fuerza a lo largo del tiempo, y llegará a su momento de mayor popularidad durante las dos primeras centurias de nuestra era, ya en contextos puramente romanos. Supone, por tanto, un argumento más, aunque débil, que demuestra el fuerte carácter celtibérico del pugio romano.

\section{Línea eVolutiva de LaS vainas (fig. 19)}

La vaina «de cañas» domina casi en régimen de monopolio la protohistoria peninsular ${ }^{453}$. Sabemos que el puñal de frontón se enfundaba en vainas de cañas y si, como parece indudable, el bidiscoidal no es otra cosa que una evolución de dicho puñal, encontraremos lógico que el prototipo evolucionado mantenga la vaina de su antecesor inmediato en la línea evolutiva.

Desde los orígenes del bidiscoidal encontramos dos subtipos de vaina de cañas conviviendo en coetaneidad, aquel de asas laterales ${ }^{454}$ y las dos variantes del sistema de anillas diagonales ${ }^{455}$. El primero ajusta su cronología a los siglos IV y III a.C. El segundo, más popular, ocupará el periodo entre finales del s. IV hasta el c/era aproximadamente, existiendo incluso algún caso en zona limetana ${ }^{456}$. De la vaina de dos anillas diagonales se desarrollará una variante local celtibérica: la vaina de dos anillas isolaterales, minoritaria y aparentemente exclusiva $^{457}$ del siglo II a.C.

El traslado del bidiscoidal a la cultura romana supondrá un cambio completo en el género de vaina. El bidiscoidal romano y sus variantes se enfundan en vainas ya no de cañas sino de dos chapas unidas por sus bordes y ya no de dos sino de cuatro anillas de suspensión ${ }^{458}$, sistema

447 Tumba 1386. Quesada 1997a: n. ${ }^{\circ}$ cat. 5997; Cabré Herreros y Morán Cabré, 1991: fig. 28; Cabré Herreros y Morán Cabré, 1991: 341-346.

448 Tumba 80. Museo Numantino 95/5/1119/c-80; Jimeno; De la Torre; Berzosa y Martínez, 2005.

${ }^{449}$ CAP91 / LO-1 / Calle Occtal; Quesada, 1997a: n. ${ }^{\circ}$ cat. 5327; Berrocal Rangel, 1993: 366, lám. 17; Berrocal Rangel, 2003: 185-217.

${ }^{450}$ Museo Celtibérico de Soria, n. ${ }^{\circ}$ inv. 1428; Quesada 1997a: n. ${ }^{\circ}$ cat. 4419; Schüle, 1969: taf. 36.2; García Merino, 1973: 31 y ss; Cabré de Morán, 1990: 205-225; Lorrio Alvarado, 1994b: 212-257 y fig. 2.

${ }^{451}$ Schüle, 1969: taf. 166, 2

452 División ajedrezada de la superficie, separando las casillas por alteraciones de la superficie del metal en forma de líneas protuberantes. El espacio entre las líneas tiende a ser cuadrangular, creándose así una división de la vaina en superficies planas, a menudo sin otro tipo de decoración, separadas por elevaciones protuberantes desarrolladas longitudinalmente.

${ }^{453}$ Con excepción de la vaina laténica, en comparación muy minoritaria. Ésta se define por dos láminas unidas en sus extremos o una lámina doblada sobre sí misma.

${ }^{454}$ En virtud de los ejemplos conocidos: Cogotas 1 (tumba 383), Osera 3 (tumba 311), Osma 6 y Osma 9. Los dos últimos pertenecen a la necrópolis de Portuguí (Osma, Soria, antigua Uxama), la más antigua de las pertenecientes a esa ciudad.

${ }_{455}$ Con los ejemplares n. ${ }^{\circ}$ cat. Carratiermes 4, 5 y 7, Ciruelos 1 , Descontextualizado 1 y 6, Numancia 1,2 y 17, Osma 7 y 10, Palencia 2, Quintanas de Gormaz 2, Romazal 1 y Turó del Vent 1.

456 Titelberg 1 (n. ${ }^{\circ} 1$ del catálogo de Scott 1985).

${ }^{457}$ No obstante las estelas funerarias de los soldados Gnaeus Musius y Minucius Lorarius podrían demostrar la pervivencia del tipo en épocas posteriores (cesariana y augustea). Sin embargo no es seguro que representen el tipo exacto que aquí tratamos, pudiéndose tratar de suspensiones por correaje sin necesidad de ayuda de anillas, como sería el caso celtibérico.

${ }^{458}$ Que posiblemente sea influencia peninsular. Ver apartado «Comparación entre vainas celtibérica y romana». 


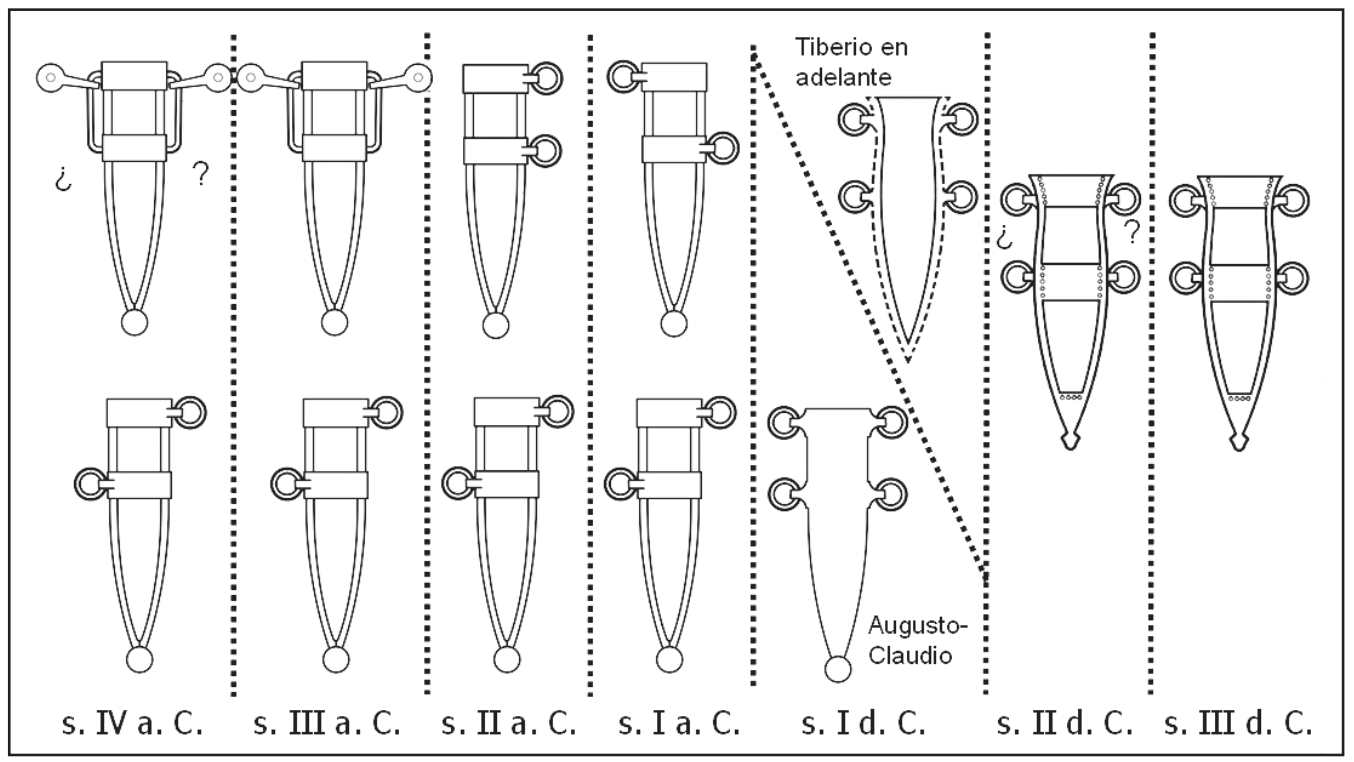

Figura 19. Tipos de vaina por siglos.

este último que ya nunca se abandonará ${ }^{459}$. El primer modelo de este tipo, denominado «Tipo $\mathrm{A} »^{460}$ aparece hacia mediados del s. I a.C. o poco después y pervivirá hasta el reinado de Claudio. Convivirá por breve periodo con la vaina «tipo $\mathrm{B} »{ }^{461}$, eminentemente orgánica ${ }^{462}$ (entre Tiberio ${ }^{463}$ y fines s. I). Por último, hacia época trajanea aparece un nuevo género de vaina romana que podríamos denominar «Tipo $\mathrm{C} »^{464}$ que acompaña al pugio hasta su ocaso a fines del III d.C.

Resumimos los datos arriba citados en una tabla crono-tipológica de vainas (por siglos):

\begin{tabular}{|c|c|c|c|c|c|c|}
\hline & IV & III & II & I & II & III \\
\hline $\begin{array}{r}2 \text { anillas } \\
\text { diagonales }\end{array}$ & & & & & & \\
\hline $\begin{array}{r}2 \text { anillas } \\
\text { Isolaterales }\end{array}$ & & & & & & \\
\hline $\begin{array}{r}\text { Asas } \\
\text { Laterales }\end{array}$ & & & & & & \\
\hline $\begin{array}{l}4 \text { anillas } \\
\text { (Tipo A) }\end{array}$ & & & & & & \\
\hline $\begin{array}{l}4 \text { anillas } \\
\text { (Tipo B) }\end{array}$ & & & & & & \\
\hline $\begin{array}{l}4 \text { anillas } \\
\text { (Tipo C) }\end{array}$ & & & & & & \\
\hline
\end{tabular}

${ }^{459}$ Los últimos ejemplares de bidiscoidal conocidos (modelo de pezuña) aún conservaban una vaina de cuatro anillas en el momento de desaparecer, cosa que sucede hacia el ocaso del s. III d.C.

460 «A sheath», Scott, 1985.

461 «B sheath», Scott, 1985.

${ }^{462}$ Fabricada en madera o cuero y cubierta por la cara vista con una fina lámina metálica que la decora.

463 Cronología propuesta por Scott, 1985: 166.

464 Denominación propia para distinguirlo de los modelos anteriores. 


\section{COMPARACIÓN DE VAINAS CELTIBÉRICAS Y ROMANAS}

Las vainas celtibérica y romana comparten dos elementos principales: la suspensión por medio de anillas y la contera discoide. Pero se distinguen claramente en su estructura: en el caso peninsular la pieza principal de la vaina son las cañas laterales. El resto de piezas sólo sirven para mantener las cañas unidas (caso de los puentes) o para sostener el conjunto (caso de los goznes y anillas). En el caso romano, por el contrario, la vaina se forma por unión de dos chapas (delantera y trasera) unidas por los bordes o bien una única chapa doblada sobre sí misma $^{465}$. Esta es la razón por la que los puentes - cuyo fin era mantener unidas las cañas - se vuelven innecesarios al no existir éstas. En su lugar las vainas romanas presentan una chapa completa, carente por tanto del «esqueleto» que suponían las cañas laterales. Las anillas de suspensión en los casos celtibéricos penden de prolongaciones de las abrazaderas en forma de gozne. En el caso romano, al no existir la abrazadera, las anillas se sostienen de una pieza independiente (gozne) que une anillas con el cuerpo de la vaina. Creemos que tanto uno como otro modelo contenían un forro interior de algún material orgánico, cuero o madera, que separaba la vaina del arma.

Las vainas romanas en su mayoría adoptan la silueta pistiliforme del arma que contienen, característica que no comparten sus homólogos peninsulares. Es por tanto éste uno de los elementos definitivos a la hora de determinar la adscripción cultural de una vaina, y por lo tanto útil también para aproximar su cronología. Se trata en suma de dos construcciones muy distintas que sólo comparten la contera discoide y un mismo sistema de suspensión por anillas, aunque en distinto número (dos en el caso celtibérico ${ }^{466}$, cuatro en el romano ${ }^{467}$ ).

La aparición de la vaina de chapa metálica podría representar una técnica mixta de tendencias peninsulares y galas. La técnica de elaborar una vaina únicamente con dos láminas metálicas, prescindiendo del «esqueleto» que unas cañas laterales suponen, es un sistema típicamente galo ${ }^{468}$; mientras que la suspensión por anillas es sistema casi exclusivo del mundo celtíbero $^{469}$. Es por tanto posible que los herreros romanos aunaran soluciones técnicas de ambos mundos - la estructura gala y la suspensión celtibérica - para el diseño de sus vainas.

\section{SÍNTESIS: LAS PECULIARIDADES MORFOLÓGICAS DE LOS PUÑALES ROMANOS FRENTE A LOS CELTIBÉRICOS}

\section{ELEMENTOS DE DIFERENCIACIÓN}

A. El puñal romano (pugio) se documenta arqueológicamente a partir de un momento muy posterior a la aparición del bidiscoidal, e igualmente perdurará hasta un momento muy posterior. El bidiscoidal peninsular se documenta posiblemente a partir de fines del s. IV a.C., con seguridad desde el s. III a.C., y perdurará hasta el cambio de era. A partir de ese momento los puñales peninsulares, muy escasos, seguirán patrones roma-

\footnotetext{
465 Posiblemente se trate de una influencia de las vainas laténicas propias del mundo celta galo.

466 A excepción del enigmático caso de El Molón (Valencia), aún no interpretado con seguridad.

467 Salvo el caso excepcional de Titelberg (Luxemburgo), que creemos factura hispana.

${ }^{468}$ Dado que los primeros ejemplares conocidos proceden de la segunda mitad del s. I a.C., podrían ser consecuencia del gran momento de comunicación entre las armas galas y romanas, i. e. la conquista de las Galias por César.

${ }^{469}$ Los celtas galos hacían uso del pontet [del fr. Pontet (puente), gozne soldado a la vaina generalmente por su cara posterior. A través de este gozne se pasaba el cinturón o algún otro género de correaje para facilitar su suspensión], los griegos de cintas de cuero anudadas, y en último extremo anillas solidarias con la estructura de la vaina. Pero ninguno de esos modelos guarda tanto parecido con el romano como el celtibérico.
} 
nos y no propios. Por su parte, el puñal romano aparece como verdadera pieza indispensable de la panoplia militar desde mediados-finales del I a.C. ${ }^{470}$, para desaparecer a fines del III d.C.

B. El bidiscoidal celtíbero se reduce al área peninsular, con preferencia por el área celtibérica o vettona, mientras que el pugio romano se distribuye a lo largo de todo el Imperio, con preferencia por el Limes renano o danubiano.

C. La hoja del pugio romano presenta dimensiones superiores a las del puñal peninsular, tanto longitudinal como transversalmente. La longitud media del bidiscoidal peninsular es de $18,18 \mathrm{~cm}^{471}$, mientras que la del pugio romano es de $22,05 \mathrm{~cm}^{472} \mathrm{La}$ anchura también es algo superior en el caso romano.

D. La hoja del pugio romano es casi inevitablemente pistiliforme, mientras que la del bidiscoidal bascula casi al 50\% entre la hoja pistiliforme ${ }^{473}$ y la de base dilatada ${ }^{474}$, con algunos ejemplares minoritarios de tipo triangular o de filos paralelos. En el caso romano la práctica mayoría de los ejemplares presentan una hoja marcadamente pistiliforme, habiendo también una minoría de hojas triangulares, curiosamente concentradas preferentemente en las islas británicas.

E. Las empuñaduras peninsulares siguen por lo común diseños ligeramente distintos a sus homólogos romanos. Incluso en los casos más cercanos, se pueden apreciar pequeñas diferencias. Los modelos más cercanos son sin duda el modelo de $\operatorname{aristas}^{475}$, peninsular, y el semidisco ${ }^{476}$ e híbrido disco-semidisco ${ }^{477}$ por parte romana. El modelo de aristas surge hacia fines del s. II a.C., mientras que los otros dos hacia fines del s. I a. C, momento en el que por breve periodo de tiempo, los tres modelos convivirán. El híbrido disco-semidisco, romano, se distingue del modelo de aristas peninsular en que presenta un corte y tres remaches en el extremo distal del pomo, haciéndolo ligeramente más corto. El modelo de semidisco presenta ese mismo corte pero mucho más avanzado, llegando a alcanzar el eje del pomo, por lo que éste deja de ser un disco para convertirse en semidisco, dando así nombre al tipo. El resto de elementos (forma discoide del pomo, nudo central discoide, arriaz tipo B, abatido y longitud interna de aristas) son compartidos por los tres modelos, pero las leves diferencias en el pomo ya referidas hacen de ellos tres modelos fácilmente diferenciables, siempre que las condiciones de conservación sean perfectas. El resto de empuñaduras, tanto peninsulares como romanas, son diferenciables con mucha mayor claridad. Pertenecen al mundo indígena peninsular las empuñaduras:

- De Pletina Plana.

- De Discos Concéntricos.

- De Pomo Globular.

- De Aristas.

${ }^{470}$ Ya existen ejemplares de puñal en contexto romano desde momentos anteriores, pero con la sospecha de que su factura es indigena, no romana. Sólo a partir de fines del I a.C. será cuando el puñal aparece como una pieza popularizada, claramente documentada en todas las latitudes del Imperio Romano.

471 Ver apartado «Dimensiones de Hoja».

${ }^{472}$ Sobre 38 ejemplares limetaneos analizados.

473 Ver apartado «Hoja pistiliforme».

${ }^{474}$ Ver apartado «Hoja de base dilatada».

475 Ver apartado «Empuñadura de aristas».

476 Ver apartado «Empuñadura de semidisco».

477 Ver apartado «Empuñadura híbrido disco-semidisco». 
- Calada.

- Cúbica ${ }^{478}$.

- Creciente Lunar ${ }^{479}$.

Por su parte pertenecen al mundo romano las empuñaduras:

- De Semidisco.

- Híbrido Disco-Semidisco.

- De Pezuña (o tipo Künzing).

F. La hoja del bidiscoidal peninsular presenta casi sin excepción nervio central y siempre singular. En el caso romano, el nervio central también es la norma, pero a menudo multiplicado por dos o tres veces en cada hoja de puñal.

G. Posiblemente hacia principios del II d.C., con seguridad ya en el s. III d.C., los puñales romanos adoptan un modelo de arriaz bastante distinto al peninsular y claramente distinguible de éste. Se trata del modelo «C» o de «T invertida», que presenta gavilanes estrechos, alargados y completamente rectos ${ }^{480}$.

H. Los puñales prerromanos se hallan por lo general en contextos de poblado fortificado (castro) o necrópolis, fundamentalmente en contexto y territorio celtíbero o vettón y generalmente en lugares de difícil acceso, a menudo serrano y de gran altitud. Por su parte, los puñales romanos se encuentran en contexto castramental o urbano, y con tendencia a aparecer en planicies o territorios de poca altitud, posiblemente en consonancia con el revolucionario modelo de hábitat romano, con preferencia por las zonas en 11 ano ${ }^{481}$.

I. El modelo de vaina asociada al bidiscoidal peninsular será aquel de cañas laterales ${ }^{482}$ mientras que su homólogo romano seguirá una estructura completamente distinta, bien de dos chapas metálicas unidas por sus bordes o de estructura orgánica. Asimismo, la suspensión por asas o por dos anillas propia de los ejemplares peninsulares se sustituye por suspensión por cuatro anillas en el caso romano.

J. La vaina romana cobrará desde sus primeros modelos una silueta marcadamente pistiliforme ${ }^{483}$, al contrario que en el caso peninsular, donde las cañas laterales son, sin excepción, verticales y rectilíneas. En el caso romano, al contrario, la norma son las vainas con perfil, silueta, pistiliforme ${ }^{484}$.

K. Entre las representaciones iconográficas ${ }^{485}$ plenamente romanas aparecen varios modelos de puñal no correspondientes con la definición de «bidiscoidal» que deben pertenecer a modelos aún no identificados. Lo extraño de este hecho es que arqueológicamente no se documenta ningún otro tipo de puñal que no sea de la familia de los bidiscoidales $^{486}$. Por tanto es posible que el legionario romano hiciera uso de otros

\footnotetext{
478 Se trata de una evolución peninsular de una factura romana, la empuñadura de Semidisco.

479 Según creemos se trata de una variante peninsular de un modelo romano, la empuñadura de «Pezuña».

480 Ver apartado «Evolución de los arriaces».

481 Ver mapas de dispersión.

482 Ver apartado «Generalidades de las Vainas».

483 Ver apartado «Evolución de las vainas».

484 «Waisted sheath» en terminología anglosajona.

485 Ver apartado «Iconografía».

486 A excepción del puñal de espiga y empuñadura orgánica, ya mencionado.
} 
modelos de puñal no pertenecientes al tipo bidiscoidal, aunque la ausencia de sanción arqueológica nos impide pronunciarnos al respecto.

Hasta aquí los principales elementos diferenciadores entre los puñales bidiscoidal peninsular y puñal militar romano. A continuación presentamos el análisis inverso, incidiendo sobre los puntos de unión entre ambos conjuntos de armas:

\section{ELEMENTOS COMUNES}

A. Posiblemente el primero y, cuantitativamente, más importante de todos los modelos de empuñadura romana, aquella denominada de «Semidisco» ${ }^{487}$, así como su muy cercana variante «híbrido disco-semidisco», son modelos prácticamente idénticos al último de los modelos de bidiscoidal peninsular, el llamado modelo «de aristas» ${ }^{48}$. La similitud es casi absoluta. Los elementos de coincidencia plena son el nudo central discoidal, la estructura «de aristas» del conjunto, la forma discoidal del pomo, y el arriaz abatido (tipo «B») $)^{489}$. Lo único que los separa es un leve recorte en la esferidad del pomo que hace que los modelos híbrido disco-semidisco y semidisco presenten un pomo recortado en su extremo distal. Salvo ese pequeño detalle, los tres modelos son prácticamente idénticos y, en virtud del estado de conservación, podrían confundirse con facilidad.

B. La estructura interna de la empuñadura y sistema de sujeción de la hoja a la empuñadura es idéntico tanto en el caso peninsular como en el romano. La empuñadura se forma por un alma de espiga solidario a la hoja del arma. Ésta se cubre por dos láminas orgánicas (madera o hueso) que a su vez son cubiertas por el exterior por dos pletinas metálicas (de bronce o hierro). A su vez, todo el conjunto se afianza por medio de un conjunto de entre dos y siete remaches estratégicamente dispuestos a lo largo de la empuñadura. Por tanto la técnica de factura de ambas armas es idéntica.

C. Las hojas de los puñales romanos tienden a la pistiliformidad. En el caso prerromano, las hojas pistiliformes suponen cerca de un $50 \%$ del total. Es por tanto posible que la pistiliformidad de las armas romanas sea también una influencia celtibérica.

D. La técnica de suspensión de vainas a base de anillas laterales es, al igual que la vaina de cañas, un producto de inventiva celtibérica. Será el sistema de suspensión de las vainas de los bidiscoidales celtibéricos, así como de todo otro tipo de armas. Y este mismo sistema será el que vemos utilizado por los primeros pugiones romanos hacia fines del s. I a.C. y en adelante. El sistema de suspensión por anillas laterales nunca será abandonado por Roma, que lo seguirá utilizando en exclusiva como medio de suspensión tanto de espadas como de puñales militares hasta el fin del uso de estos últimos ${ }^{490}$.

E. El arriaz utilizado por los primeros pugiones romanos, allá a finales del I a.C. y a lo largo de todo el s. I d.C. es sencillamente idéntico al arriaz del bidiscoidal peninsular. Se trata del modelo «B» o arriaz abatido ${ }^{491}$. Más tarde, los artesanos romanos desarrollarán una

\footnotetext{
487 Ver apartado «Empuñadura de Semidisco».

488 Ver apartado «Empuñadura de Aristas».

489 Ver apartado «Evolución de los Arriaces».

490 El puñal militar romano (pugio) se abandona hacia finales del s. III d.C.

491 Ver apartado «Evolución de los Arriaces».
} 
evolución del mismo que guardará ciertas diferencias ${ }^{492}$, pero como mínimo hasta el reinado de Trajano la semejanza entre los arriaces celtibéricos y romanos es total.

F. La decoración de vainas, pero fundamentalmente de empuñaduras, tanto de los ejemplares peninsulares como romanos, es extremadamente similar, y en algunos casos sencillamente idéntica ${ }^{493}$. Determinados motivos decorativos, tales como el damasquinado en Celosía o en Zig-Zag ${ }^{494}$, a lo largo de la longitud interna de la empuñadura o el perímetro del pomo, son recurrentes tanto entre los pugiones como entre los bidiscoidales. También otros motivos, destacadamente los radios y discos concéntricos en el pomo, son igualmente compartidos por ambos grupos de armas.

Una vez analizado el verdadero peso de los elementos de diferenciación, así como los elementos comunes a ambas armas, estamos en condiciones de juzgar si las semejanzas obedecen a la casualidad, o por el contrario son el producto de una estrecha relación evolutiva en la que el bidiscoidal peninsular ocuparía la posición de eslabón inicial en el que teóricamente se inspiraría, evolucionaría y sería variante el pugio romano.

\section{PARTE III: CONCLUSIONES}

\section{CONCLUSIONES}

El argumento principal para defender un origen hispano para el pugio romano es la sencilla razón de que puñales virtualmente idénticos al pugio altoimperial ya existían en la meseta castellana en fechas tan tempranas como el siglo III a.C., y en un contexto indígena. En ninguna otra latitud del orbe romano encontramos modelos ni siquiera parecidos hasta fechas muy posteriores. Asimismo, creemos haber sido capaces de rastrear grosso modo la línea evolutiva seguida por ambos conjuntos de piezas (puñales peninsulares y romanos), y salvo error grave por nuestra parte, estas líneas coinciden perfectamente en torno a finales del s. I a.C.

Ya hemos visto cómo toda una serie de características técnicas y morfológicas son compartidas tanto por armas de clarísima adscripción cultural prerromana, como por otras halladas en contextos puramente romanos y casi siempre posteriores, como son los limetanos. Prácticamente no hay un solo detalle o una sola variante de empuñadura, hoja o vaina romana que no encuentre ejemplos similares o sencillamente idénticos en la P. Ibérica. Es más, hemos descubierto que aquellas versiones o variaciones del modelo básico más comunes en la Península, lo son también en el resto del imperio en épocas posteriores, y viceversa. Hemos visto, también, cómo en algunos $\operatorname{casos}^{495}$ los paralelismos son tan acusados que resulta prácticamente imposible distinguir el arma indígena de la romana, a pesar de sus distantes cronologías, siempre más tempranas en el caso peninsular.

También hemos podido constatar que la relación histórica entre las armas celtibéricas, de las cuales el bidiscoidal es parte, y los legionarios romanos, fue muy estrecha. Esta relación no se reducía al contacto con el enemigo en el «campo de Marte»; las fuentes documentales hacen referencia a la numerosísima presencia de soldados indígenas en los ejércitos romanos a modo de auxilia, combatiendo con su propio armamento. No sería de extrañar, por tanto,

\footnotetext{
492 Modelo de arriaz «tipo C» o «de T invertida».

493 Ver apartados «Decoración en las Empuñaduras» y «Decoración en las Vainas».

494 Ver apartado «Decoración en las Empuñaduras» y «Glosario».

495 Caso paradigmático el de los puñales de la Osera tumba 1387 y Oberaden.
} 
que los legionarios romanos, en un periodo previo a la estandarización de la panoplia, hicieran comercio de armas con las secciones de indígenas que encontrarían dentro de su mismo campamento. La presencia de bidiscoidales en los campamentos romanos queda por tanto bajo esta luz explicada.

Parece por tanto a todas luces evidente que el origen del pugio romano se encuentra en el bidiscoidal celtibérico. No obstante hemos de admitir que las cronologías aportadas para cada tipo son en muchos casos poco firmes, dado que éstas se han otorgado en virtud de materiales asociados o por extensión de la cronología genérica del yacimiento. Aún quedan, por tanto, dudas que responder. No conocemos todos los eslabones de la evolución pues hay hiatos temporales de los que no contamos —o no hemos sabido ver - ejemplos de puñal bidiscoidal o pugio. Concretamente la escasez de datos sobre la segunda mitad del siglo I a.C. nos resulta especialmente dolorosa, por tratarse precisamente del contexto transicional entre un periodo en el que Roma no parece haber hecho otra cosa que imitar fielmente el puñal indígena (quizá

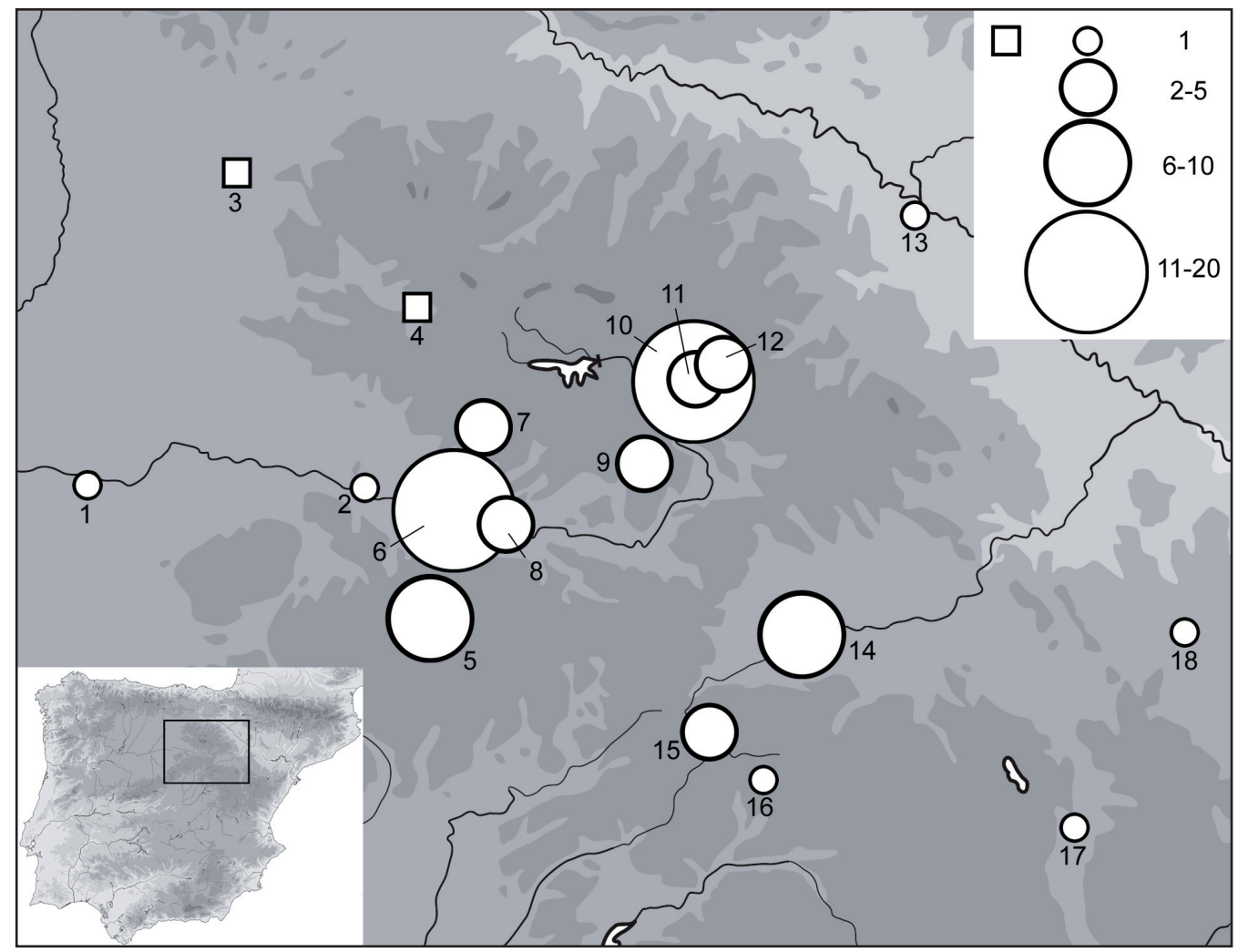

Figura 20. Mapa que muestra el área nuclear celtibérica, que coincide con la mayor concentración de hallazgos de bidiscoidal de la Península. En círculo los puñales prerromanos, en cuadrado los augusteos y posteriores: 1. Necrop. de Las Ruedas (Padilla de Duero, Valladolid); 2. Langa de Duero (Soria); 3. Sotopalacios (Burgos); 4. Cuesta del Burro (Castrillo de la Reina, Burgos); 5. Necrop. de Carratiermes (Soria); 6. Uxama (Osma, Soria); 7. Necrop. de Ucero (Soria); 8. Quintanas de Gormaz (Soria); 9. Izana (Soria); 10. Numancia (Soria); 11. Cmpto. Castillejo (Soria); 12. Cmpto. Renieblas (Soria); 13. La Azucarera (Alfaro, La Rioja); 14. Arcóbriga (Monreal de Ariza, Zaragoza); 15. Aguilar de Anguita (Guadalajara); 16. Ciruelos (Guadalajara); 17. La Caridad (Caminreal, Teruel); 18. Castellares de Herrera (Zaragoza). 
incluso se limitara a la compra del mismo), y otro periodo, altoimperial, en el que asistimos al resurgir de la factura de este peculiar arma, ya de manos de artesanos romanos.

En cualquier caso, concluimos con la certeza de que los argumentos históricos, iconográficos y sobre todo arqueológico-formales son suficientes para afirmar el origen peninsular, y concretamente bidiscoidal, del pugio romano.

\section{DISPERSIÓN GEOGRÁFICA}

En el mapa de dispersión de puñales (figs. 2 y 20) observamos un interesante fenómeno que creemos permite refrendar nuestras teorías. Los puñales más antiguos, correspondientes con las modalidades de empuñadura de pletina plana, discos concéntricos y empuñadura calada se concentran en las dos áreas nucleares, celtibérica ${ }^{496}$ y vettona, con la particularidad curiosa de no descender nunca al llano. Los casos intermedios de empuñadura de aristas se desarrollan por un espacio algo más amplio mientras que los puñales tardíos (de semidisco, creciente lunar y pezuña) se observa que su espacio de difusión es mucho más dilatado y flexible, sobrepasando ya los límites celtibéricos y vettones para aparecer tanto en el ámbito extrapeninsular como en cualquier punto de la P. I. De ello se deduce que el bidiscoidal es una factura celtibérica ${ }^{497}$, muy tempranamente adoptada por los pueblos vettones (c. principios $\mathrm{s}$. III a.C.), exportada - con toda probabilidad de mano de los ejércitos romanos- al resto de la península a finales del II a.C. y al resto del Imperio hacia el cambio de era. En cuanto a los ejemplares del resto del Imperio, éstos se ubican preferentemente en el Limes ${ }^{498}$ septentrional del Imperio, concretamente en las fronteras renana, danubiana, y britana, en coincidencia no casual con las mayores concentraciones de tropas de época imperial.

\section{UTILIDAD}

Son muchas las teorías que se han desarrollado a tenor de la pregunta que suscita este apartado. Procederemos a enumerarlas clasificándolas según el arma al que aluden:

\section{BIDISCOIDAL PENINSULAR}

La rica decoración presentada por algunos ejemplares concretos, caso de los puñales de La Osera ${ }^{499}$, Monte Cildá, Las Cogotas ${ }^{500}$, Torre de Palma ${ }^{501}$, y algunos casos descontextualizados $^{502}$ sugiere un valor del puñal como objeto de representación prestigio. No sería el primer caso de este tipo, pues otros modelos de puñal meseteño, caso paradigmático del célebre puñal

\footnotetext{
${ }^{496}$ Fundamentalmente Alto Duero.

${ }^{497}$ Sabemos también que el predecesor del Bidiscoidal, el puñal «híbrido de frontón-bidiscoidal», fue una variación celtibérica del puñal de frontón meridional. Por tanto es probable que el modelo bidiscoidal fuera también una creación celtibérica.

498 O límite físico del Imperio, v.g. fronteras del mismo.

${ }^{499}$ Caso del puñal de La Osera

500 (Ávila), tumba 383. Quesada 1997a: n. ${ }^{\circ}$ cat. 4654; Cabré Aguiló, 1932: lám. LXXV, L 75.

501 En este caso el arriaz presenta un aplique de oro en el extremo de uno de los gavilanes, si bien es probable que en origen la lámina cubriera el arriaz entero o puede que incluso toda la empuñadura. Puñal de Torre de Palma, Villa de Basilii, tardorromana; Museu Arqueologico Nacional (Portugal), n. ${ }^{\circ}$ inv. 2001.5.9

502 Señaladamente el ejemplar del Römisch-Germanischen Zentralmuseum, Mainz, n. ${ }^{\circ}$ inv. O.40559 y O.40504; Egg, 1986: 906.
} 
denominado «Montebernorio» o «Miraveche», han sido, con toda justicia, considerados como objetos de valor práctico nulo ${ }^{503}$ y más que probable valor de representación.

Conocemos multitud de sociedades en las que las armas han sido consideradas símbolo de la libertad para quien las posee, una analogía, por otra parte, perfectamente coherente. Tal fue el caso en el occidente medieval, y, más recientemente y de forma paradigmática, en el moderno Yemen o entre las comunidades Sikh de la India y Pakistán. Es posible por tanto que algo similar ocurriese en el contexto prerromano peninsular. Esta teoría tiene a su favor no sólo la rica decoración que presentan algunas armas sino el hecho de que muchas de ellas se han hallado formando parte del ajuar funerario, hecho sólo comprensible bajo la premisa del fuerte valor simbólico del arma. Por tanto es probable que, independientemente de su valor militar, el puñal contuviera algún género de valor simbólico que lo relacionara posiblemente con alguna casta social. Es evidente que no se puede tratar de un símbolo de élite, puesto que son demasiado numerosos los ejemplares hallados, demasiados para reducirse a la élite de la sociedad. Pero sí puede tratarse de un símbolo adscriptivo del grupo de los ciudadanos libres, tal y como ocurría con el anillo de hierro en Roma.

Según Fernández Gómez ${ }^{504}$ los bidiscoidales hallados en El Raso (Candeleda, Ávila) obedecen a un uso cinegético y no bélico. Aunque mantenemos abierta la posibilidad, dudamos de que se trate del uso principal de este objeto.

Es posible que la realidad fuera tan heterogénea como las versiones de la misma aquí mentadas. No obstante, debemos recordar que las fuentes literarias mencionan recurrentemente el valor militar del puñal (no sabemos si en alusión concreta al bidiscoidal, pero es posible que sí) como arma específicamente militar usada tanto por íberos como por celtíberos y lusitanos. No debemos olvidar que en el contexto de una batalla un arma corta podría servir tanto como arma secundaria en el caso de perder la primera, como sucedáneo de escudo esgrimida con la mano izquierda ${ }^{505}$, y sobre todo esto, en la circunstancia de una mêlée $e^{506}$ muy cerrada, tal vez ser incluso más útil que una espada, digamos por ejemplo laténica, cuyas dimensiones la habrían hecho inmanejable en el reducido espacio entre compañeros y enemigos. Recordemos que el puñal que aquí tratamos no tiene unas dimensiones que podamos considerar demasiado reducidas, siendo la media de hoja de $18 \mathrm{~cm}$ de longitud. Tanto es el caso que en algunos extremos ha sido confundido por algún autor como espada. Por tanto sus dimensiones la hacen viable como arma corta. A modo de sanción de esta teoría, consideramos que el hecho de que sean precisamente los militares romanos, y no la población civil, quienes eventualmente adopten el puñal indígena, lo que sugiere que éste también tenía una consideración castrense en el mundo indígena.

Por todo ello concluimos que, aunque viable para otros usos civiles, el puñal bidiscoidal peninsular debía tener un doble valor, simbólico, adscriptivo de su poseedor a algún grupo social, posiblemente al de la mera ciudadanía ${ }^{507}$, al tiempo que, como indican las fuentes, servía como arma - secundaria pero efectiva - en combate cuerpo a cuerpo.

${ }^{503}$ A tenor de lo reducido de las dimensiones de la hoja en contraste con los desproporcionadamente voluminosos arriaz y vaina.

${ }^{504}$ Fernández Gómez, 2001: 299.

${ }^{505}$ Esta opción nos parece poco probable, pues si bien hay ejemplos históricos del uso de un puñal como escudo (p. ej. la mítica vizcaína), en esos casos el puñal siempre contaba con voluminosos gavilanes o arriaces que sirvieran de tope a la espada contraria. En el caso del bidiscoidal, el arriaz es mínimo y completamente incapaz de parar un golpe de espada.

${ }_{506}$ Mêlée: vocablo de origen galo que alude al combate cuerpo a cuerpo entre dos masas de guerreros.

507 Recordemos que en muchas cultura de la Antigüedad era preciso pertenecer al contingente militar para poder ser considerado ciudadano. 


\section{Pugio Romano}

En cuanto al puñal romano (pugio) no hay duda de que se trata de un elemento adscriptivo de su portador a la condición de militar. Tanto es así que la misma palabra pugio aludía para los latinos al mundo castrense. Por tanto la relación del pugio con el mundo militar romano es innegable. No obstante, también se ha suscitado la duda acerca de su verdadera función práctica dentro del mundo militar, puesto que las fuentes no se pronuncian al respecto.

M. Feugère ${ }^{508}$ defiende que el puñal romano tiene un valor simbólico, y no funcional, apoyándose en que el tipo o modelo no evolucionó prácticamente nada a lo largo del periodo desde su eventual adopción (ss. II o I a.C.) hasta el fin de uso del arma (hacia fines del s. III d.C.), así como por la rica decoración que cubre estas armas, tanto en la empuñadura como sobre todo en la vaina, sugiriendo un distanciamiento del cualquier uso práctico. También se ha sugerido que se trate de un arma «multi-uso» a modo de la celebérrima navaja reglamentaria del ejército suizo moderno, más conocida como «navaja suiza». Según esta teoría el pugio tendría poco valor militar, y más valor como herramienta para todo tipo de heterogéneos usos. No obstante otros autores han contestado y criticado esta teoría con dureza, destacadamente los británicos Bishop y Coulston ${ }^{509}$ quienes defienden que el puñal romano era un arma «formidable» y que «no debe compararse con la navaja del Boy-Scout». El enorme tamaño del pugio romano (con una media de hoja de $22,05 \mathrm{~cm}^{510}$ ), superior al bidiscoidal celtibérico (18 $\mathrm{cm}$ de longitud de hoja), es uno de los argumentos más poderosos a favor de su valor militar.

Según nuestra opinión, el pugio romano es sin duda alguna un arma útil en combate, a modo de arma secundaria o de emergencia; como revela su voluminoso tamaño. Esto no es óbice para que tanto la vaina como la empuñadura presenten ricos motivos decorativos, damasquinados y demás. Debemos recordar que para un militar altoimperial, sin posibilidad legal de contraer matrimonio ni formar familia ${ }^{511}$, el ejército absorbería todas las facetas de su existencia. Creemos por tanto verosímil que un legionario, enfrentado a la perspectiva de vestir durante años con un mismo arma al cinto, se viera tentado a decorarla e individualizarla del resto. Pero no por ello habría de mermar su valor práctico.

No creemos que se trate de una herramienta multiuso por tres razones: primero, porque su gran tamaño la hace inútil para cualquier otra labor que no sea la militar; segundo porque en los campamentos romanos se han hallado multitud de objetos metálicos y cuchillos mucho más aptos para fines civiles; y en tercer lugar, porque el pugio tenía para los antiguos romanos un contenido militar simbólico muy fuerte, que no hubiera tenido de haberse tratado de una simple herramienta.

Concluimos por tanto defendiendo que ambas armas, celtibérica y romana, comparten un doble valor práctico y simbólico, con la diferencia de que en el caso celtibérico la alusión simbólica podría ser a un grupo social relativamente amplio (acaso el de los hombres libres) mientras que en el romano alude a la adscripción militar de su posesor.

\section{MOMENTO DE LA ADOPCIÓN ROMANA DEL PUÑAL (figs. 21 y 22)}

Una vez demostrada la filiación entre las armas celtíbera y romana, queda por establecer el momento en que Roma adopta el modelo. Sabemos que el contacto se produjo en un momento

\footnotetext{
508 Feugère, 2002: 163.

${ }^{509}$ Bishop y Coulston, 1993: 76.

510 Sobre 38 ejemplares limetaneos analizados.

511 A excepción de las célebres focale o amancebadas. No será hasta el reinado de Septimio Severo cuando se permita a los militares contraer matrimonio.
} 
muy temprano, puede que de mano de los mercenarios celtíberos de Aníbal ${ }^{512}$ o más probablemente a partir de las campañas romanas sobre Celtiberia, aquellas que el cónsul M. Porcio Catón inaugurara en el 195 a.C.

Sabemos también que en los campamentos romanos de Castillejo y La Atalaya de Renieblas, el primero frente a Numancia, el segundo a escasos cuatro kilómetros, encontramos bidiscoidales, aunque es posible que en ambos casos pertenecieran a auxiliares indígenas. En el caso de La Atalaya de Renieblas podrían incluso datarse a principios del siglo II a.C. ${ }^{513}$.

También encontramos ejemplares en el Campamento de Cáceres el Viejo, de época sertoriana $^{514}$, y en el depósito de La Azucarera, cuya discutida cronología se sitúa entre fines del s. II y principios del I a.C. Por último, en el campamento de la Legio IIII Macedonica en Herrera de Pisuerga ${ }^{515}$ hallamos dos claros ejemplares de bidiscoidal que hemos de situar entre los años 15-20 a.C. y 39 d.C., fechas correspondientes a la ocupación del campamento.

Entendemos que la permeabilidad de la panoplia romana debió ser mucho más acusada en los tiempos en que el legionario se armaba de su propio peculio, i. e., antes de la profesionalización del ejército que el cónsul Cayo Mario llevó a cabo aproximadamente entre los años 107 y 100 a.C. Además podemos aducir que, con excepción de las Guerras Sertorianas, la gran mayoría de las campañas militares sobre Celtiberia datan de un periodo anterior al año 100 a.C. En virtud de estos argumentos parece más probable que fuera antes de esta fecha cuando se produjera la adopción del puñal.

A continuación enumeramos los indicios que podrían permitirnos establecer una datación del momento preciso en que el arma fue adoptada por parte de los ejércitos romanos. Todos ellos son hallazgos tempranos de bidiscoidales efectuados en contextos de probada conexión con la cultura romana: (figs. 21 y 22)
A. Empuñaduras de puñal del Campamento de Renieblas ${ }^{516}$, Soria $\left(195^{517}-133\right.$ a.C.)
B. Bidiscoidales (4x) del campamento de Castillejo ${ }^{518}$, Soria (153-133 a. C).
C. Bidiscoidal de la ciudad romana de La Caridad ${ }^{519}$, Teruel (133-75 a.C.).
D. Puñal del depósito de La Azucarera ${ }^{520}$, La Rioja (fines II-ppios. I a.C.).
E. Bidiscoidales (6x) del campamento de Cáceres el Viejo ${ }^{521}$ (c. 80 a.C.).

512 Pues, como es sabido, gran número de celtíberos militaron como mercenarios en las líneas de Aníbal Barca, participando en su campaña sobre la P. Itálica. Es muy probable que llevaran puñales bidiscoidales consigo, ergo posible que fuera así como los pueblos itálicos, romanos incluidos, tomaran conciencia de la existencia de esta arma.

$513 \mathrm{Si}$ aceptamos la tesis de Schulten acerca de una inicial ocupación del cerro por las tropas de M. Porcio Catón en su campaña del 195 a.C. Otros autores (Morillo Cerdán, 2003) cuestionan esta cronología tan elevada.

${ }^{514}$ Concretamente se ha datado este campamento alrededor del año 80 a.C. Tras una breve ocupación fue destruido por un incendio, posiblemente consecuencia de alguna acción bélica, ya que el abandono del campamento viene acompañado del abandono de gran cantidad de materiales y piezas de panoplia que en circunstancias normales no se habrían abandonado.

515 Antiguo campamento de Pisoraca.

${ }^{516}$ Römisch-Germanischen Zentralmuseum, n. ${ }^{\circ}$ inv. R - 68 y R-69; Luik, 2002: 68-69, Abb. 171.

${ }^{517} \mathrm{La}$ fecha del 195 a.C. se debe a la posible relación de este yacimiento con las campañas del cónsul Catón el Censor, defendida por Schulten, 1914. Sin embargo esa relación no ha sido probada, y es posible que el yacimiento de Renieblas sólo sea ocupado a partir de la campaña de Nobilior contra Numancia del 153-152 a.C.

518 Römisch-Germanischen Zentralmuseum, n. ${ }^{\circ}$ inv. C 202, C203, C204 y C205; Luik, 2002: Abb. 91. 202-205. El campamento de El Castillejo se relaciona con la campaña del cónsul Nobilior sobre Numancia (153-2 a.C.) y subsiguientes hasta la derrota final de la urbe celtibérica (133 a.C.).

${ }^{519}$ Luik, 2002: 88, Abb 52. 4; Ezquerra Lebrón, 2005: 205.

${ }^{520}$ Quesada 1997a: n. ${ }^{\circ}$ cat. 6260; Iriarte; García; Filloy; Gil y Sesma, 1996: 173-154; Iriarte; Gil; Filloy y García, 1999: 233-250 y fig. 21.

${ }^{521}$ Ulbert, 1984: taf. 25, 195-200. 
F. Bidiscoidales (2x) del campamento de Pisoraca $^{522}$, Herrera de Pisuerga, Palencia (15/20 a.C. -100 d.C.).

G. Probable campamento militar romano de Monte Cildáf ${ }^{523}$, Palencia (26 a.C.-50 d.C.)

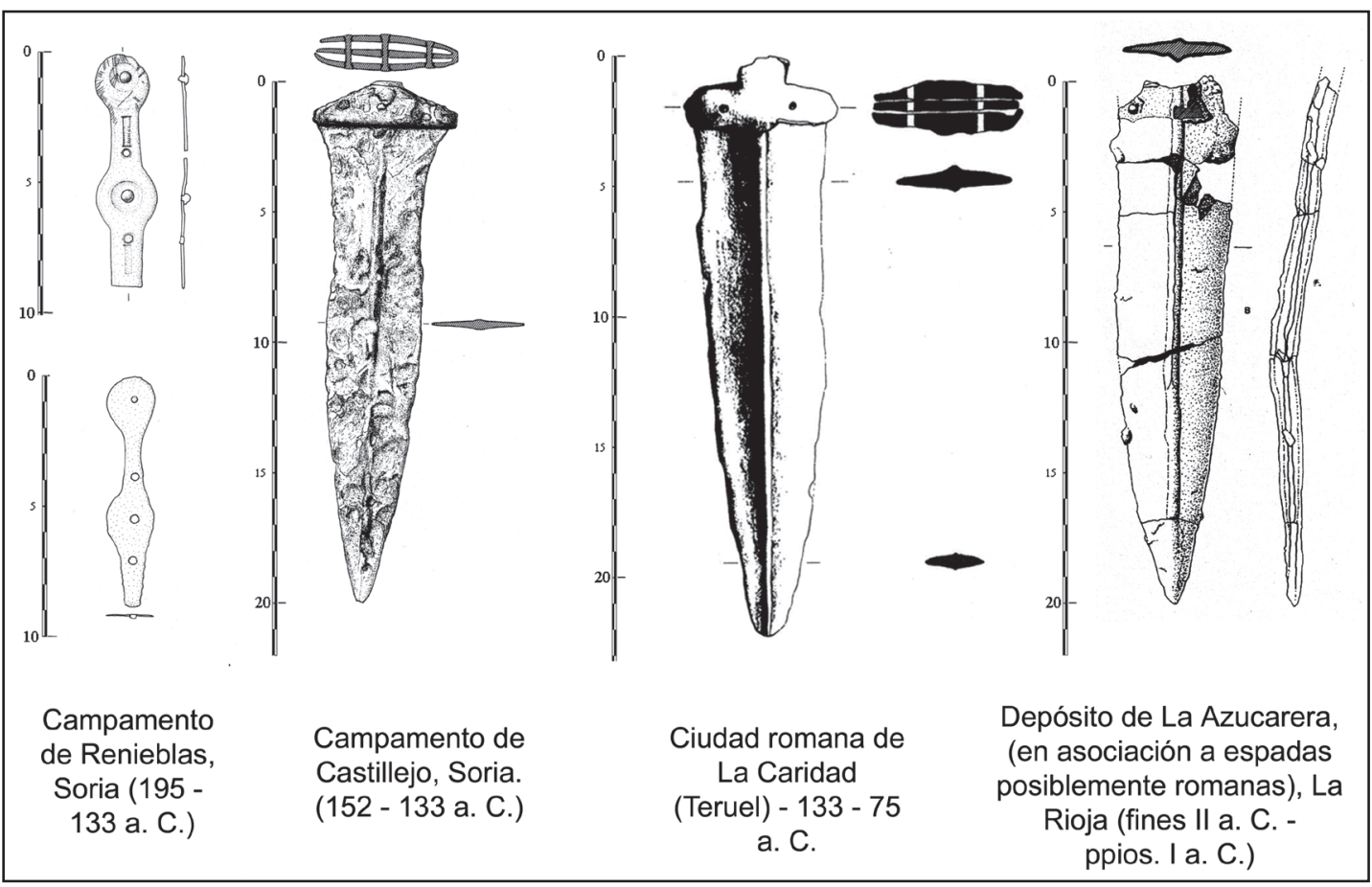

Figura 21. Puñales hallados en contexto romano (1): republicano.

La temprana datación del campamento de La Atalaya de Renieblas (195 a.C.) no es segura, y tampoco tenemos indicios de que las dos cachas de bidiscoidal halladas en ese yacimiento pertenezcan a los niveles más antiguos del mismo. Por tanto modernizamos prudentemente la datación post quem de esas piezas y la colocamos en la primera Guerra Numantina o inicio de las Guerras Celtibéricas (153 a.C.), momento en que tenemos la seguridad de que el yacimiento fue ocupado.

Siendo así, los primeros indicios de bidiscoidal en manos romanas se sitúan en el 153-2 a.C., con los hallazgos de Renieblas y Castillejo. El problema es que no sabemos si esos puñales pertenecieron a romanos o a auxiliares indígenas. En cualquier caso podemos considerar esa fecha como el momento en que con relativa seguridad, tropas romanas si no utilizan, al menos conviven con puñales bidiscoidales.

Por tanto la adopción del puñal podría haberse producido durante las Guerras Celtibéricas, hecho no sólo refrendado por los hallazgos en los campamentos de Numancia, sino por la pre-

${ }^{522}$ Dos puñales distintos, el primero: Fernández Ibáñez, 1999: 335-342 y fig. 1; Fernández Ibáñez, 2005b: fig. 1.2 y fig. 7. El segundo puñal: Pérez González, 1996: 91-102, fig. 3; Fernández Ibáñez, 2005b: fig. 1,1 y 7.

523 Alonso Gregorio, 2004: 35-45, figs. 2 y 3. 
sencia poco después de un puñal en ámbito civil pero romano, caso del puñal de La Caridad (Teruel). El hallazgo de La Azucarera guarda particular importancia pues se halló en asociación a armas, espadas laténicas — posibles gladii-y cascos de tipo Montefortino, todo ello de probable filiación romana ${ }^{524}$. Por tanto con ello tenemos un refrendo más seguro a la adopción romana del bidiscoidal. Éste continuaría en uso durante las Guerras Sertorianas (Campamento de Cáceres el Viejo) para afianzarse progresivamente en el tiempo.

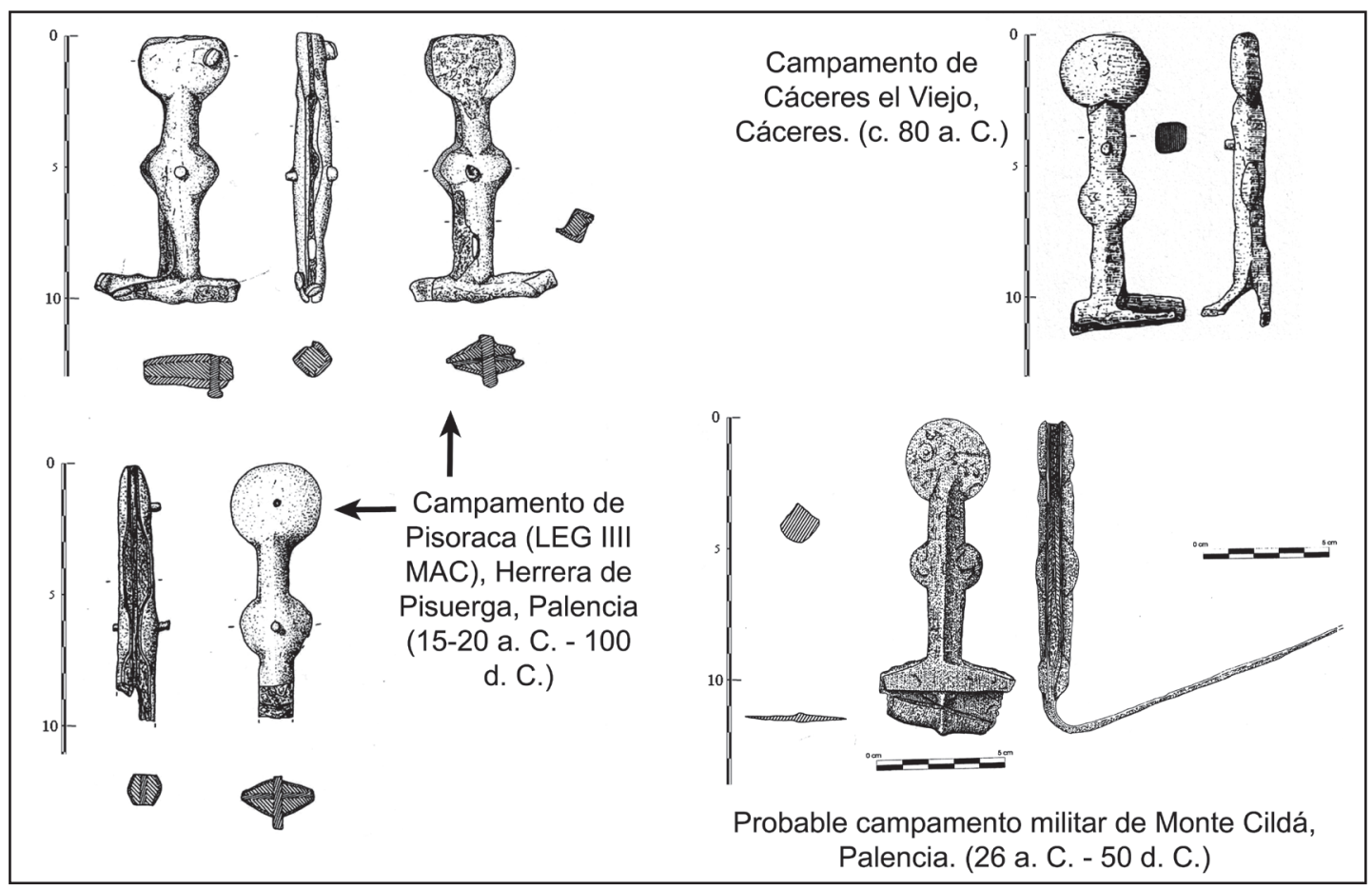

Figura 22. Puñales hallados en contexto romano (2): republicano-augusteo.

La presencia de puñales en los campamentos militares de Cáceres el Viejo ${ }^{525}$ y Herrera de Pisuerga ${ }^{526}$ es especialmente interesante, pues ya no nos encontramos en el ámbito celtibérico, sino posiblemente lusitano en el primer caso y cántabro en el segundo. Esto significa que son los legionarios romanos quienes llevan estas armas consigo hasta tierras lejanas a la celtibérica. Aunque aún posible, ya es menos probable que se trate de armas de los auxiliares indígenas. Por tanto es evidente que ya en este momento las tropas que ocupan esos campamentos poseen bidiscoidales.

No obstante, la difusión del puñal bidiscoidal en el resto de la República parece no producirse hasta un momento bastante posterior, entre César y Augusto, sugiriendo que es entonces cuando se adopta en el Imperio en su conjunto. Por tanto es incluso posible que la adopción se produjera mucho antes pero se redujera a los contingentes romanos peninsulares y sólo hacia mediados-finales del I a.C. se trasladara al resto del Imperio. Los ejemplares de tipo bidiscoi-

\footnotetext{
${ }^{524}$ Iriarte; García; Filloy; Gil y Sesma, 1996: 173-154; Iriarte; Gil; Filloy y García, 1999: 233-250.

${ }_{525}$ Ulbert, 1984: taf. 25, 195-200.

${ }^{526}$ Dos puñales distintos, el primero: Fernández Ibáñez, 1999: 335-342 y fig. 1; Fernández Ibáñez, 2005b: fig. 1.2 y 7. El segundo puñal: Pérez González, 1996: 91-102, fig. 3; Fernández Ibáñez, 2005b: fig. 1.1 y 7.
} 
dal extrapeninsulares más antiguos conque contamos proceden del cerco de Alesia ${ }^{527}$ (Francia) y de Titelberg ${ }^{528}$ (Luxemburgo). El primero lo podemos datar con seguridad en el contexto del cerco a la urbe protagonizado por César, en el año 52 a.C. y el segundo ha sido datado en torno a los años 30-10 a.C.

La estela del centurión Minucius Lorarius ${ }^{529}$ de la Legio Martia demuestra el uso del puñal legionario en un momento tan temprano como mediados del I a.C., fecha que conocemos merced a que la Legio Martia fue destruida en el año 42 a.C., luego forzosamente la estela ha de ser algo anterior.

A partir de finales del I a.C., principios del I d.C. contamos con multitud de documentos epigráficos, literarios ${ }^{530}$, pero sobre todo arqueológicos que demuestran la presencia del bidiscoidal como objeto plenamente romano, cuya adopción y difusión se han consumado ya plenamente.

Según su lectura podemos saber que, aunque probablemente iniciado antes, será a partir de mediados y fundamentalmente finales del s. I a.C., tal vez coincidiendo con el progresivo ascenso al poder de Augusto, cuando el puñal bidiscoidal se extienda a lo largo del Imperio convirtiéndose en un referente castrense, un símbolo de la condición de militar de su propietario. Hemos de comprender que un extremo como ese (convertirse en símbolo adscriptivo de profesión) es sólo posible tras una generalización total o prácticamente total del modelo. Dicho de otro modo, sólo se considerará al bidiscoidal un símbolo militar si todos y cada uno de los militares poseen un ejemplar.

Precisamente este razonamiento es el que nos dará lo que creemos es la clave para concretar la posible fecha en que el puñal bidiscoidal fue, no adoptado, pues ya lo estaba desde antes, sino difundido a lo largo de toda la República y transformado en un objeto de identificación no ya extranjera y bárbara, sino plenamente romana. De lo segundo contamos con un documento de gran importancia: la moneda de M. Junio Bruto que conmemora el asesinato de César ${ }^{531}$. En esa moneda se aprecia claramente la representación plástica de un indiscutible bidiscoidal. Dado que la moneda fue acuñada en el año 44 a.C., debemos pensar que en esa fecha el bidiscoidal ya era conocido por el grueso de la población. Dado que el puñal representa el acto patriótico de los conjurados contra el dictador César, no es verosímil que se recurriera a un arma exótica. Es por tanto mucho más probable que en ese momento el bidiscoidal ya no fuera considerado un arma exótica, sino hasta cierto punto romana. Para ello es preciso que el bisdiscoidal fuera usada por ciudadanos romanos, $y$, como parece más probable, legionarios.

Por tanto, dado que, merced a documentos literarios, pero sobre todo merced a la célebre moneda que celebra el asesinato de J. César (acuñada 42 a.C.) (fig. 23), conocemos de la existencia de esa relación semiológica en esa fecha, juzgamos que, como mínimo a partir de esa fecha es cuando el bidiscoidal se difunde por toda la República.

Debemos señalar el importante dato, que no creemos baladí, de la coincidencia entre uno de los principales focos de puñales altoimperiales romanos, la ciudad de Maguncia, y la presencia en ese mismo lugar de la Legio IIII Macedonica, un contingente trasladado en el año 39 d.C. desde el campamento de Pisoraca (Herrera de Pisuerga, Palencia), hasta Maguncia ${ }^{532}$. Precisamente en Pisoraca se han hallado dos ejemplares de puñal bidiscoidal ${ }^{533}$.

527 Se trata de un ejemplar que guarda un sospechoso parecido con un bidiscoidal hallado en la ciudad de La Caridad (Teruel). Luik, 2002: Abb 52, 6.

528 Metzler y Weiller, 1977; Helmig, 1990: Abb. 3, a; Scott, 1985: 185.

529 Ref: AE 1982, 395; Keppie, 1991: 115-121.

530 Ver apartado correspondiente a «Documentación».

531 Sear 1439; Crawford 508/3; Sydenham 1301.

532 Pérez González, 1996: 95.

533 Fernández Ibáñez, 2005b: fig. 1.1 y 2. 


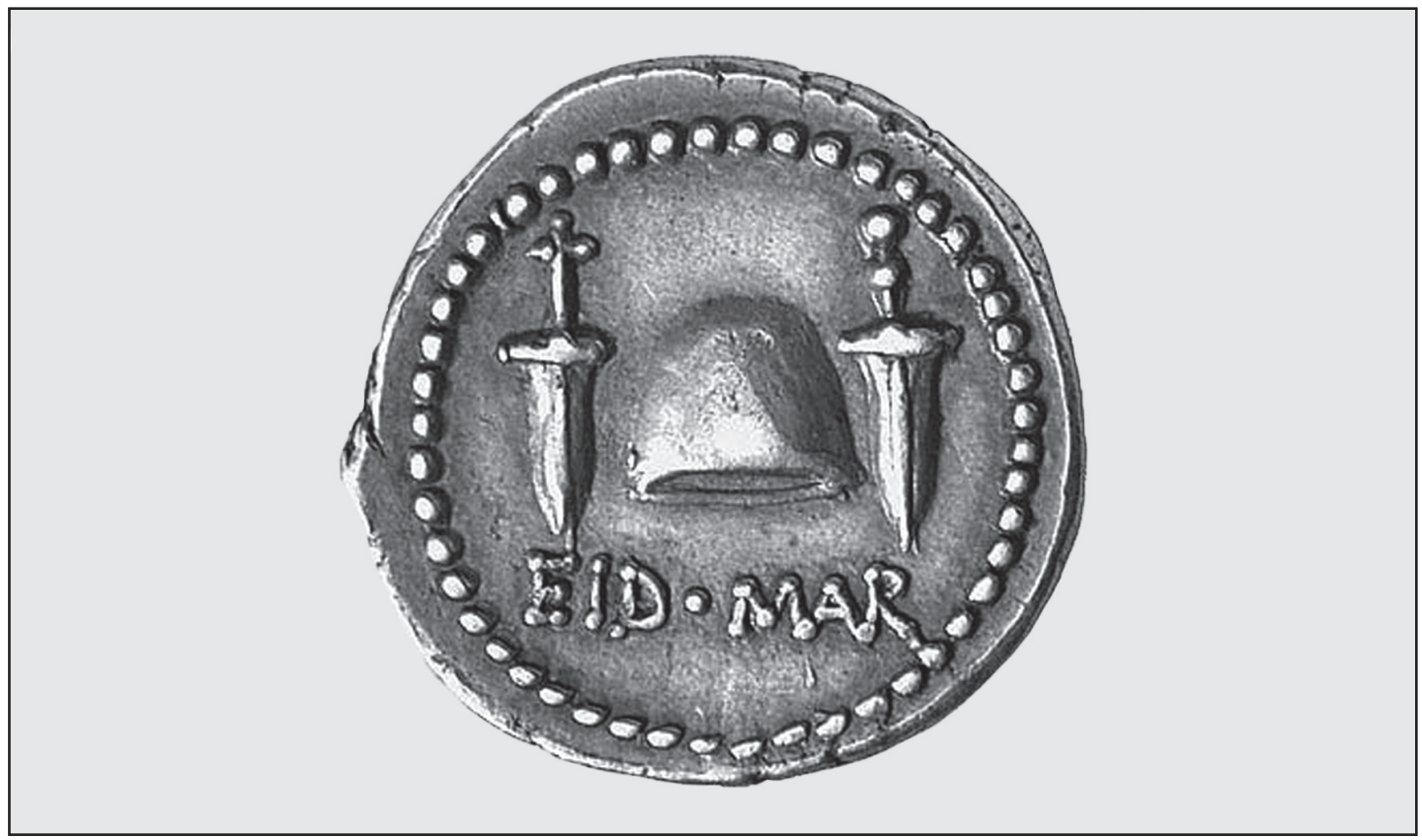

Figura 23. Moneda de Marco Junio Bruto conmemorativa del asesinato de Julio César. Nótese el puñal bidiscoidal claramente representado a la diestra.

Por tanto, resumimos los más antiguos indicios de bidiscoidal extrapeninsular:
A. Puñal de Alesia ${ }^{534}$, Francia (52 a.C.).
B. Moneda de Bruto ${ }^{535}$ conmemorativa del asesinato de J. César, Roma (42 a.C.).
C. Estela del centurión Minucius Lorarius ${ }^{536}$, Padua, (ante quem 42 a.C.).
D. Puñal de Titelberg ${ }^{537}$, Luxemburgo (30-10 a.C.).
E. Puñal de Dangstetten ${ }^{538}$ (Alemania) (15-10 a.C.)

Según estos indicios la deducción más lógica es pensar que no será hasta época de César cuando el bidiscoidal se generalice por todo el Imperio, llegando a la popularización total en época de Augusto, momento en que se documenta por multitud de hallazgos arqueológicos, todos ellos limetanos.

No obstante, es posible que la difusión del modelo se diera desde un momento anterior pero aún no hayamos sido capaces de documentarlo. Según hemos visto, indudablemente dentro de territorio peninsular la adopción fue muy anterior, como demuestran los indicios ya citados, y es posible que en el bien comunicado Mediterráneo romano se trasladara la costumbre - de manos de legionarios romanos asentados en Hispania - a otros puntos de la República. En hecho de que esta difusión no se haya podido constatar hasta época de César no significa que no se pudiera haber dado antes.

\footnotetext{
534 Luik, 2002: Abb 52, 6.

535 Sear 1439; Crawford 508/3; Sydenham 1301.

536 Ref: AE 1982, 395. Ver apartado «Documentación iconográfica».

537 Metzler y Weiller, 1977; Helmig, 1990: Abb. 3, a; Scott, 1985: 185.

538 Helmig, 1990: 160, Abb 3, b.
} 
Por tanto concluimos que la adopción del bidiscoidal por las tropas romanas probablemente se diera en algún momento entre las Guerras Numantinas (153-133 a.C.) y sertorianas (80-72 a.C.), pero no se difundiera al resto de la República hasta los tiempos de Julio César, convirtiéndose en elemento castrense indispensable en tiempos de Augusto.

\section{ApÉNDICE I: Glosario}

Dada la confusión terminológica existente, y el empleo en este trabajo de algunos términos con significado específico y preciso, se adjunta un breve glosario de términos empleados para facilitar la comprensión.

Arriaz (pl. arriaces): (del árabe ar-riyas: el puño de la espada). También denominado guarda. Parte de la empuñadura correspondiente a la parte superior de la mano que la ase, destinado tanto a crear un tope para la mano que facilite la prensión del arma como a presentar una pequeña protección para la mano asidera.

Base de la hoja: entendemos como tal al extremo proximal de la hoja, v. g., el extremo opuesto a la punta de la hoja (o extremo distal).

Cacha (pl. cachas): se denomina cachas a los laterales de la empuñadura, y por extensión a las piezas que la componen, que son generalmente dos, una por cada lado.

Contera: extremo inferior de la vaina donde se unen las cañas laterales.

Extremo distal: parte de la hoja del arma más próxima a la punta de la hoja. También se denomina «último tercio»».

Extremo proximal: parte del arma más próxima al pomo. En la hoja, parte más próxima a la guarda o arriaz. En el caso de referirse a una hoja, también se denomina «base de la hoja».

Hombros de la hoja: expresión de origen anglosajón (blade shoulders). Hace referencia a los laterales del extremo proximal de la hoja (o base de la hoja) anterior al arranque de la espiga.

Limetano: propio del Limes o frontera física del territorio romano. A menudo utilizado concretamente en alusión a las fronteras Renana, Danubiana y Britana.

Nervio: engrosamiento del centro de la hoja de un arma que se prolonga desde su base hasta, por lo común, al menos el tercio medio de la misma. Su finalidad es reforzar estructuralmente la hoja.

Nudo central: en los puñales de tipo bidiscoidal, ensanchamiento que experimenta la empuñadura en su mitad longitudinal.

Pomo: extremo superior de la empuñadura correspondiente al lugar que cubre la parte inferior de la mano al asir el arma (ver apartado «generalidades»).

Pugio (pl. pugiones): término latino para referirse al puñal específicamente militar.

Tercio: la hoja de un arma se divide comúnmente en tres tercios, denominándose éstos primero, segundo y tercero (o último) en función de su mayor o menor cercanía a la empuñadura.

\section{BIBLIOGRAFÍA}

Aguilera y Gamboa, E. (1911): Páginas de la Historia Patria, por mis excavaciones arqueológicas, obra inédita.

Almagro, M. et alii (1996): «El poblado ibérico de "El Molón"». Revista de Arqueología, 181: 8-16.

Alonso Gregorio, O. A. (2004): «Sobre el hallazgo de un puñal biglobular en Monte Cildá (Aguilar de Campoo, Palencia): La panoplia militar indígena al servicio de Roma». Sautuola, X: 35-45.

Álvarez Gracia, A.; Cebolla Berlanga, J. L. y Blanco Morte, A. (1990): «Elementos metálicos de tipo celtibérico: la colección Pérez Aguilar», F. BuRillo Mozota (coord.), II simposio sobre los celtíberos. (1988, Daroca, Zaragoza): 287-304. 
Argente Oliver, J. L. (1994): Las fíbulas de la Edad del Hierro en la Meseta Oriental. Valoración tipológica, cronológica y cultural. Excavaciones Arqueológicas en España, 168, Madrid.

Argente Oliver, J. L. (2001): Tiermes V Carratiermes necrópolis celtibérica campañas 1977 y 19861991. Valladolid, Junta de Castilla y León.

Argente Oliver, J. L. y Díaz Díaz, A. (1990): «La Necrópolis de Carratiermes (Tiermes, Soria)», F. Burillo Mozota (coord.), II simposio sobre los celtíberos. (1988, Daroca, Zaragoza): 51-58.

Argente Oliver, J. L.; Díaz Díaz, A. y Bescós Corral, A. (1991): «La Necrópolis de Carratiermes». Revista de Arqueología, 5 (n. ${ }^{\circ}$ extra: Los Celtas en la Península Ibérica): 114-119.

Artiñano y Galdacano, P. M. (1919): Exposición de hierros antiguos españoles; catálogo. Madrid.

BAATZ, D. (1962): «Mogontiacum». Limesforschungen, 4.

Baquedano Beltrán, I. (1990): «Elementos relacionados con el caballo en la necrópolis de la Osera (Zona II)», F. BuRILLo Mozota (coord.), II simposio sobre los celtíberos. (1988, Daroca, Zaragoza): 279-286.

Baquedano Beltrán, I. (2001): «La Necrópolis de La Osera», M. Almagro-Gorbea; M. Mariné y J. Álvarez SAnchís (eds.), Celtas y Vettones, Catálogo de la Exposición. Ávila, Diputación de Ávila: 303-313.

Baquedano, I. y Escorza, C. M. (1996): «Distribución espacial de una necrópolis de la II Edad del Hierro: la Zona I de La Osera en Chamartín de la Sierra, Ávila». Complutum, 7: 175-194.

Barril, M. y SALVE, V. (1998): «Reexcavando Aguilar de Anguita a través de los documentos escritos y los materiales depositados en el M.A.N». Kalathos, 17.

Beltrán (1976): Arqueología e Historia de las ciudades antiguas del Cabezo de Alcalá de Azaila (Teruel). Monografías Arqueológicas I.F.C., 19: 175-176.

Beltrán Lloris; Ezquerra Lebrón; Hernández Prieto; Tovar, J. et alii (1987): Arcóbriga. Excavaciones inéditas del Marqués de Cerralbo en Monreal de Ariza (Zaragoza). Zaragoza.

Berrocal Rangel, L. (1993): Los pueblos célticos del suroeste peninsular. Complutum Extra 2. Lámina 17 (p. 366).

Berrocal Rangel, L. (2003): «Poblamiento y defensa en el territorio céltico durante la época republicana», Morillo; Cadiou Y Hourcade (eds.), Defensa y territorio en Hispania de los Escipiones a Augusto (espacios urbanos y rurales, municipales y provinciales), (Casa de Velázquez 2001): 185-217.

Bishop, M. C. y Coulston, J. N. C. (2006, 1995 y 1993): Roman Military Equipment from the Punic Wars to the fall of Rome. Oxford, Oxbow Books (ediciones revisadas y ampliadas).

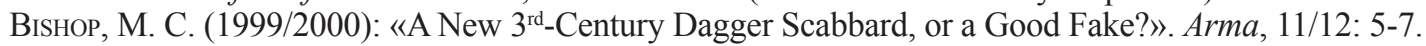

Bonnamour, L. y Fernoux, H. (1969): «Un poignard romain trouvé dans la Saone». Gallia, XXVII: $178-185$.

Born, H. (1997): «Ziertechniken auf Iberischen Eisenwaffen», MüLler-KarPe y Brandt (eds.), Studien Zur Archeologie Der Kelten, Römer und Germanen Rahden. Westfallen, 2342: 23-42.

Bosman, A. V. A. J. (1995): «Velserbroek B6 - Velsen 1 - Vensen 2 - Is there a Relationship between the military equipment from a ritual site and the fortresses of Velsen?». Journal of Roman Military Equipment Studies, 6: 89-98.

BREEZE, D. J. (1976): «The ownership of weapons». Britannia 7: 93-95.

Burillo Mozota, F. (2005): «Los Castellares de Herrera de los Navarros», A. Chaín Galán y J. I. De LA Torre (coords.), Celtíberos. Tras la estela de Numancia. Soria, Junta de Castilla y León: 109-118.

Burillo Mozota, F. y Sus Giménez, M. L. DE (1986): «Estudio microespacial de la casa 2 del poblado de época ibérica «Los Castellares» de Herrera de los Navarros (Aragón)». Arqueología Espacial, 9: 209.

Burillo Mozota, F. y Sus Giménez, M. L. De (1988): «La casa “A” de Herrera». Celtíberos, 62-67.

CAbré Aguiló, J. (1931): «Tipología del Puñal en la Cultura de «Las Cogotas»». Archivo Español de Arte y Arqueología, 21: 222-223.

CABré Aguiló, J. (1932): «Excavaciones de Las Cogotas, Cardeñosa (Ávila) II La Necrópoli», Memoria de la Junta Superior de Excavaciones y Antigüedades, n. ${ }^{\circ} 120$ (n. 4 de 1932).

CABRé Aguiló, J. (1950): El castro y la necrópolis del hierro céltico de Chamartín de la Sierra (Avila). Madrid, Ministerio de Educación Nacional, Comisaría General de Excavaciones Arqueológicas.

Cabré Aguiló, J. y Cabré Herreros, M. E. (1933): «Datos para la cronología del puñal de la cultura de las Cogotas». Archivo Español de Arqueología, 24: 37-47. 
CABré De Morán, M. E. (1988): «Espadas y puñales de la Meseta Oriental en la II Edad del Hierro», F. Burillo et alii (eds.). Celtíberos. Zaragoza, Diputación provincial de Zaragoza: 123-126.

CABré de Morán, M. E. (1990): «Espadas y puñales de las necrópolis celtibéricas», F. Burillo Mozota (coord.), II simposio sobre los celtíberos. (1988, Daroca, Zaragoza): 205-224.

Cabré de Morán, M. E. y Baquedano Beltrán, M. ${ }^{a}$ I. (1991): «La guerra y el Armamento». Revista de Arqueología, 5 (n. ${ }^{\circ}$ extra: Los Celtas en la Península Ibérica): 58-71.

CABré Herreros, E. y Morán CABré, J. A. (1991): «Puñales dobleglobulares con probable simbología astral en el pomo de la empuñadura». XX Congreso Nacional de Arqueología: 341-346.

Campano Lorenzo, A. y Sanz Mínguez, C. (1990): «La Necrópolis celtibérica de Fuentelaraña (Soria)», F. Burillo Mozota (coord.), II simposio sobre los celtíberos. (1988, Daroca, Zaragoza): 65-74.

Cerdeño Serrano, M. L. (1978): «Los broches de cinturón peninsulares de tipo céltico». Trabajos de Prehistoria 35: 279-306.

Chaín Galán, A. y De La Torre, J. I. (coords.) (2005): Celtíberos. Tras la estela de Numancia. Soria, Junta de Castilla y León.

Chirila, E., Gudea, N., Lucacel, V. y Pop, C. (1972): Das Romerlager van Buciumi. Beitrage zur Untersuchung des Limes der Dacia Porolissensis. Cluj.

Connolly, P. (1997): «Pilum, Gladius and Pugio in the Late Republic». Journal of Roman Military Equipment Studies, 8: 41-57.

Couissin, P. (1926): Les armes romaines: essai sur les origines et l'évolution des armes individuelles du légionnaire romain. Paris, Honoré Champion: 302-313.

Pinta, J. L. DE LA; Rovira I Port, J. y Gómez, R. (1987-88): «Yacimientos arqueológicos de Camporrobles (Comarca de Utiel - Requena) y áreas cercanas: una zona de contacto entre la meseta y las áreas costeras». Cuadernos de prehistoria y arqueología castellonenses, 13: 291-332.

EnRíquez Navascués, J. J. (1981): «Dos falcatas ibéricas y un puñal de la provincia de Cáceres en el Museo Arqueológico provincial de Badajoz». Revista de Estudios Extremeños, 33, 1: 47-56.

ExNER, K. (1940): «Römische Dolchsheiden mit Taushieren und Email-verzierung». Germania, 24: 22-28.

Ezquerra Lebrón, B. (2005): «La ciudad romana de «La Caridad» (Caminreal, Teruel)», A. Chaín Galán y J. I. De la Torre (coords.), Celtíberos. Tras la estela de Numancia. Soria, Junta de Castilla y León: 205-212.

FernáNDEZ IbÁÑEZ, C. (1999): «Placa de tahalí para la suspensión de las dagas en el ejército romano: entre la república y el Imperio». Sautuola, VI: 335-342.

Fernández IbáÑ̃z, C. (2004): «Metales romanos de Herrera de Pisuerga (Palencia). El yacimiento de «El Cuartel-I»: Los primeros asentamientos militares». Sautuola, X: 237-280.

FERnÁNDEZ IBÁÑEZ, C. (2005a): «Metalistería militar romana en el norte de la Península Ibérica durante los períodos republicano y altoimperial», C. Fernández OchoA y P. García Díaz (eds.), Unidad $y$ diversidad en el Arco Atlántico en época romana. III Coloquio Iternacional de Arqueología en Gijón. (Gijón, 2002).

FernáNDEZ IbÁÑeZ, C. (2005b): «Objetos metálicos del asentamiento militar romano de Herrera de Pisuerga (Palencia). Excavaciones de A. García y Bellido (1960-61)», Bendala (coord.), La Arqueología Clásica peninsular ante el tercer milenio en el centenario de A. García y Bellido (1903-1972). Anejos del Archivo Español de Arqueología, XXXIV.

FERnÁNDEZ GómEz, F. (1986): Excavaciones arqueológicas en el Raso de Candeleda I-II. Ávila, Institución Gran Duque de Alba de la Diputación Provincial.

Fernández Gómez, F. (1986-87): «Evolución y Cronología de El Raso de Candeleda». Zephyrus, 39-40: 265.

Fernández Gómez, F. (1997): La necropolis de la Edad del Hierro de «El Raso» (Candeleda. Ávila), «Las Guijas, B». Zaragoza, Junta de Castilla y León. Consejería de Educación y Cultura.

Fernández Gómez, F. (2001): «El Raso de Candeleda», M. Almagro-Gorbea; M. Mariné y J. Álvarez Sanchís (eds.), Celtas y Vettones, Catálogo de la Exposición. Ávila, Diputación de Ávila.

Feugère, M. (1993): Les armes des romains. De la Republique a la Antiquité Tardive.

Feugère, M. (1994): «L'Equipement militaire d'epoque republicaine en Gaule». Journal of Roman Military Equipment Studies, 5: 3-27.

FeUGĖRE, M. (2002): Weapons of the Romans. Stroud.

Feugère, M. y Alonso, G. (1997): «Militaria de la Gaule Meridionale, 6 Bollène (Vaucluse) et environs». Arma, 9, 2: 19-20. 
Filloy Nieva, I. y Gil Zubillaga, E. (1997): «Las armas de las necrópolis celtibéricas de Carasta y La Hoya (Álava, España). Tipología de sus puñales y prototipos del pugio». Journal of Roman Military Equipment Studies, 8: 137-150.

Filloy Nieva, I. (2002): «Los puñales con empuñadura globular de frontón en la necrópolis de la II Edad del Hierro de la Hoya, (Laguardia, Álava)». Gladius, XXII: 57-72.

Franzius, G. (1995): «Die Römischen Funde aus Kalkriese 1987-95 und ihre Bedeutung für die Interpretation und Datierung militärischer Fundplätze der augusteischen Zeit im nordwesteropäischen Raum». Journal of Roman Military Equipment Studies, 6: 69-88.

García Bellido, M. ${ }^{a}$ P. (1963): «Puñal romano de Iulióbriga». Archivo Español de Arqueología, 36: 200-201.

García Merino, C. (1973): «La evolución del poblado de Gormaz (Soria) desde la Edad del Hierro a la Edad Media». Boletín del Seminario Español de Arte y Arqueología, 39: 31 y ss.

García Merino, C. (2005): «Uxama Argaela», A. Chaín Galán y J. I. De la Torre (coords.), Celtíberos. Tras la estela de Numancia. Soria, Junta de Castilla y León: 177.

García Soto Mateos, E. (1990): «Las necrópolis de la Edad del Hierrro en el Alto valle del Duero», en Burillo Mozota (ed.): Necrópolis celtibéricas: II Simposio sobre los celtíberos (Daroca, 1988).

García-Soto Mateos, E. (1992): «Tumba con puñales de tipo Monte Bernorio en la necrópolis de S. Martín de Ucero». II Symposium de Arqueología Soriana.

Gerhartl-Witteveen, A. M. y Hubrecht, A. V. M. (1990): «Survey of Swords and daggers in the Provinciaal Museum G.M. Kam, Nijmegen». Journal of Roman Military Equipment Studies, 1: 99-107.

Gilliam, J. F. (1981): «Notes on a New Latin Text». Zeitschrift für Papyrologie und Epigraphik, 41: 277-80.

GonzÁlez Zamora, C. (1999): Fíbulas en la Carpetania. Zaragoza.

Gutierrez Palacios (1955): «Castros Abulenses». Noticiario Arqueológico Hispánico, 2: 195.

Helmig, G. (1990): «Hispaniensis Pugiunculus? - Technologische Aspekte und Anmerkungen zum Fund einer Militärdolchscheide aus Basel». Archäologie der Schweiz, 13: 158-164.

Hernández Hernández, F. y Galán Domingo, E. (1996): «La necrópolis de "El Mercadillo" (Botija, Cáceres)». Extremadura Arqueológica, VI.

Illarregui Gómez, E. (2001): «Acerca de los campamentos altoimperiales de Herrera de Pisuerga y su entorno», A. Morillo Cerdán (ed.). Arqueología militar Romana en Hispania. Anejos de Gladius, 5: $155-165$.

Iriarte, A.; García, M. L.; Filloy, I.; Gil, E. y Sesma (1996): «El Depósito de armas de la Azucarera, (Alfaro, La Rioja)». Cuadernos de Arqueología de la Universidad de Navarra: 173-154.

Iriarte, A.; Gil, E.; Filloy, I.; GarcíA, M. L. (1999): «A votive deposit of Republican weapons at Graccurris (Alfaro, La Rioja, España)», M. FEUGÈre (dir.), L'équipement militaire et l'armement de la République (IVe-Ier s. avant J.-C.). Journal of Roman Military Equipment Studies, 8, 1997 [1999]: 233-250.

IzQuierdo Peraile, I. (1999): «Un lote de armamento ibérico procedente de la necrópolis del Mas de Barberán (Nogueruelas, Teruel)». Gladius, XIX: 97-120.

JimenEZ DE GREgORIo (1992): «Aproximaciones al mapa arqueológico del Occidente Toledano». Actas de las Jornadas de Arqueología de Talavera y sus tierras: 5-38.

Jimeno, A. y Arlegui, M. (1995): «El poblamiento en el Alto Duero», F. Burillo Mozota (coord.). Poblamiento Celtibérico, III Simposio sobre los celtíberos: 93-126.

Jimeno, A.; Revilla, M. a L.; Torre, J. I. De la; Berzosa, R. y Martínez, J. P. (2002): Numancia. Guía del Yacimiento. Soria, Junta de Castilla y León. Asociación de Amigos del Museo Numantino.

Jimeno, A.; Torre, J. I. de la; Berzosa, R. y Martínez, J. P. (2005): La Necrópolis Celtibérica de Numancia. Memorias de la Junta de Castilla y León, n. ${ }^{\circ} 12$.

KeppIE, L. (1991): «A Centurion of Legio Martia at Padova?» Journal of Roman Military Equipment Studies, 2: 115-121.

KreKović, E. (1994): «Military equipment on the territory of Slovakia». Journal of Roman Military Equipment Studies, 5: 211-25.

Kurtz, W. (1987): La Necrópolis de Las Cogotas. Volumen 1: Ajuares. Revisión de los materiales de la Necrópolis de la Segunda Edad del Hierro en la cuenca del Duero (España). B.A.R., International series, 344. Oxford.

Lenerz-De WiLde, M. (1991): Iberia Celtica. Archäologische Zeugnisse keltischer Kultur auf der Pyreäenhalbinsel, Stuttgart. 
Lindenschmidt, L. (1900): Die Altertümer unserer Heidnische Vorzeit. Maguncia.

López Mullor, A.; Rovira Port, J. y Sanmartí Greco, E. (1983): «Excavaciones en el asentamiento layetano de Turó del Vent (Llinars del Vallès, Barcelona)». XVI Congreso Nacional de Arqueología: 615.

Lorrio Alvarado, A. (1994a): «L'armement des Celtibères: phases et groupes». Aquitania, XII: 391-414.

Lorrio Alvarado, A. (1994b): «La evolución de la panoplia celtibérica», Madrider Mitteilungen, 35: 212-257.

Lorrio Alvarado, A. (1995): «El armamento de los celtíberos a través de la iconografía monetal». Anejos del Archivo Español de Arqueología, XVI: 76-80.

Lorrio Alvarado, A. (2004): «El armamento». Iberia, Hispania, Spania. Una mirada desde Ilici. Alicante, CAM Cultural: 163-164.

Luik, M. (2002): Die Funde aus den Römischen Lagern um Numantia im Römisch-Germanischen Zentralmuseum. Maguncia.

Manning, W. H. (1985): Catalogue of the Romano-British iron tools, fittings and weapons in the British Museum: 153-159 y figs. 73-75.

Mañanes, T.; Gutierrez, M. A. y Agúndez, C. (2002): «El mosaico de la villa romana de Santa Cruz (Cabezón de Pisuerga, Valladolid)», R. Bohigas (ed.), Trabajos de Arqueología de Cantabria, V.

Martín Valls, R. y Esparza, A. (1992): «Génesis y evolución de la Cultura Celtibérica». Complutum, 2-3: 253-279.

Martínez García, J. M. (1990): «Materiales de la Segunda Edad del Hierro en la Plana de Utiel». Anales de la Academia de Cultura Valenciana, 66: 79-105.

Mélida, R. y Taracena, B. (1921): «Excavaciones en Numancia». Memoria de la Junta Superior de Excavaciones y Antigüedades, 49.

Metzler, J.; Weiler, R. (1977): «Beiträge zur Archäologie und Numismatik des Titelberges». Publications de la Section Historique (Musée de Luxembourg) 91.

Monteverde, J. L. (1957): «El puñal de Sotopalacios». Boletín de la Institución Fernán González, 141: 792.

Morel, J. M. A. W. (1989): «The Roman Dagger and Belt Fittings from Velsen, Netherlands». Exercitus, 2, 6: 93-101.

Morel, J. M. A. W. y Bosman, A. V. A. J. (1989): «An Early Roman Burial in Velsen I». Roman Military Equipment Conference, V, BAR 476: 177-191.

Morillo Cerdán, A. (2003): «Los establecimientos militares temporales: conquista y defensa del territorio en la Hispania republicana», Morillo; CAdiou y Hourcade (eds.). Defensa y territorio en Hispania de los Escipiones a Augusto (espacios urbanos y rurales, municipales y provinciales). (Casa de Velázquez 2001): 41-80.

NúÑez Pariente de León, E. y Muñoz Tinoco, J. (1988): «Excavación en la Necrópolis del "Cerro de las Balas”, Écija, Sevilla». Anuario Arqueológico de Andalucía, 3: 429-433.

NúÑEZ PARIENTE, E. y QuesADA, F. (2000): «Una sepultura con armas de baja época ibérica (o época romana republicana) en la necrópolis del “Cerro de las Balas» (Écija, Sevilla)». Gladius, XX: 191-220.

Obmann, J. (1992): «Zu einer elfenbeinernen Dolchgriffplatte aus Nida-Heddernheim/Frankfurt am Main». Journal of Roman Military Equipment Studies, 3: 37-40.

Pérez González, C. (1996): «Asentamientos militares en Herrera de Pisuerga», C. Fernández OchoA (coord.), Los Finisterres Atlánticos en la Antigüedad. Época romana y prerromana. (Gijón 1995): 91-102.

Petulescu, L. (1995): «Military Equipment graves in Roman Dacia». Journal of Roman Military Equipment Studies, 6: 124-133.

Quesada SANz, F. (1997a): El armamento ibérico. Estudio tipológico, geográfico, funcional, social y simbólico de las armas en la Cultura Ibérica (siglos VI-I a.C.), I y II, M. Mergoil (ed.). Monographies Instrumentum, 3. Montagnac.

QuesAda SAnz, F. (1997b): «Gladius hispaniensis: an archaeological view from Iberia», M. Feugère (ed.), L'equipement militaire et l'armement de la république (Ive-Ier s. Avant J.-C.). Journal of Roman Military Equipment Studies 8: 251-270.

Quesada SAnz, F. (1997c): «¿Qué hay en un nombre?. La cuestión del gladius hispaniensis». Boletín de la Asociación Española de Amigos de la Arqueología, 37: 41-58.

Quesada Sanz, F. (2000): «Puñal legionario». La Aventura de la Historia, 15: 100-101.

Quesada SAnZ, F. (2003): «¿Espejos de piedra? Las imágenes de armas en las estatuas de los guerreros llamados galaicos». Madrider Mitteilungen, 44: 87-112. 
Ramos Folqués, A. y Ramos Fernández, R. (1976): Excavaciones en la Alcudia de Elche: durante los años 1968 al 1973. Madrid, Servicio de Publicaciones del Ministerio de Educación y Ciencia.

Requejo Osorio (1978): «Una sepultura de Quintanas de Gormaz (Soria)». Celtiberia, 58: 227-238.

Revilla, M.; Martínez, J. P.; Torre, J. I.; Berzosa, R. y Jimeno, A. (2005): «Numancia», A. Chaín GaLÁN y J. I. DE LA TORRE (coords.), Celtíberos. Tras la estela de Numancia. Soria, Junta de Castilla y León: 161-175.

Reuter, M. (1999): «Späte Militärdolche vom Typ Künzing. Anmerkungen zur Datierung und Verbreitung». Journal of Roman Military Equipment Studies, 10: 121-124.

Rovira HorTALÀ, M. C. (1999): «Las armas-trofeo en la cultura ibérica: pautas de identificación e interpretación». Gladius, XIX: 13-32.

Ruiz Coвo, J. y Sмiтн, P. (2001): The Archaeology of the Matienzo Depression, North Spain. Bar International Series, 975, Oxford.

SÁnchez-Lafuente, J. (1979): «Aportaciones al estudio del Campamento romano de "La Cerca" (Aguilar de Anguita-Guadalajara)». Wad-Al-Hayara, 6: 77-82.

Sanz Mínguez, C. (1998): Los Vacceos, Cultura y ritos funerarios de un pueblo prerromano del valle medio del Duero (Valladolid). Memorias de la Junta de Castilla y León.

Sanz Mínguez, C. y Velasco Vázquez, J. (2003): Pintia. Un oppidum en los confines orientales de la región vaccea. Investigaciones Arqueológicas Vacceas, Romanas y Visigodas (1999-2003). Valladolid, Universidad de Valladolid.

SchüLE, W. (1969): Die Meseta-Kulturen del Iberischen Halbinsel, I y II. Madrider Forschungen, 3.

Sсотт, I. R. (1985): «First Century Military Daggers and the Manufacture and Supply of Weapons for the Roman Army», M. C. Bishop (ed.), The Production and Distribution of Roman Military Equipment, Proceedings of the Second Roman Military Equipment Research Seminar, Bar International Series, 275, Oxford: 160-213.

Sсотт, I. R.: (1989): «First Century Military Daggers with inlaid sheaths». Roman Military Equipment Conference, 1: 27-28.

Sumner, G. (1997): Roman Army: Wars of the Empire. London, Herndon: 105-6.

Taracena, B. (1927): «Excavaciones en las provincias de Soria y Logroño». Memoria de la Junta Superior de Excavaciones y Antigüedades, 86: 18 y lám. XI.

Taracena, B. (1932): «Excavaciones en la provincia de Soria». Memoria de la Junta Superior de Excavaciones y Antigüedades, 119 (n. 3 de 1931, publicado en 1932): 59 y 60.

Thiel, A. y Zanier, W. (1994): «Römische Dolche - Bemerkungen zu den Fundemständen». Journal of Roman Military Equipment Studies, 5: 59-81.

Ulbert, G. (1984): Cáceres el Viejo. Ein spatrepublikanisches legionslager in Spanisch-Extremadura. Madrider Beitrage, 11.

Vanden Berghe, L. (1996): «Some Roman Military Equipment of the First Three Centuries AD in Belgian museums». Journal of Roman Military Equipment Studies, 7: 66.

Vanden Berghe, L. y Simkins, M. (2001/2): «Construction and reconstruction of the Titelberg dagger». Journal of Roman Military Equipment Studies, 12/13: 75-84.

VARIA (1975): «Puñal romano de la villa de las Minas en Pinilla de Toro». Boletín del Seminario Español de Arte y Arqueología, 40-41: 461-463.

VV. AA. (1993a): «Römischer Dolch und Scheide mit Taushierungen aus Mali Drinić, Kroatien. (Um Christi Geburt)». Jahrbuch des Römisch-Germanischen Zentralmuseum, Mainz, n. ${ }^{\circ} 43.2: 733$ y Abb. 55.

VV. AA. (1993b): «Römischer Dolch aus Tell Schech Hamad, Syrien (Um Christi Geburt)». Jahrbuch des Römisch-Germanischen Zentralmuseum, Mainz, n. ${ }^{\circ}$ 43.2: 733-5 y Abb. 56.

VV. AA. (2003): «Twei römisce dolche aus Sisak, Kroatien (fruhes 1 Jahrhundert n. Chr.)». Jahrbuch des Römisch-Germanischen Zentralmuseum, Mainz, n. ${ }^{\circ}$ 50.2: 677 y Abb. 19.

Webster, G. (1986): «Decorated Dagger Scabbards Found in Britain». Exercitus, 2: 21-22.

WebsteR, G. (1989): «Decorated Dagger Scabbards - a brief note of work in hand». Roman Military Equipment Conference, 1: 5.

Recibido: $19 / 03 / 2008$

Aceptado: 25/08/2008 